\title{
ANÁLISE FAUNISTICA DE COLEÓPTEROS COLETADOS COM ARMADILHAS LUMINOSAS, EM TRÊS REGIÕES CANAVIEIRAS DO ESTADO DE SÃO PAULO
}

\author{
FRANCISCO JORGE CIVIDANES
}

Engenhelro-Agrónomo

Orientador: Sinval Silveira Neio

Disserłação apresentada à Escola Superior de Agricultura "Luiz de Queiroz", da Universidade de São Paulo, para obłenção do título de Mestre em Entomologia.

PIRACICABA

Estado de São Paulo - Brasil

Agosto, 1979 


\author{
Aos meus pais \\ Maria Aparecida e Francisco Antônio
}

$D E E D I C D$ 
Ao Dr. Sinval Silveira Neto, Professor Adjunto do Departa mento de Entomologia da Escola Superior de Agricultura "Luiz de Queiroz" - USP, pelo constante apoio e orientação neste trabalho;

Ao Corpo Docente e Funcionärios do Departamento de Entomolo gia da ESALQ/USP, na pessoa do seu Chefe Dr. Domingos Gal lo, pela amizade e ensinamentos;

Aos Colegas de curso pela amizade;

A Coordenadoria Regional-Sul do Planalsucar, na pessoa do Engo-Agro Paulo Sérgio Machado Botelho, pela coleta das amostras;

A Fundação Universidade do Amazonas, pela bolsa de estudos concedida durante a realização do curso;

Aos Drs. Ubirajara R. Martins, Sérgio Vanin, Cleide Costa e Maria Eulina Jorge da Silva, pertencentes ao Museu de Zoo logia da USP; Pe. Francisco S. Pereira, do Instituto Bio lögico, SP; Dr. Antonio Martínez, do Instituto Entomoló gido San Miguel, Argentina e Dr. Richard E. White, do Beltsville Agricultural Research Center, U.S.A., pelas dentificações das espēcies;

Ao Dr. Nilson Augusto Villa Nova, Prof. Adjunto do Departamento de Física e Meteorologia da ESALQ/USP, pela conces são dos dados meteorolögicos; 
Ao Dr. Humberto de Campos, Prof. Adjunto do Departamento de Matemática e Estatística da ESALQ/USP, pela colaboração na escolha do método de correlação;

Ao Dr. Flávio Moscardi, Pesquisador do Centro Nacional de Soja, EMBRAPA, pela elaboração do "Summary";

Ao Eng:-Agr: José Fernando Soares Dias, Professor da Univer sidade do Maranhão, pela elaboração do programa para o cálculo de um índice faunístico;

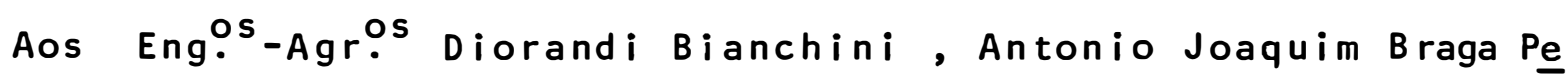
reira Braz e Murilo Fazolin, pela colaboração na separação e catalogação das espécies;

Ao Sr. Paulo José de Gáspari, pelos serviços de datilogra fia e impressão. 


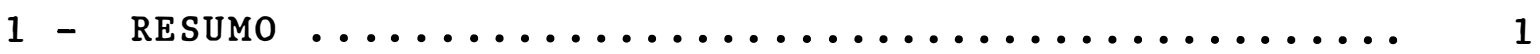

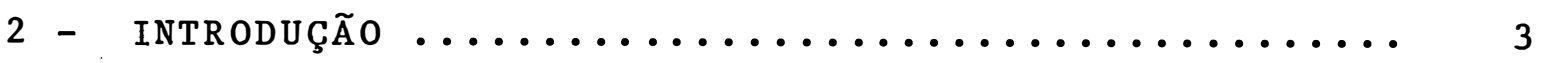

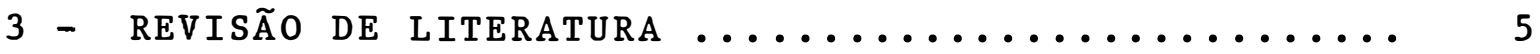

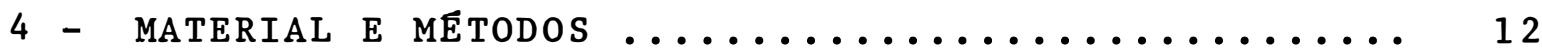

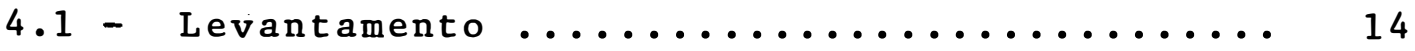

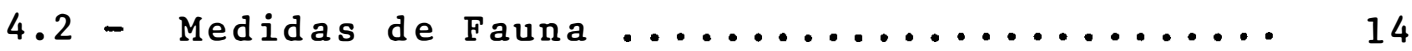

$4.2 .1-$ Constância ....................... 14

4.2 .2 - Dominância ...................... 15

$4.2 .3-$ Abundância ...................... 16

4.2 .4 - Indice de diversidade ........... 17

4.2.5 - Quociente de similaridade ......... 18

4.2 .6 - Porcentagem de similaridade ....... 19

4.3 - Flutuações Populacionais .............. 19

4.4 - Correlação com Fatores Meteorológicos ..... 20

5 - RESUltados E DISCUSSÃo .................. 22

$5.1-$ Levantamento ..................... 22

5.2 - Medidas de Fauna ................... 41

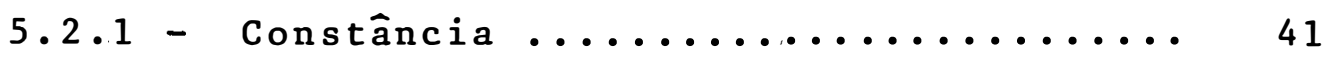

5.2 .2 - Dominância .................. 43

$5.2 .3-$ Abundância ................... 43

5.2 .4 - Indice de diversidade ........... 45 
Pàg.

5.2.5 - Quociente e porcentagem de similaridade ...................... 46

5.3 - Flutuações Populacionais e Influência dos Fatores Meteorológicos ............... 48

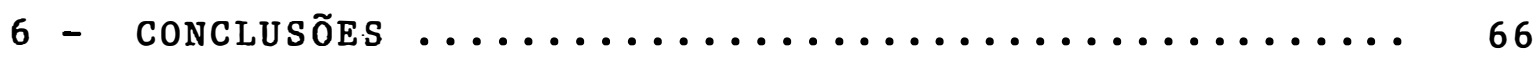

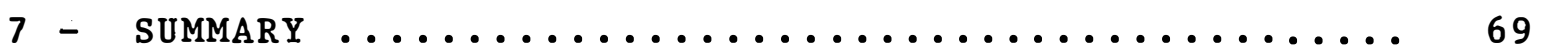

8 - Literatura citada ................... 71 
vi .

\section{LISTA DE TABELAS}

Pàg.

TABELA 1 - Média mensal de coleópteros coletados em Assis, Barra Bonita e Pradópolis, com ar madilhas luminosas de 1976/78, e dados de constância, abundância e dominância das

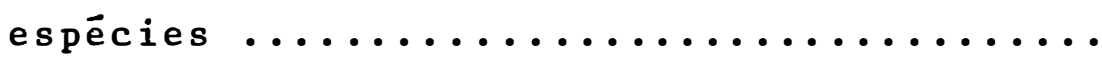

TABELA 2 - Total de coleópteros coletados nas três localidades, pertencentes às famílias pre judiciais à cultura da cana (1976/78) .....

TABELA 3 - Total de coleópteros coletados nas três localidades, pertencentes às subfamílias da Scarabaeidae

TABELA 4 - Número e porcentagem de coleópteros clas sificados quanto à constância para as três localidades $(1976 / 78) \ldots \ldots \ldots \ldots \ldots$

TABELA 5 - Número e porcentagem de coleópteros clas sificados quanto à abundância para as três localidades $(1976 / 78) \ldots \ldots \ldots \ldots \ldots$

TABELA 6 - Número de espécies (S), número de indivíduos (N) e indice de diversidade $(\alpha)$ da fauna de coleópteros estudada nas três localidades $(1976 / 78) \ldots \ldots \ldots \ldots \ldots \ldots$ 
vii.

Pàg.

TABELA 7 - Quocientes e porcentagens de similaridade obtidos entre as localidades, referen tes às espécies de coleópteros seleciona

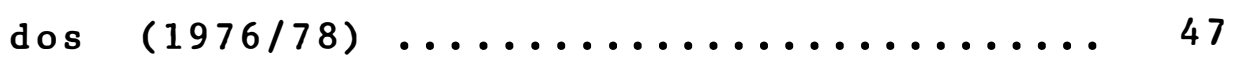

TABELA 8 - Total mensal de coleópteros conhecidos como associados à cultura da cana-de-açu car, coletados nas três localidades $(1976 / 78)$

TABELA 9 - Médias mensais da temperatura e total men sal da precipitação, registradas nas três localidades $(1976 / 78) \ldots \ldots \ldots \ldots \ldots \ldots \ldots \ldots \ldots \ldots \ldots \ldots \ldots$

TABELA 10 - Valores obtidos no teste de correlação de Kendall entre as espécies selecionadas e os fatores meteorológicos, das três loca 1 idades $(1976 / 78) \ldots \ldots \ldots \ldots \ldots \ldots \ldots$

TABELA 11 - Total de coleópteros conhecidos como as sociados à cultura da cana-de-açūcar, co letados nas três localidades $(1976 / 78)$... 
viii.

\section{LISTA DE FIGURAS}

Pāg.

FIGURA 1 - Locais de instalação e áreas de influência das armadilhas luminosas, em três re giões do Estado de São Paulo. Escala $1: 10.000 \ldots \ldots \ldots \ldots \ldots \ldots \ldots \ldots \ldots \ldots \ldots \ldots . \ldots \ldots \ldots$

FIGURA 2 - Flutuação populacional de Conoderus scaZaris (Germ.) nas três localidades.

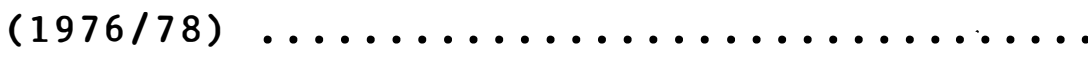

FIGURA 3 - Flutuação populacional de Conoderus s $\mathrm{p}_{6}$ nas três localidades $(1976 / 78) \ldots \ldots . . . . .50$

FIGURA 4 - Flutuação populacional de Cyclocephala me Zanocephala (Fabr.) nas três localidades.

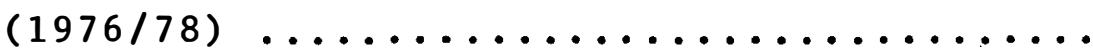

FIGURA 5 - Flutuação populacional de Diabrotica speciosa (Germ.) nas três localidades.

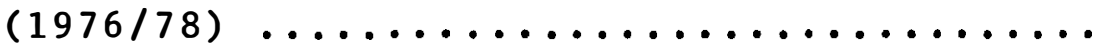

FIGURA 6 - Flutuação populacional de Discynetus dubius (01iv.) nas três localidades.

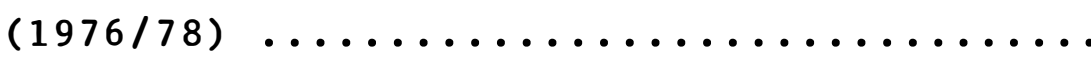

FIGURA 7 - Flutuação populacional de Euetheola humiIis (Burm.) nas duas localidades.

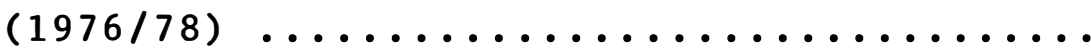

FIGURA 8 - Flutuação populacional de Ligyrus fossor (Latreille) em Barra Bonita, SP. $(1976 / 78)$ 
Pàg.

FIGURA 9 - Flutuação populacional de Ligyrus gyas (Erichson) nas três localidades.

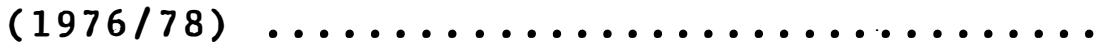

FIGURA 10 - Flutuação populacional de Maecolaspis perturbata Weise, nas três localidades.

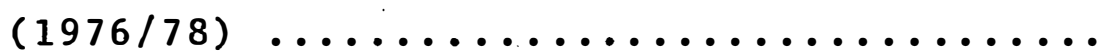

FIgURA 11 - Flutuação populacional de Paranapiacaba significata Gahan nas três localidades.

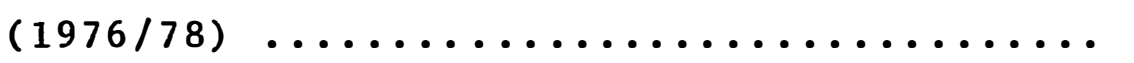


1 - RESUMO

No presente trabalho, efetuou-se um levantamento da fauna de coleōpteros, atravēs de armadilhas luminosas, nos mu nicípios paulistas de Assis, Barra Bonita e Pradōpolis; e es tudou-se a constância, abundância, dominância, îndice de diversidade, quociente e porcentagem de similaridade das espēcies, assim como a flutuação populaciónal e correlação com fá tores meteorológicos de algumas espécies associadas à cultura da cana-de-açūcar.

A anālise dos resultados mostrou que:

- 91.197 coleōpteros de 207 espēcies diferentes foram coletá dos nas três localidades;

- Barra Bonita mostrou menor fauna de coleōpteros prejudiciais à cultura da cana-de-açūcar;

- As familias Carabidae, Chrysomelidae, Elateridae e Scara baeidae foram as mais numerosas; 
- A espécie Selenophorus sp (Carabidae) representou 59,8\% do total coletado;

- Apenas cinco espécies foram constantes em Assis, quatro em Barra Bonita e cinco em Pradópolis;

- 82 espécies foram dominantes em Assis, 109 em Barra Bonita e 98 em Pradópolis;

- 23 espécies foram muito abundantes ou abundantes em Assis, 26 em Barra Bonita e 17 em Pradópolis;

- A fauna de Assis apresentou indice de diversidade 14,1, Barra Bonita 15,5 e Pradópolis 13,7;

- As três localidades apresentaram similaridade média;

- Estudou-se a flutuação populacional das seguintes espécies: Conoderus scalaris (Germ., 1824); Conoderus $\mathrm{sp}_{6}$; Cyclocephala melanocephala (Fabr., 1775) ; Diabrotica speciosa (Germ., 1824) ; Discynetus dubius (01iv., 1789) ; Euetheo la humilis (Burm., 1747); Ligyrus fossor (Latreille, 1833); Ligyrus gyas (Erichson, 1848) ; Maecolaspis perturbata Weise, 1921 e Paranapiacaba significata (Gahan, 1891);

- A temperatura média mensal, foi o fator meteorológico que apresentou maior número de correlações positivas com as es pēcies estudadas. 
3 .

2 - INTRODUÇAOO

Os insetos constituem um sucesso biológico, pois ha bitam a Terra há mais de 300 milhões de anos e são encontra dos em quase todos os locais. 0 seu pequeno tamanho, sua capacidade de voar, seus sistemas especializados de reprodução, e, principalmente, sua enorme diversidade de espécies, contrí buiram para que se adaptassem muito bem ao ambiente. Entre as espécies de insetos conhecidas, aproximadamente $40 \%$ são co leópteros, dos quais a maioria é fitófaga, o que aumenta sua importāncia sob o ponto de vista agrícola e justifica os programas que visem estudar a ecologia desses organismos.

Atualmente o Brasil é o maior produtor mundial de cana-de-açúcar, e nas āreas ocupadas por essa cultura, a diversidade de espécies de coleópteros deve ser muito grande. Portanto, hã necessidade de se obter informações sobre o comportamento de suas populações, para possibilitar programas de 
controle de pragas de forma mais racional. Estudos semelhantes, abrangendo insetos de vārias categorias taxonōmicas, vêm sendo desenvolvidos no Brasil, utilizando-se principalmente armadilhas luminosas nos levantamentos.

0 presente trabalho teve por objetivo, utilizando se armadilhas luminosas, realizar um levantamento das espécies de coleópteros que ocorrem em trēs regiões de cultura da cana-de-açūcar, visando-se observar a constāncia, abundāncia,do mināncia e diversidade das espécies e o quociente e porcentagem de similaridade entre elas. Propōs-se realizar tambēm, uma anālise das flutuações populacionais de vārias espécies, bem como verificar a influēncia de fatores meteorológicos sobre suas populações. 
Entre os métodos conhecidos para se coletar insetos nos diferentes habitats existentes, o uso de armadilhas luminosas é uma prātica muito difundida.

Desta maneira, através das revisões de FROST (1952) e HIENTON (1974), fica-se sabendo da frequēncia de utilização das referidas armadilhas e dos resultados obtidos até essa época nos E. U. A.

ANDERSEN e GREVE (1975) estudando a ordem Neuroptera na Noruega, coletaram 30 espécies durante os anos de $1972 /$ 73.

HAGEN (1976) averiguou o vôo do noctuídeo Loxogrotis albicosta (Smith) em Nebraska, E.U.A., jā ELLIOTT (1977) observou a flutuação populacional do piralídeo ostrinia nubiZalis no Canadá, enquanto GARCIA (1978) apresentou informações sobre os esfingideos da Venezuela. 
0 emprego de armadilhas luminosas na captura de coleópteros também é freqüente.

Assim, GENUNG (1972) estudou a flutuação populacional de elaterīdeos na Flórida (E.U.A.), enquanto DAY et alii (1973) avaliaram a efetividade dessas armadilhas no controle da praga da batata Conoderus falzi Lane, na Carolina do Sul (E.U.A.).

A existēncia de trēs curculionīdeos: Curculio elephas (Gylh.) , C. gladium Marsham e C. venosus (Gráv.) foi de terminada por TADIC (1974) na Iugosiávia, durante os anos 1973/74. Nesse mesmo pais, MESZAROS et alii (1976) apresenta ram os resultados de um estudo realizado em 1971 , sendo as es pécies coletadas pertencentes às famîlias: Carabidae, Ceram bycidae, Curculionidae e Scarabaeidae, enquanto TADIC (1977) relatou os resultados de uma coleta de insetos, onde se captú rou principalmente coleópteros.

Com relação à famîlia Scarabaeidae, VEERESH (1974), na India, usou armadilhas luminosas para controlar Adoretus bicolor Brenske, considerada praga da videira nesse país. TÁ DIC (1976) após estudos em vārias partes da Iugosiávia, concluiu que essas armadilhas são eficientes para determinar a atividade de vōo de Mezolontha mezolontha (L.). SRIVASTAVA et alii (1976) estudaram na India, o controle de adultos de Holotrichia consanguinea Blanchard. TEETES et alii (1976) co letaram no Texas (E.U.A.), adultos de PhyZZophaga crinita (Burm.). 
No Brasil, a coleta de insetos atravēs de armadilhas luminosas está bastante generalizada.

Assim, SILVEIRA NETO et alii (1968) estudaram a flu tuação de pragas da cana-de-açūcar em Piracicaba, SP, obser vando que as populações de Ligyrus humizis e Stenocrates spp foram mais elevadas durante agosto-dezembro. Jā SILVEIRA NET0 et alii (1973) em Assis, SP, mostraram a flutuação populacional de pragas da soja, concluindo que o maior nivel popula cional coincide com o ciclo da cultura.

A ocorrēncia da broca Diatraea saccharalis (Fabr.), na cultura da cana-de-açūcar, foi observada por LARA (1974) em Piracicaba, SP, mostrando que a coleta de maior número de individuos foi na primavera. Enquanto na cultura do algodão, BOTELHO (1975) verificou a flutuação populacional do cu ruquerè Alabama argizlacea (Hueb.), nos municípios paulistas de Araras, Jaboticabal, Piracicaba e Tietē.

0 estudo do comportamento dos animais sempre inte ressou aos pesquisadores, pois muitas das resoluções tomadas ao se programar um manejo racional do ambiente, dependem de conhecimentos sobre a fauna existente na região.

Assim, BARNES e BARNES (1955) observaram a freqũência e constância das espēcies de aracnídeos em quatro estados norte-americanos. ODUM et alii (1960), através de dados obtị dos com moluscos marinhos, formularam um postulado para inter pretação da distribuição das espécies e da evolução do ecos sistema. PIANKA (1973) estudou aspectos da comunidade de rép 
teis (lacertîlicos) nos desertos da Africa, Austrālia e E.U.A. Para o conhecimento da fauna de insetos, muitos estudos jā foram feitos.

Desta maneira, MURDOCK et alii (1972) observaram a diversidade de homōpteros em Michigan, E.U.A. Na Africa OWEN e CHANTER (1972) estudaram a abundância e diversidade de ninfalideos. Na Āustria, MALICKY (1975) analisou a fauna das famîlias Chrysopidae e Hemerobiidae. LOUREIRO e PEDIGO (1977) estudaram a dinâmica populacional quantitativa e qualitativa de insetos nos agrossistemas de soja, milho, aveia e soja-miTho em Ames (Iowa - E.U.A.).

A fauna de coleōpteros também tem merecido a aten ção dos pesquisadores, assim BINAGUI (1972) indicou a distribuição desses insetos nos pântanos da ilha Elba (Itālia), coletando 42 espécies em 1971. Posteriormente, BINAGUI (1974) capturou em vārias regiões da Itālia, espécies pertencentes às familias Curculionidae, Eucnemidae, Pselaphidae, Scarabaei dae e Staphylinidae, enquanto CHANTAL (1975), apresentou cinco espécies novas, relativas às famîlias Cerambycidae, Dytiscidae, Elateridae e Melandryidae, pertencentes à fauna de Que bec, Canadā.

No Egito, ISMAIL (1974) estudou a abundāncia anual para os anos 1970/71 do estafilinídeo Paederus alfieri Koch, considerado um importante predador, jā SHILOV (1975) apresentou um estudo sobre a distribuição e ecologia da fauna de insetos dessa mesma famīlia, na Rússia. 
FERREIRA (1976.a) analisou a fauna de escarabeídeos da subfamîlia Coprinae, no Vale do Zambeze, Moçambique, apresentando 70 espécies. Ainda FERreira (1976.b), estudou espēcies de escarabeídeos das subfamîlias Cetoniinae e Trichinae. No mesmo local, FERREIRA (1976) mostrou a distribuição geogrā fica de espécies pertencentes à famîlia Cerambycidae, coletadas durante os anos 1972/74.

Alguns trabalhos relatam as influências climāticas na captura de coleōpteros, como mostra o estudo feito por PAL (1976) na India, onde fez levantamentos populacionais de esca rabeídeos, concluindo que as espécies observadas ocorreram em maior abundância nos dias em que a umidade relativa ambiental era alta e a temperatura baixa. Já OSANGER (1976) na Carolí na do Sul (E.U.A.), relatou as influências causadas pelas estações do ano e variações do tempo, principalmente temperatura, na captura de adultos do elaterídeo Conoderus falli Lane, durante os anos 1956 a 1967. Observou, o referido autor, que aumentos repentinos na temperatura ocasionaram acréscimos relativos de individuos capturados.

WOOLDRIDGE (1976) estudou a famîlia Hydrophilidae na Austrāila, fornecendo a descrição e distribuição do gênero Paracymus, enquanto PALM (1977), analisando a mesma famīlia nas Ilhas Canārias, forneceu a descrição, distribuição e ecologia dos gêneros Cercyon e Pachysternum. KNIE (1977) na Alemanha 0cidental, estudou em 1973/74 a fauna de besouros aquāticos relacionando 40 espécies. 
Na Finlândia, SILFVERBERg (1977) observou a fauna de coleópteros, apresentando o nome de 66 espécies. MIKSIC (1977) em Montenegro, Iugosiávia, fez estudos faunisticos relativos às espécies pertencentes às famîlias: Cerambycidae, Ciccindelidae, Dytiscidae, Hydrophilidae e Meloidae, enquan to que BOSC (1977), estudando a fauna na França, relatou a lo calização e frequência de espécies pertencentes às famílias: Carabidae, Cerambycidae e Scarabaeidae.

Com relação à famīlia Carabidae, RIVARD (1974) encontrou mais de 60 espécies em um pomar de maçãs, concluindo que por serem predadoras e carnivoras, poderiam contribuir significativamente nos programas de controle das pragas nesses pomares. EL-BOROLLOSY e AWADALLAH (1974) investigaram por quatro anos a flutuação populacional de Calosoma chlorostictum Deg. KNIE (1975) na Alemanha Ocidental, estudou os co leópteros dessa famīlia, fornecendo dados sobre a variedade das espécies e número de indivíduos. JONES (1976), na Inglaterra, analisou esses coleópteros em trigo de inverno, notando que as populações eram modificadas por emigração e imigração dos indivíduos. ALVES (1976) apresentou 37 espécies pertencentes à fauna de Moçambique em 1972. PERRAULT (1977) estudou a fauna do Haiti, apresentando o relacionamento zoogeogrāfico de algumas das espécies. DEVEAUX (1978) na França, relatou a distribuição e diversidade de espécies em agrossistemas de batata e milho, observando que a maioria delas foram influenciadas pelo tipo de cultura. 
No Brasil, pesquisas sobre a fauna de insetos também são feitas, desta maneira SILVEIRA NETO (1972), utilizando-se de uma rede de armadilhas luminosas instaladas em nove localidades do Estado de São Paulo, estudou a diversidade dos insetos coletados.

TARRAGo (1973) em Santa Maria, RS, mediu a influẹn cia do hospedeiro sobre a diversidade de noctuídeos usando o indice fisiogrāfico, jā LINK (1976) na mesma localidade, estudou os aspectos faunisticos de abundância relativa a fenolo gia de alguns Scarabaeoidea.

A fauna de noctuídeos dos municípios paulistas de Jaboticabal e Piracicaba, foi estudada por LARA (1976), que verificou a constāncia, o Indice de diversidade, o quociente de similaridade e as porcentagens de similaridade das espécies pertencentes aos dois locais.

COELHO (1977) realizou uma anālise faunistica de es fingideos e piralideos, a partir de um levantamento feito em Piracicaba, SP, enquanto BUSOLI (1979), fez um estudo seme lhante para insetos das ordens Coleoptera, Lepidoptera, He miptera, Homoptera e Orthoptera, em Jaboticabal, SP. 
12.

4 - MATERIAL E METODOS

As coletas foram feitas nos municípios paulistas de Assis (Usina Nova América), Barra Bonita (Usina da Barra) e Pradópolis (Usina São Martinho), Figura 1 . Para tal, utili zou-se armadilhas luminosas modelo "Luiz de Queiroz" (SILVEIRA NETO e SILVEIRA, 1969), com làmpadas fluorescentes, ultravioleta, modelo F $15 \mathrm{~T} 8 \mathrm{BL}$, da General Eletric. As mesmas pos suiam altura regulável, e permaneceram em funcionamento uma noite por semana, de agosto de 1976 a junho de 1978.

Nos três locais, os insetos foram retirados das armadilhas por técnicos da Secção de Entomologia, da Coordenado ria Regional-Sul do Planalsucar, sendo posteriormente mortos com éter, acondicionados em sacos plásticos e enviados ao Laboratōrio de Ecologia do Departamento de Entomologia da Escola Superior de Agricultura "Luiz de Queiroz" da Universidade de São Paulo (ESALQ/USP), Piracicaba, onde foram separados, contados e catalogados. 

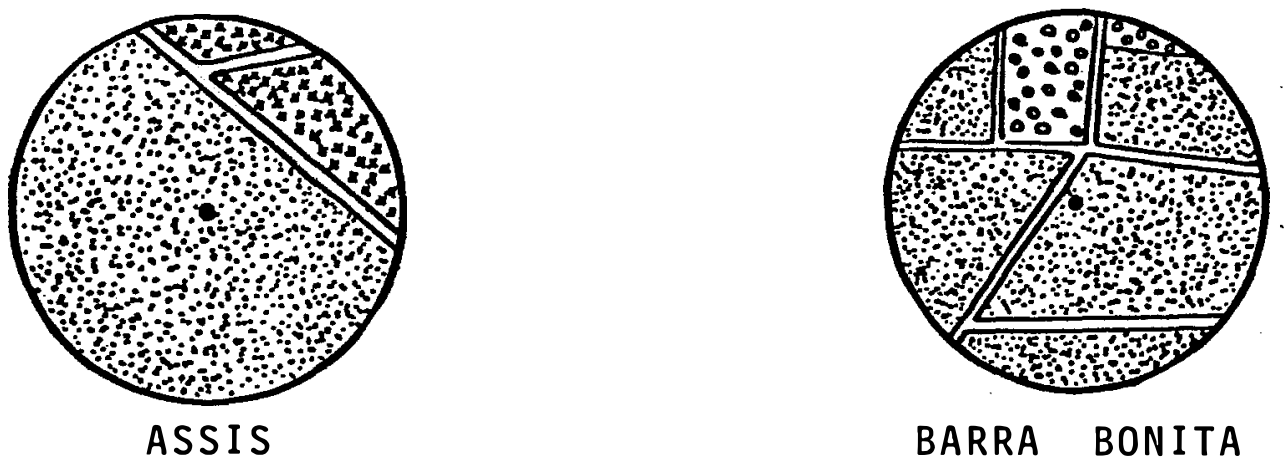

BARRA BONITA
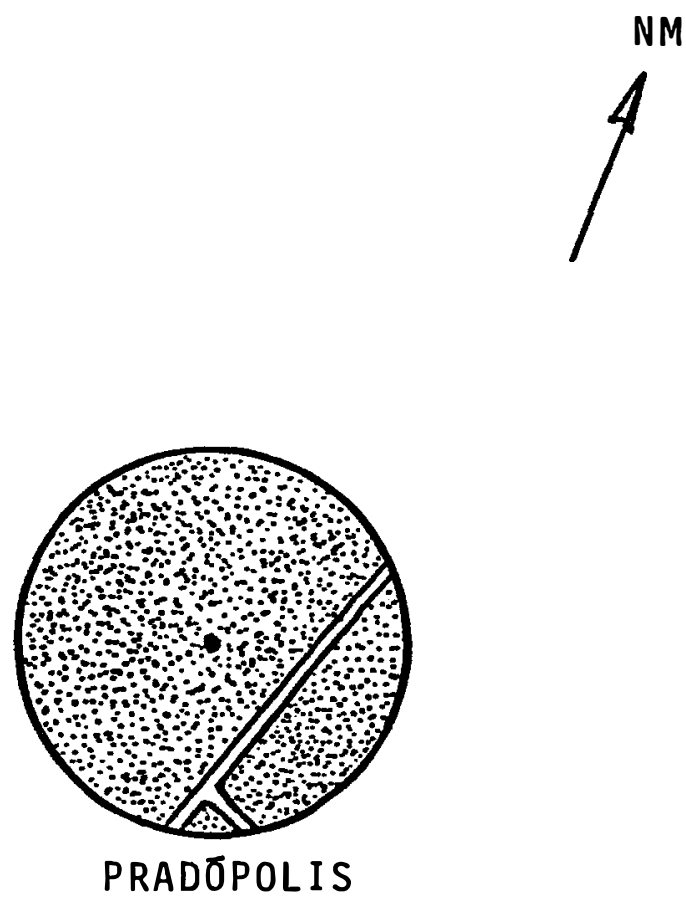

- Local da armadilha

Cultura da cana-de-açūcar

Sede

Pomar

Estradas

Fig. 1 - Locais de instalação e āreas de influēncia das armadilhas luminosas, em trēs regiões do Estado de São Paulo - Escala 1:10.000. 
Os seguintes aspectos foram estudados:

\section{1 - Levantamento.}

A maior parte das espécies foi identificada pelas Dras Cleide Costa, Maria Eulina Jorge da Silva e Drs. Sérgio Vanin e Ubirajara R. Martins, pertencentes ao Museu de Zoologia da Universidade de São Paulo; pelo Pe. Francisco S. Pe reira, do Instituto Biológico de São Paulo, Dr. Antonio Martīnez, do Instituto Entomológico San Miguel, Argentina e Dr. Richard E. White, do Beltsville Agricultural Research Center, E.U.A. Algumas espécies foram identificadas por comparação, com exemplares pertencentes ao Museu do Departamento de Ento mologia da ESALQ/USP, Piracicaba, SP.

Para a apresentação, os dados semanais foram catalo gádos pela média mensal dos dois anos, tendo os seus valores sido arredondados.

\section{2 - Medidas de Fauna}

Caracteristicas das Comunidades.

\subsection{1 - Constāncia}

Através desta medida, fez-se uma comparação das populações coletadas durante os dois anos nas três localidades. 
Para tal, somou-se os dados semanais 2 a 2 transformando-os em quinzenais, sendo:

$$
C(\%)=\frac{P}{N} \cdot 100
$$

onde:

$P=$ nūmero de coletas contendo a espécie estudada;

$N=$ nūmero total de coletas efetuadas.

Obtidas as porcentagens, as espēcies foram separadas em categorias de acordo com a classificação citada em DAJoZ (1973). Assim, considerou-se as seguintes categorias:

espécies constantes (W): presentes em mais de $50 \%$ das coletas;

espécies àcessōrias ( $Y$ ) : presentes em $25-50 \%$ das coletas; espécies acidentais $(Z)$ : presentes em menos de $25 \%$ das co letas.

\section{2 .2 - Domināncia}

Para cada localidade de coleta, determinou-se a domināncia das espécies para o total dos dois anos. Desta maneira, baseou-se no método citado em SAKAGAMI e MATSUMURA (1967), utilizando-se as equações:

Limite Superior $(L S): \frac{n_{1} F_{0}}{n_{2}+n_{1} F_{0}} \cdot 100$ onde: 


$$
\begin{aligned}
& n_{1}=2(k+1) ; \\
& n_{2}=2(N-K+1) .
\end{aligned}
$$

Limite Inferior $(L I):\left[1-\frac{n_{1} F_{0}}{n_{2}+n_{1} F_{0}}\right] \cdot 100$

onde:

$$
\begin{aligned}
n_{1}= & 2(N-K+1) ; \\
n_{2}= & 2(K+1) ; \\
N= & \text { número total de indivīduos capturados; } \\
K= & \text { nümero de indivî́duos de cada espécie; } \\
F_{0}= & \text { valor obtido através da tabela de distribuição de } \\
& F \text {, ao nīvel de } 5 \% \text { de probabilidade, nos graus de } \\
& \text { liberdade estabelecidos pelos valores de } n_{1} \text { e } n_{2} .
\end{aligned}
$$

As espécies consideradas dominantes, apresentaram

LI maior que o LS calculado com o valor de $K=0$. Os cálcu los foram feitos pelo computador do Departamento de Matemática e Estatística da ESALQ, USP, através do programa feito pe10 Engo-Agrọ José Fernando Soares Dias, Professor da Universi dade do Maranhä́o.

Neste cālculo, a espécie Sezenophorus sp não foi in cluîda, devido ter apresentado um número excessivo de indivíduos coletados.

\section{2 .3 - Abundāncia}

Para o cálculo da abundāncia das populações em cada 
localidade, empregou-se uma medida de dispersão conforme SILVEIRA NETO et alii (1976), através do cálculo do desvio padrão, erro padrão da média e intervalo de confiança (IC), para o qual utilizou-se o teste "t" a 5 e $1 \%$ de probabilidade. Estabeleceu-se as seguintes classes de abundāncia para as espécies:

rara (-) : nūmero de indivíduos menor que o limite inferior do IC a $1 \%$ de probabilidade;

dispersa (0): nūmero de indivíduos situado entre os limites inferiores do IC a 5 e $1 \%$;

comum $(=)$ : número de indivīduos situado dentro do IC a $5 \%$; abundante $(+)$ : número de indivíduos șituado entre os limi tes superiores do IC a 5 e $1 \%$;

muito abundante $(X)$ : número de indivĩduos maior que o limite superior do IC a $1 \%$.

Devido o nūmero de indivíduos da espécie selenophorus sp exceder em muito o das demais, foi classificada como ex cessivamente abundante, sem ter sido incluĩda nos cálculos des critos anteriormente.

\subsection{4 - Indice de diversidade}

A diversidade da fauna coletada em cada localidade, foi calculada atravēs do indice de diversidade $(\alpha)$ proposto por MARGALEF (1951), sendo: 


$$
\alpha=\frac{S-1}{L N} \text {. }
$$

onde:

$S=$ nūmero de espécies;

$L N=$ logarítmo neperiano do numero de indivíduos.

\section{Comparação das Comunidades}

\subsection{5 - Quociente de similaridade}

Estimou-se a similaridade entre as trēs localidades para os dois anos de coleta, baseando-se no quociente de similaridade proposto por SORENSEN (1948), onde:

$$
\text { Q. S. }=\frac{2 \mathrm{~J}}{a+b}
$$

sendo:

a : nūmero de espécies no habitat $A$;

b : nūmero de espécies no habitat $B$;

$\mathrm{J}:$ nūmero de espécies encontradas em ambos os habitats.

Neste caso, considerou-se as espécies classificadas como excessivamente abundante, muito abundantes, abundantes e comuns, no item 4.2.3.

Os quocientes de similaridade obtidos, foram comparados entre si atravēs do mesmo cālculo de dispersão empregado na estimativa da abundāncia, sendo que o intervalo de confiança (IC) foi calculado para "t" a 5\% de probabilidade. 


\subsection{6 - Porcentagem de similaridade}

Foi verificada a semelhança entre as espécies consi deradas excessivamente abundante, muito abundantes, abundan tes e comuns, não sō quanto a composição de espécies, mas tam bém considerando-se o nūmero de indivíduos coletados. Para isto, baseou-se em SOUTHWOOD (1971), em que:

$$
\% S=\Sigma(\% a+\% b+\ldots+\% n)
$$

sendo:

$\% a=$ menor porcentagem da espécie a observada no confronto de dois locais;

$\% b=$ menor porcentagem da espécie b observada no confronto de dois locais;

$\% \mathrm{n}=$ menor porcentagem da espécie $\underline{\mathrm{n}}$ observada no confronto de dois locais.

As porcentagens de similaridade obtidas, foram comparadas entre si, usando-se o mesmo método do ítem anterior.

\section{3 - Flutuações Populacionais}

Para tal estudo, selecionou-se as espécies associadas à cultura da cana-de-açūcar, baseando-se em SILVA (1968) e GUAGLIUMI (1972).

Os dados médios dos dois anos, foram catalogados men salmente, sendo também mostrados em grāficos para uma melhor visualização. 
4.4 - Correlação com Fatores Meteorológicos

Com os dados de temperatura e precipitação obtidos junto às usinas: Nova América, da Barra e São Martinho, procurou-se observar as possiveis influências desses fatores sobre as populações das espécies selecionadas no item anterior. Empregou-se o teste de correlação de Kendall segundo CAMPOS (1979), utilizando-se os dados mensais das espécies selecionadas, a temperatura mensal e a precipitação total men sal dos dois anos, totalizando 24 pares em cada correlação.

0 valor $K^{*}$ para aproximação normal, foi calculado pela fórmula:

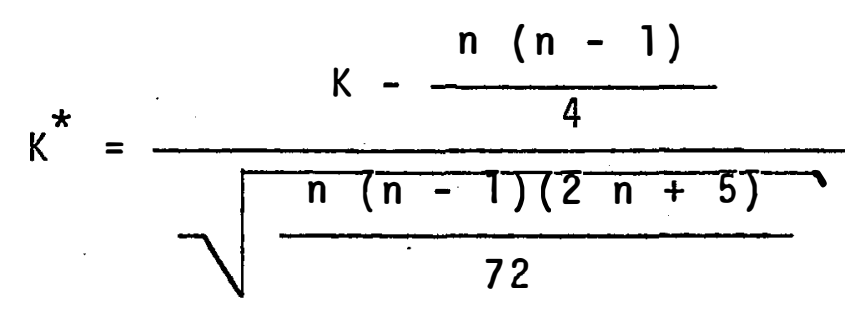

onde:

$$
\begin{aligned}
& K=\text { nūmero de pares concordantes: } \\
& n=\text { nūmero de pares a serem correlacionados. } \\
& \text { O valor de a foi tomado em dobro devido ser um tes- }
\end{aligned}
$$
te bilateral, e no presente trabalho, considerou-se uma corre lação estatisticamente significativa, para valores de $\alpha$ até 0,10 .

No cālculo de $\bar{\tau}$ usou-se a fórmula;

$$
\bar{\tau}=\frac{4 k}{n(n-1)}-1
$$


21.

onde:

$K=$ nümero de pares concordantes;

$n=$ nümero de pares a serem correlacionados.

Os valores positivos de $\bar{\tau}$ indicam uma correlação

positiva, e os valores negativos, uma correlação contrāria. 
5.1 - Levantamento

Os resultados das coletas de coleópteros efetuadas em Assis, Barra Bonita e Pradōpolis, se acham na Tabela 1, catalogados por espécie e média mensal do nūmero de indiví duos capturados de 1976 a 1978, bem como os índices faunistí cos de abundāncia, constāncia e domināncia. 
TABELA 1 - Mēdia mensal de coleópteros coletados em Assis, Barra Bonita e Pradópolis com armadi Thas luminosas de 1976/78 e dados de constância, abundāncia e domināncia das espécies.

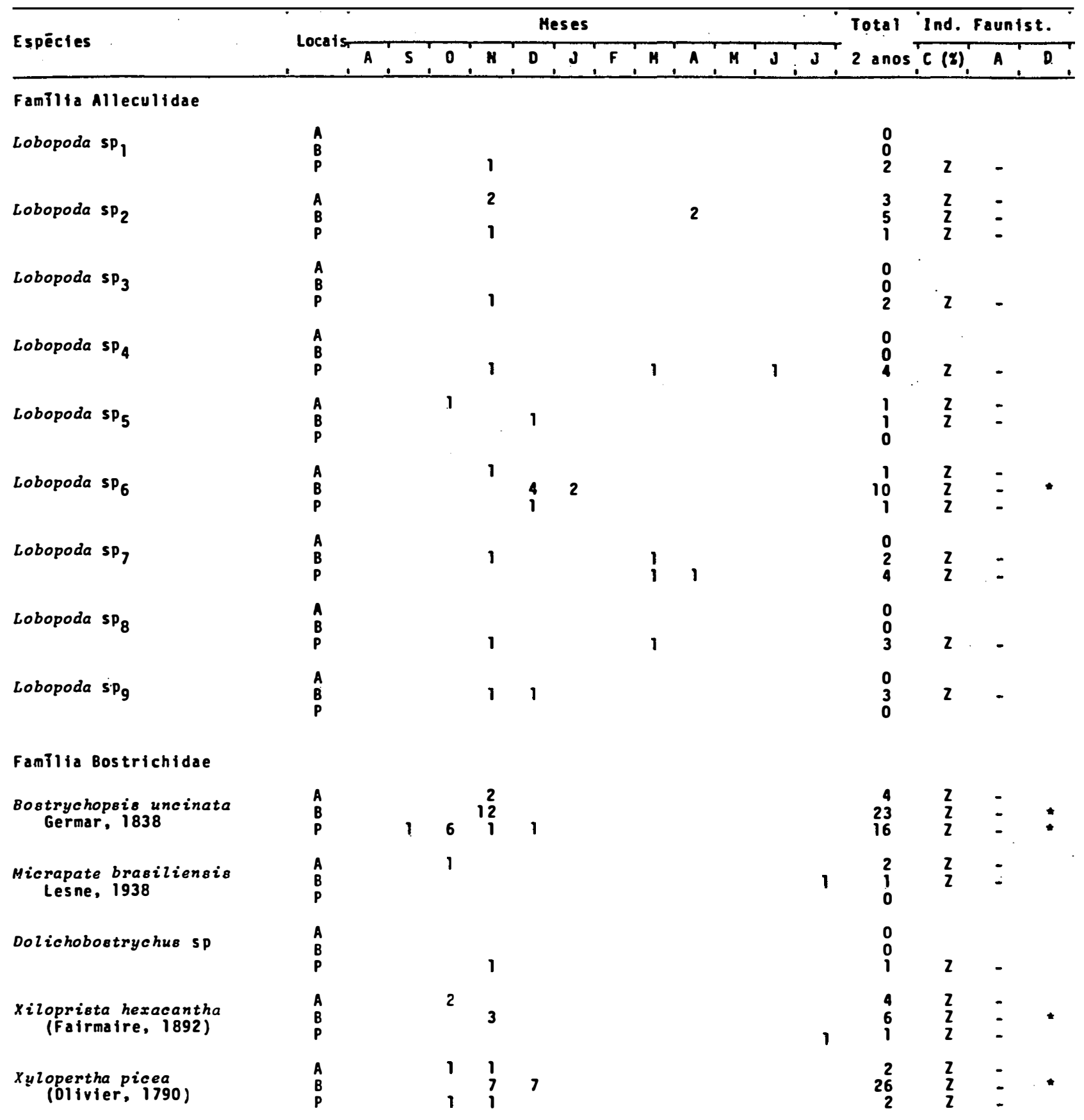

Familia Carabidae

\begin{tabular}{|c|c|c|c|c|c|c|c|c|c|c|c|}
\hline $\begin{array}{l}\text { Anisotarsus cupripennis } \\
\text { Germar. } 1824\end{array}$ & $\begin{array}{l}\hat{A} \\
B \\
P\end{array}$ & $\begin{array}{l}91 \\
29 \\
24\end{array}$ & $\begin{array}{l}40 \\
88 \\
13\end{array}$ & $\begin{array}{r}5 \\
116 \\
25\end{array}$ & $\begin{array}{r}5 \\
26 \\
4\end{array}$ & $\begin{array}{r}3 \\
20 \\
2\end{array}$ & $\begin{array}{l}2 \\
3 \\
2\end{array}$ & & $\begin{array}{l}288 \\
563 \\
139\end{array}$ & $\begin{array}{l}Z \\
y \\
y\end{array}$ & $\begin{array}{l}x \\
x \\
=\end{array}$ \\
\hline Aspidoglo88a SP & $\begin{array}{l}A \\
B \\
P\end{array}$ & ו'ו & $\begin{array}{l}35 \\
18\end{array}$ & $\begin{array}{r}1 \\
33 \\
43\end{array}$ & $\begin{array}{r}2 \\
18 \\
6\end{array}$ & 2 & $\begin{array}{l}1 \\
2\end{array}$ & $?$ & $\begin{array}{r}4 \\
172 \\
164\end{array}$ & $\begin{array}{l}z \\
z \\
y\end{array}$ & $\begin{array}{l}\bar{x} \\
+\end{array}$ \\
\hline $\begin{array}{l}\text { Arthrostictus puberulus } \\
\text { (Oejean. 1829) }\end{array}$ & $\begin{array}{l}A \\
B \\
P\end{array}$ & $\begin{array}{r}37 \\
3 \\
2\end{array}$ & $\begin{array}{r}209 \\
22\end{array}$ & $\begin{array}{r}1 \\
46 \\
16\end{array}$ & $\begin{array}{l}2 \\
1\end{array}$ & $\begin{array}{l}4 \\
8 \\
1\end{array}$ & i & 6 & $\begin{array}{r}498 \\
183 \\
39\end{array}$ & $\begin{array}{l}Z \\
Y \\
Z\end{array}$ & $\begin{array}{l}x \\
x \\
0\end{array}$ \\
\hline
\end{tabular}


TABELA 1 - Continuação

\begin{tabular}{|c|c|c|c|c|c|c|c|c|c|c|c|c|c|c|c|c|c|}
\hline \multirow{2}{*}{ Espéctes } & \multirow{2}{*}{ Local: } & \multicolumn{12}{|c|}{ Meses } & \multirow{2}{*}{$\begin{array}{l}\text { Total } \\
2 \text { anos }\end{array}$} & \multirow{2}{*}{ Ind. } & \multicolumn{2}{|c|}{ Faunist. } \\
\hline & & A & $\mathbf{S}$ & 0 & N & D & $\mathbf{J}$ & $\mathbf{F}$ & $M$ & $A$ & $M$ & $\mathbf{J}$ & $\mathbf{J}$ & & & A & D \\
\hline \multicolumn{18}{|l|}{ Familia Carabidae } \\
\hline $\begin{array}{l}\text { Arthrostictus speciosus } \\
\text { (Dejean. 1829) }\end{array}$ & $\begin{array}{l}\text { A } \\
\text { B } \\
P\end{array}$ & & & 6 & $\begin{array}{r}11 \\
2\end{array}$ & $\begin{array}{r}1 \\
5 \\
37\end{array}$ & . & & & & & & & $\begin{array}{r}24 \\
9 \\
85\end{array}$ & $\begin{array}{l}2 \\
2 \\
2\end{array}$ & $\overline{-}$ & : \\
\hline $\begin{array}{c}\text { Arthrostictus oulcatulus } \\
\text { (Dejean, 1829) }\end{array}$ & $\begin{array}{l}\mathbf{A} \\
\mathbf{B} \\
\mathbf{P}\end{array}$ & & $\begin{array}{l}1 \\
4\end{array}$ & 4 & 137 & 10 & & & & & & & & $\begin{array}{r}0 \\
275 \\
33\end{array}$ & $\begin{array}{l}2 \\
2\end{array}$ & $\begin{array}{l}x \\
0\end{array}$ & : \\
\hline Abaris Sp & $\begin{array}{l}\mathbf{A} \\
\mathbf{B} \\
\mathbf{P}\end{array}$ & & & $\begin{array}{r}8 \\
27\end{array}$ & 1 & $\begin{array}{r}4 \\
96\end{array}$ & 2 & & & & & & & $\begin{aligned} 16 \\
11 \\
246\end{aligned}$ & $\begin{array}{l}2 \\
2 \\
2\end{array}$ & $\bar{x}$ & : \\
\hline Barypus Sp & $\begin{array}{l}\hat{A} \\
\hat{P}\end{array}$ & & & & & 24 & $\cdot$ & & & & & & & $\begin{array}{r}0 \\
D \\
48\end{array}$ & 2 & * & - \\
\hline Brachinus SP & $\begin{array}{l}\mathbf{A} \\
\mathbf{B} \\
\mathbf{P}\end{array}$ & & & 2 & $\begin{array}{r}7 \\
30\end{array}$ & 2 & & $\begin{array}{l}.1 \\
2\end{array}$ & $\begin{array}{l}2 \\
3\end{array}$ & 1 & 1 & 1 & & $\begin{array}{r}23 \\
73 \\
1\end{array}$ & $\begin{array}{l}z \\
z \\
z\end{array}$ & $\dot{-}$ & $\ddot{*}$ \\
\hline $\begin{array}{l}\text { Callida scutellaris } \\
\text { Chaudoir, } 1872\end{array}$ & $\begin{array}{l}A \\
B \\
P\end{array}$ & & & & 2 & $\begin{array}{l}1 \\
4 \\
3\end{array}$ & 1 & & 1 & & & & & $\begin{array}{r}1 \\
12 \\
8\end{array}$ & $\begin{array}{l}2 \\
2 \\
2\end{array}$ & - & * \\
\hline Callida sp & $\begin{array}{l}\text { A } \\
B \\
P\end{array}$ & & & & & 12 & & & & & & & & $\begin{array}{r}0 \\
4 \\
22\end{array}$ & 2 & - & $\bullet$ \\
\hline $\begin{array}{l}\text { Calosoma al ternans } \\
\text { (Fabricius. } 1791 \text { ) }\end{array}$ & $\begin{array}{l}A \\
B \\
P\end{array}$ & & & $\begin{array}{l}1 \\
1\end{array}$ & $\begin{array}{l}5 \\
6\end{array}$ & $\begin{array}{l}1 \\
7 \\
4\end{array}$ & $\begin{array}{l}2 \\
2 \\
2\end{array}$ & 2 & & & & & & $\begin{array}{l}10 \\
26 \\
25\end{array}$ & $\begin{array}{l}2 \\
2 \\
2\end{array}$ & 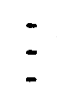 & : \\
\hline Camptodontus Sp & $\begin{array}{l}\mathbf{A} \\
\mathbf{B} \\
\mathbf{P}\end{array}$ & & & 5 & $\begin{array}{l}8 \\
5 \\
1\end{array}$ & $\begin{array}{r}2 \\
9\end{array}$ & $\begin{array}{l}4 \\
1\end{array}$ & 2 & & & & & & $\begin{array}{l}18 \\
64 \\
31\end{array}$ & $\begin{array}{l}z \\
y \\
z\end{array}$ & $\begin{array}{l}- \\
0\end{array}$ & : \\
\hline Clivine sp. & $\begin{array}{l}\mathbf{A} \\
\mathbf{B} \\
\mathbf{P}\end{array}$ & & & & 48 & 2 & 8 & & $\cdot$ & & & & & $\begin{array}{r}16 \\
99 \\
0\end{array}$ & 2 & $\overline{-}$ & : \\
\hline Colliuris sp & $\begin{array}{l}\mathbf{A} \\
\mathbf{B} \\
\mathbf{P}\end{array}$ & & & 1 & 1 & $\begin{array}{l}\mathbf{5} \\
\mathbf{5}\end{array}$ & & & & & 2 & & & $\begin{array}{r}0 \\
10 \\
16\end{array}$ & 2 & $\overline{-}$ & : \\
\hline Coptia sp & $\begin{array}{l}A \\
B \\
P\end{array}$ & & & & & 1 & & & & & & & & $\begin{array}{l}0 \\
0 \\
1\end{array}$ & 2 & - & \\
\hline $\begin{array}{l}\text { Eucheila otrandi } \\
\text { (Liebke, 1939) }\end{array}$ & $\begin{array}{l}A \\
B \\
P\end{array}$ & & & & 1 & & $\begin{array}{l}1 \\
1 \\
2\end{array}$ & $\begin{array}{l}1 \\
1\end{array}$ & $\begin{array}{l}1 \\
2 \\
3\end{array}$ & 4 & & & 1 & $\begin{array}{l}7 \\
13 \\
12\end{array}$ & $\begin{array}{l}2 \\
2 \\
2\end{array}$ & $\begin{array}{l}- \\
-\end{array}$ & * \\
\hline $\begin{array}{c}\text { Galerita collaris } \\
\text { Dejean, } 1826\end{array}$ & $\begin{array}{l}A \\
B \\
P\end{array}$ & 1 & 1 & $\begin{array}{l}3 \\
7 \\
9\end{array}$ & $\begin{array}{r}1 \\
18 \\
1\end{array}$ & $\begin{array}{l}1 \\
22 \\
14\end{array}$ & 3 & 3 & & & & & & $\begin{array}{r}9 \\
105 \\
48\end{array}$ & $\begin{array}{l}z \\
y \\
z\end{array}$ & $\begin{array}{l}- \\
= \\
=\end{array}$ & $\vdots$ \\
\hline $\begin{array}{c}\text { Galerita cootal imai } \\
\text { Reichardt, } 1967\end{array}$ & $\begin{array}{l}A \\
B \\
P\end{array}$ & & & & 1 & $\begin{array}{l}1 \\
1\end{array}$ & & & & & & & & $\begin{array}{l}1 \\
1 \\
1\end{array}$ & $\begin{array}{l}2 \\
2 \\
2\end{array}$ & $\begin{array}{l}- \\
-\end{array}$ & \\
\hline $\begin{array}{c}\text { Galerita occidentalis } \\
\text { (Olivier, 1795) }\end{array}$ & $\begin{array}{l}A \\
B \\
P\end{array}$ & & & & 1 & 1 & & - & & & & & & $\begin{array}{l}0 \\
0 \\
2\end{array}$ & 2 & - & \\
\hline $\begin{array}{l}\text { Helluobrochus ares } \\
\text { Reichardt. } 1974\end{array}$ & $\begin{array}{l}\text { A } \\
B \\
\mathbf{P}\end{array}$ & & & $\begin{array}{l}1 \\
1\end{array}$ & 1 & 1 & & & & & & & & $\begin{array}{l}1 \\
4 \\
1\end{array}$ & $\begin{array}{l}2 \\
2 \\
2\end{array}$ & $\dot{-}$ & \\
\hline
\end{tabular}


TABELA 1 - Continuação

I.spictier

Familia Carabidae

Helluobrochus cribricollis
(Chaudoir, 1872)
Helluomorpha squiresi
(Chaudoir, 1872 )
Lebia concinna
Brulle, 1837
Lebia gaudichaudi
Laporte, 1835
.
Lebia rugifrons
Dejean, 1831
Lebia vittigera
Dejean, 1831

$\stackrel{A}{B}$

$A$
$B$
$P$

A
B
$\mathbf{P}$

A
B
P

$A$
$B$
$P$

A
B
P

Leptotrachelus sp

Morion Sp

Physea Sp

Pionycha sp

Polpochila sp

Pseudomorpha Sp

Scarites Sp

Selenophorus sp

Tichonia Sp

Trichopselaphoss subiridescens Chaudoir, 1843

Familia Cerambycidae

Acanthoderes jaspidea (Germar. 1824)

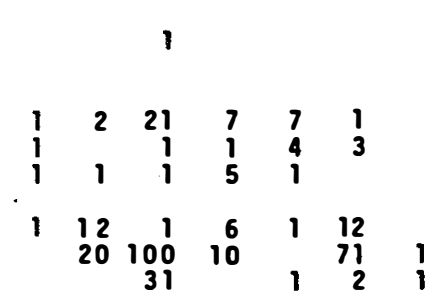

218

$\begin{array}{rrrr}1 & 10 & & 1 \\ 1 & 1 & 8 & 1\end{array}$

2

$2 \quad 1$

1

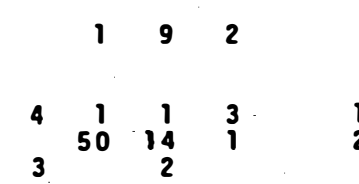

2

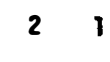

2

$\begin{array}{lllllllll}42 & 9 & 87 & 3017 & 1532 & 434 & 127 & 14 & 2\end{array}$ $\begin{array}{rrrrrrrrr}1 & 1772 & 4104 & 3017 & 1532 & 434 & 127 & 14 & 2 \\ 20 & 632 & 363 & 5149 & 3239 & 218 & 718 & 1 & 1\end{array}$

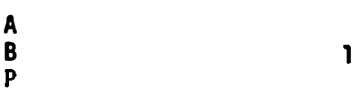

A 2 $\begin{array}{rrr}0 & & \\ 1 & 2 & - \\ 0 & & \\ 76 & Y & = \\ 17 & 2 & = \\ 17 & 2 & - \\ 66 & \gamma & = \\ 400 & 2 & x \\ 66 & 2 & =\end{array}$

$\begin{array}{lll}0 & & \\ 1 & 2 & -\end{array}$

$\therefore \quad 21$

212 -

$\begin{array}{lll}1 & 2 \\ 2 & 2 & -\end{array}$

$\begin{array}{rrr} & 26 & 2 \\ 11 & 19 & 2 \\ 11 & 55 & 2\end{array}$

$\begin{array}{lll}3 & 2 & - \\ 5 & 2 & -\end{array}$

$\begin{array}{ll}0 & \\ 1 & 2 \\ 0 & \end{array}$

0
22
0

$\begin{array}{rrr}19 & 2 & - \\ 133 & 2 & x \\ 9 & 2 & -\end{array}$

$\begin{array}{rrr}0 & & \\ 0 & 2 \\ 16 & 2\end{array}$

$\begin{array}{rrr}0 & & \\ 1 & 2 & - \\ 3 & 2 & - \\ 10.523 & H & : \\ 31.378 & H & : \\ 12.668 & Y & :\end{array}$

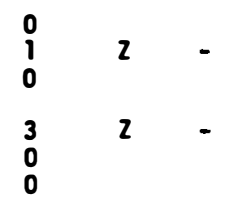


TABELA 1 - Continuacão

Espécies Locais

Familia Cerambycidae

Acanthoderes nigricans

Lameere, 1885

Acanthoderes propinqua

Melzer. 1931

Achryeon surinamum

(Linnaeus, 1767)

Adetus sp

Aerenea quadriplagiata

(Boheman. 1859)

Aerenica sp

Chrysoprasis aurigena

(German, 1824)

Coleoxestia sp

Dryoctenes scrupulosus (Germar. 1824)

Gorybia castanea

(Gounelle, 1908)

Gorybia ruficauda

(Gounelle, 1908)

Bippopsis S.P

Bypsioma gibbera

Servilie, 1835

Luscosmodicum beaver $i$ Martins, 1970

Nephalius diabolicus Lameere. 1890

Nesozineus sp

Oncideres dejeani Thomson, 1868

oreodera quinquetuberculato (Drapiez. 1820) $\begin{array}{ll}\text { A } & 1 \\ \text { B } & 1\end{array}$

$\stackrel{A}{B} \quad 1$

A 1

A 1

A
$\mathbf{P}$

A
B
P

$\begin{array}{lll}14 & 3 & 5\end{array}$

1

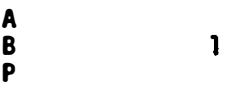

A
B
P

$\begin{array}{ll}\text { A } & 3 \\ \text { B } & \text { P }\end{array}$

$\begin{array}{ll}\text { A } & 1 \\ \text { B } & 1 \\ \text { P } & 1\end{array}$

$\begin{array}{ll}\text { A } & \text { ? } \\ \text { B } & 1\end{array}$

$\boldsymbol{\imath}$

1

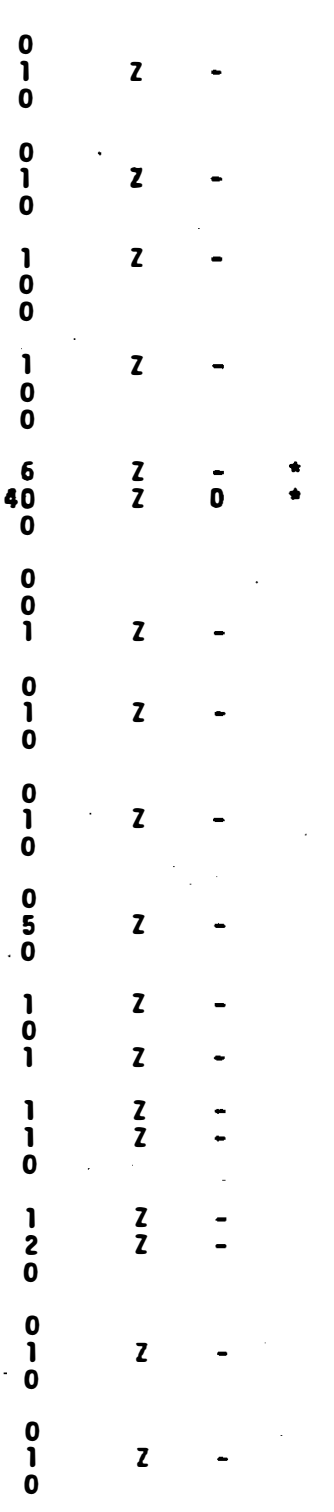

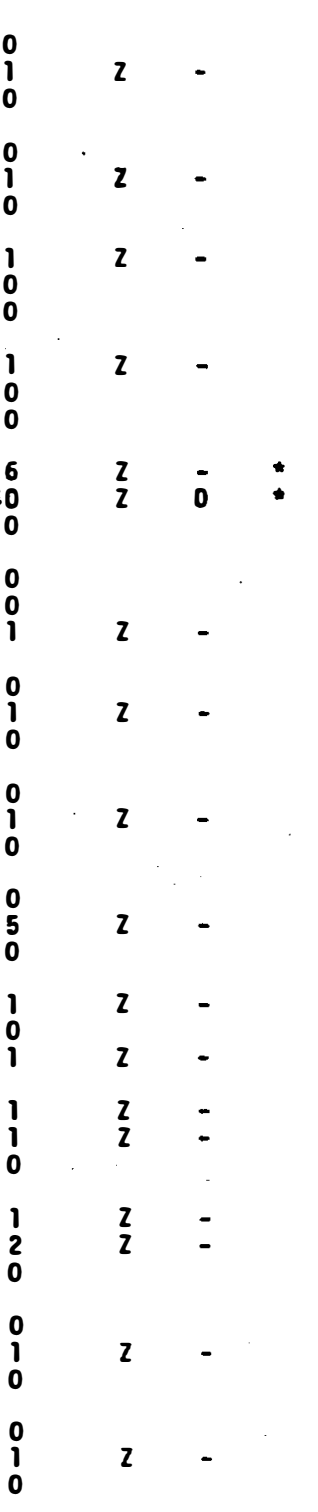

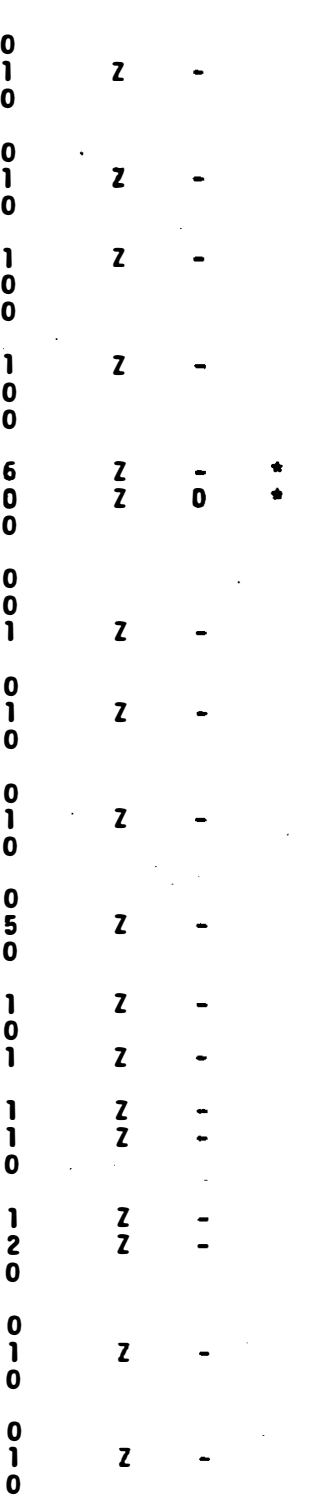

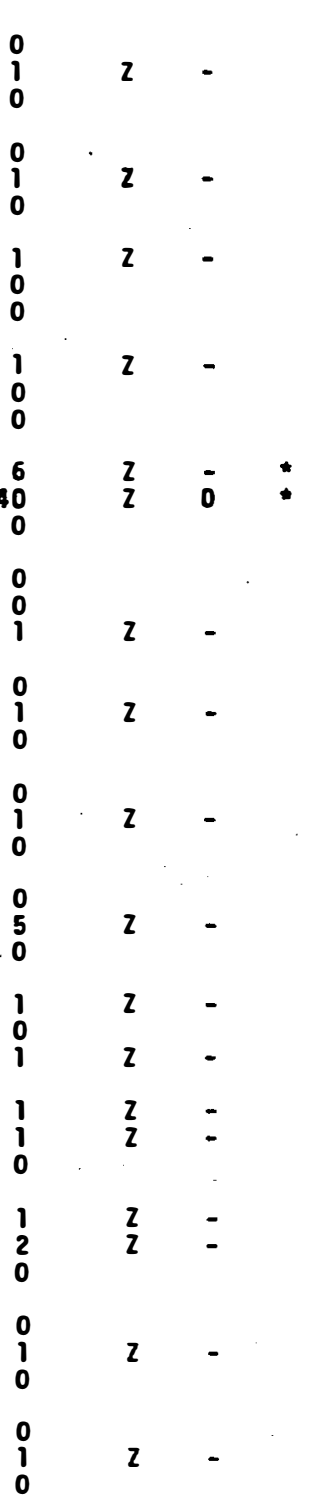

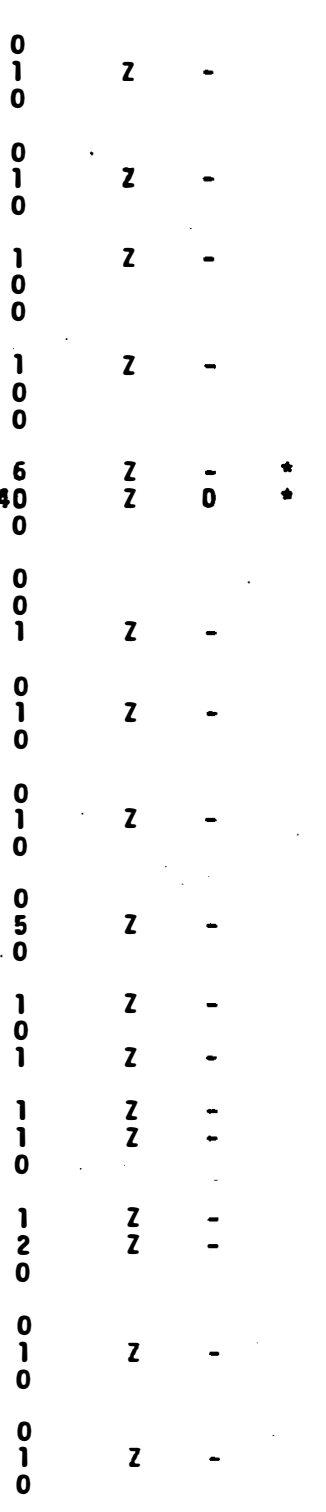

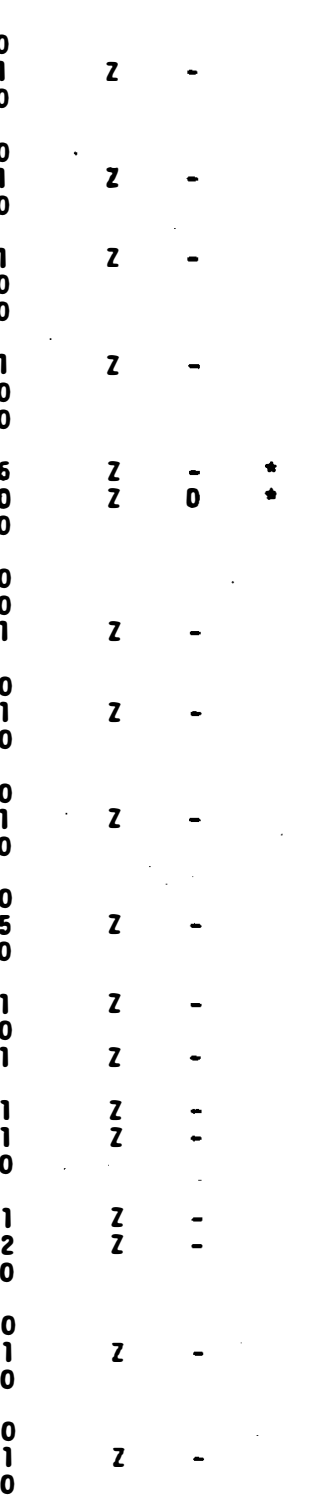

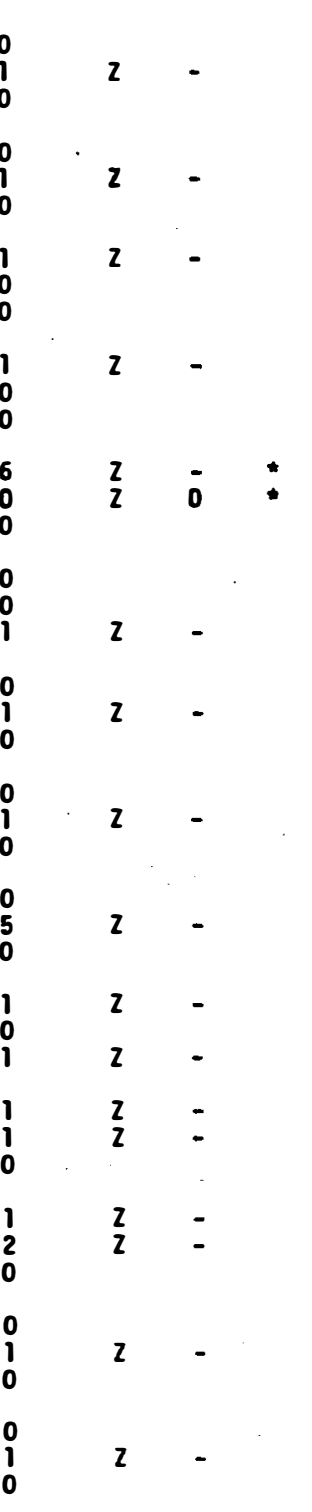

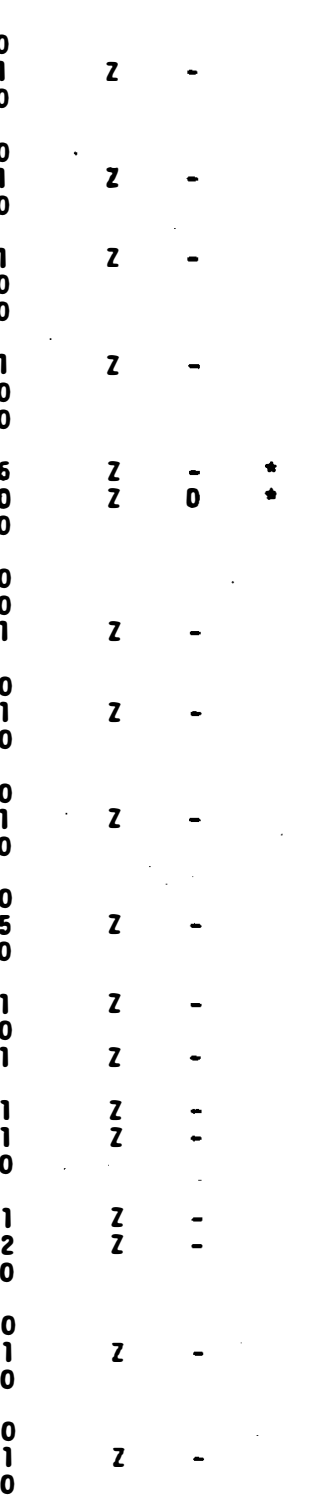

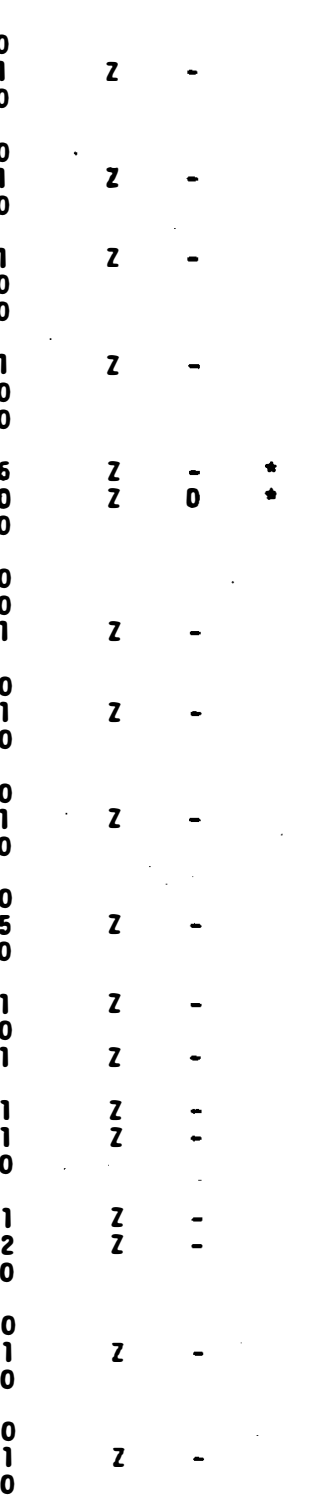

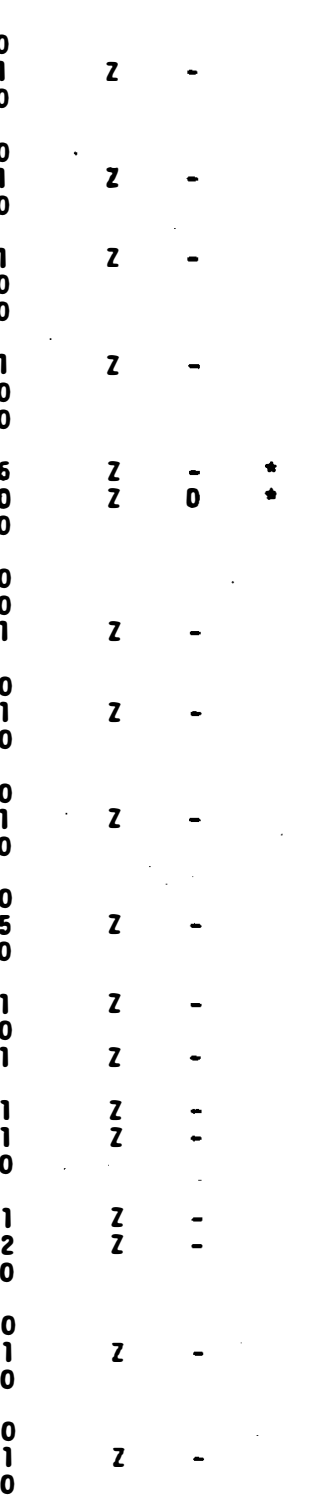

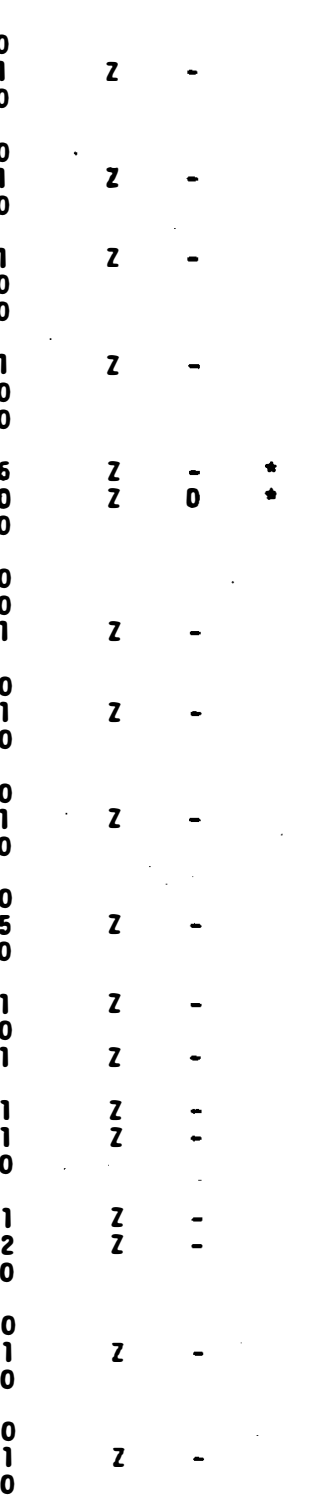

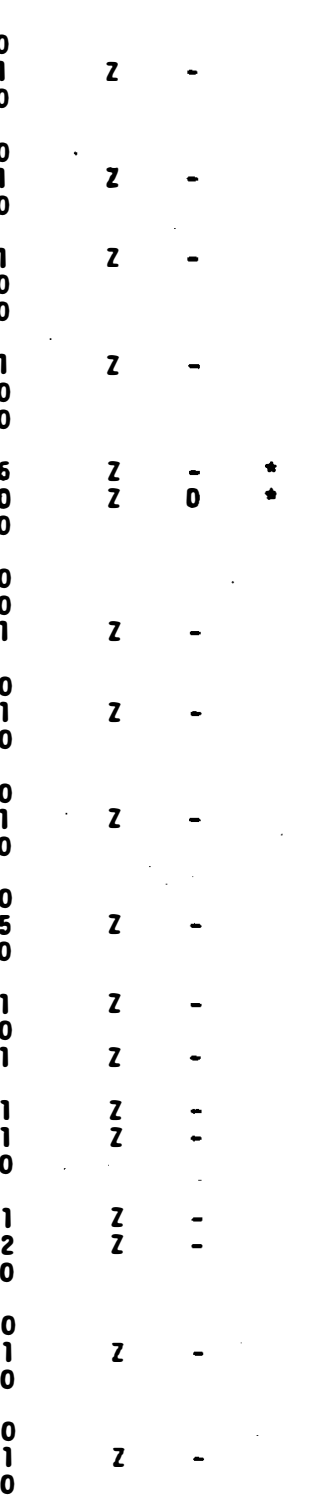

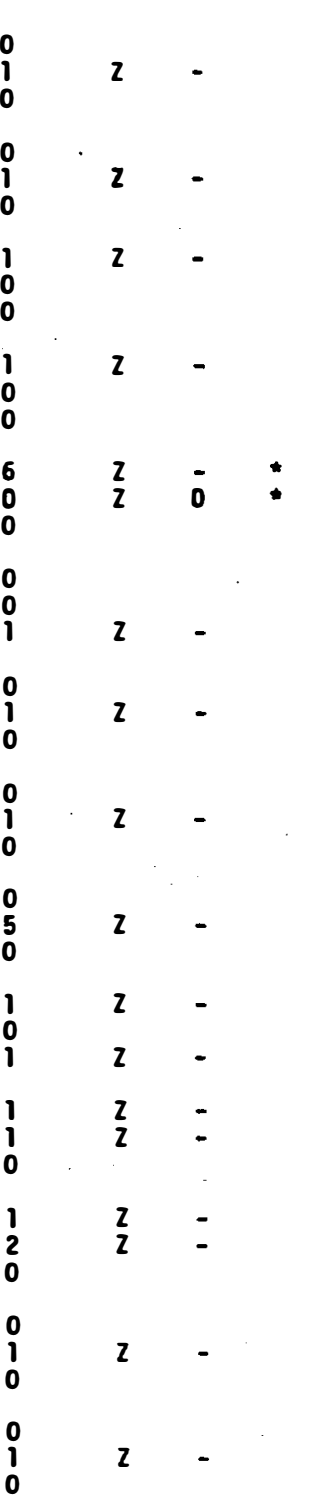

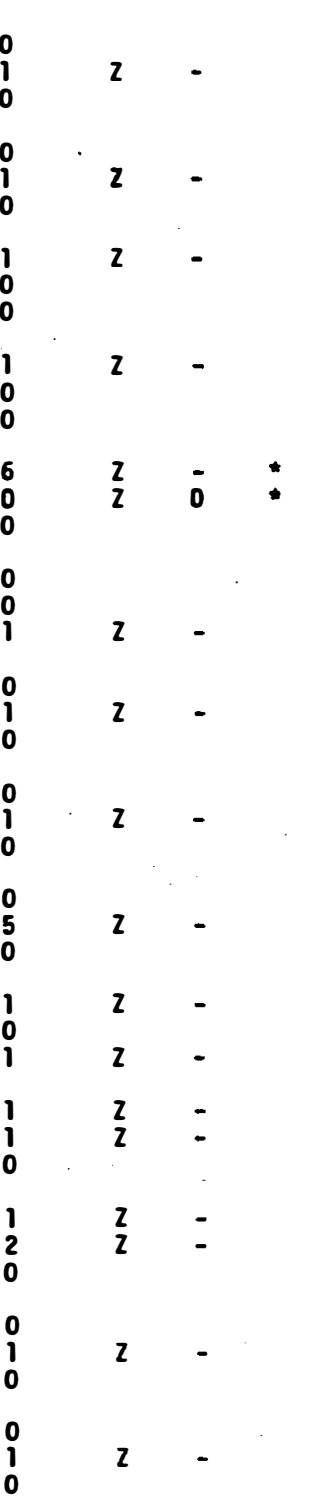

2 1

12

$\begin{array}{lll}\text { A } & 1 & 1 \\ \text { B } & & 0 \\ \text { P } & & 0\end{array}$

A

(2)

A
B
P 
TABELA 1 - Continuagāo

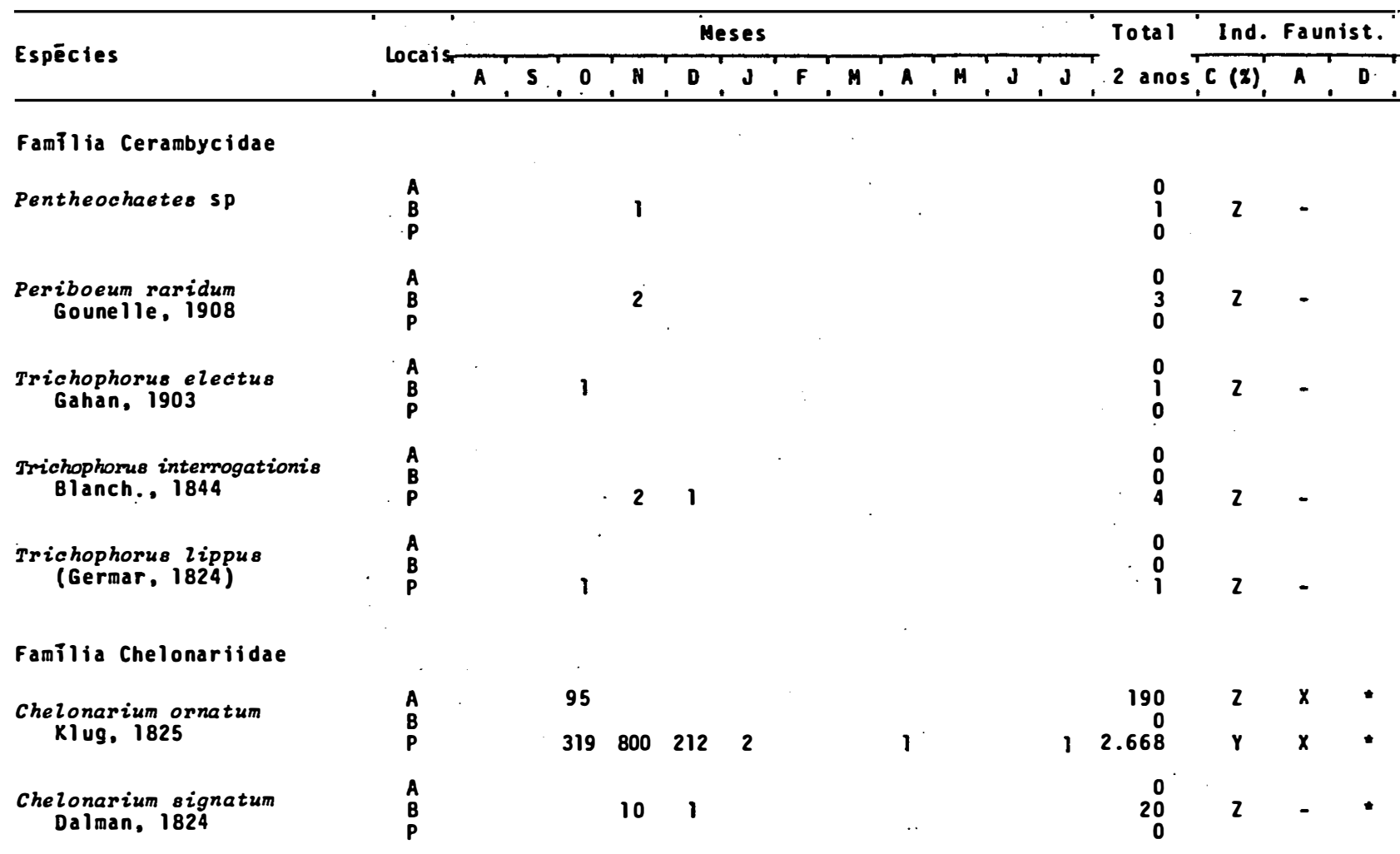

Familia Chrysomelidae

Subfamil ia Alticinae

Altica sp

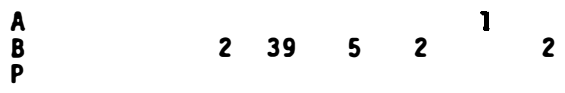

$\begin{array}{lll}1 & 2 & = \\ 97 & 2 & =\end{array}$

Subfamīl ia Eumol pinae

\begin{tabular}{|c|c|c|c|c|c|c|c|c|c|c|c|c|c|c|}
\hline $\begin{array}{c}\text { Alzocolaspis brunnea } \\
\text { Fabricius. } 1798\end{array}$ & $\begin{array}{l}\mathbf{A} \\
\mathbf{B} \\
\mathbf{P}\end{array}$ & & 1 & 65 & $\begin{array}{r}3 \\
13\end{array}$ & 1 & 1 & 1 & & & $\begin{array}{r}0 \\
8 \\
159\end{array}$ & $\begin{array}{l}2 \\
2\end{array}$ & $\dot{+}$ & : \\
\hline $\begin{array}{c}\text { Costalimaita ferruginea } \\
\text { (Fabricius, 180i) }\end{array}$ & $\begin{array}{l}A \\
8 \\
P\end{array}$ & & $\begin{array}{l}2 \\
5\end{array}$ & $\begin{array}{l}35 \\
11 \\
58\end{array}$ & $\begin{array}{r}7 \\
31 \\
3\end{array}$ & $\begin{array}{l}7 \\
4\end{array}$ & 1 & 2 & 3 & & $\begin{array}{r}101 \\
95 \\
136\end{array}$ & $\begin{array}{l}Y \\
Z \\
Z\end{array}$ & $\begin{array}{l}+ \\
= \\
=\end{array}$ & 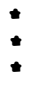 \\
\hline Colaspis paralezla & $\begin{array}{l}A \\
8 \\
P\end{array}$ & & 1 & $\begin{array}{r}23 \\
1\end{array}$ & $\begin{array}{l}6 \\
2\end{array}$ & 5 & & & & & $\begin{array}{r}0 \\
67 \\
8\end{array}$ & $\begin{array}{l}2 \\
2\end{array}$ & $=$ & : \\
\hline Colaspis Sp & $\begin{array}{l}A \\
B \\
P\end{array}$ & & & 1 & 13 & 2 & & 1 & & & $\begin{array}{r}2 \\
30 \\
0\end{array}$ & $\begin{array}{l}2 \\
2\end{array}$ & $:$ & - \\
\hline Colaspis $\mathrm{SP}_{2}$ & $\begin{array}{l}\mathbf{A} \\
\mathbf{B} \\
\mathbf{P}\end{array}$ & $\cdot$ & 1 & $\begin{array}{r}31 \\
2\end{array}$ & 9 & 1 & & & & & $\begin{array}{r}1 \\
81 \\
3\end{array}$ & $\begin{array}{l}2 \\
2 \\
2\end{array}$ & $=$ & $\bullet$ \\
\hline Colaspis $\mathrm{SP}_{3}$ & $\begin{array}{l}\mathbf{A} \\
\mathbf{B} \\
\mathbf{P}\end{array}$ & & & $\begin{array}{l}2 \\
1\end{array}$ & $\begin{array}{l}3 \\
1 \\
4\end{array}$ & $\begin{array}{l}3 \\
3 \\
2\end{array}$ & & 1 & & & $\begin{array}{r}13 \\
7 \\
11\end{array}$ & $\begin{array}{l}2 \\
2 \\
2\end{array}$ & $\begin{array}{l}\overline{-} \\
-\end{array}$ & 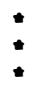 \\
\hline $\begin{array}{l}\text { Maecolaspis perturbata } \\
\text { Heise, } 1921\end{array}$ & $\begin{array}{l}\mathbf{A} \\
\mathbf{B} \\
\mathbf{P}\end{array}$ & 2 & $\begin{array}{r}8 \\
1 \\
22\end{array}$ & $\begin{array}{l}99 \\
59 \\
37\end{array}$ & $\begin{array}{l}89 \\
12 \\
14\end{array}$ & $\begin{array}{r}57 \\
9 \\
7\end{array}$ & $\begin{array}{r}43 \\
27 \\
8\end{array}$ & $\begin{array}{r}71 \\
26 \\
8\end{array}$ & $\begin{array}{l}4 \\
2 \\
3\end{array}$ & 1 & $\begin{array}{l}739 \\
269 \\
195\end{array}$ & $\begin{array}{l}W \\
Y \\
Y\end{array}$ & $\begin{array}{l}x \\
x \\
x\end{array}$ & : \\
\hline
\end{tabular}


TABELA 1 - Continuação

Espēcies Locais

Familia Chrysomelidae

Subfamilia Ga lerucinae

Diabrotica speciosa

(Germar, 1824)

Diabrotica sinuata (0livier)

Diabrotica sp

Physimerus Sp

Paranapiacaba significata (Gahan, 1891)

Familla Ciccindelidae

Brasiela sp

Megacephala brasiliensis (Kirby, 1818)

Megacephala fulgida Klug, 1834

odontochila chrysis

Fabricius, 1801

odontochila cupricolizs Kollar, 1836

Familia Coccinellidae

Cyclonsda sanguinea (Linnaeus, 1775)

olza abdominalis Say, 1824

Familia Curculionidae

Coelosternus sp

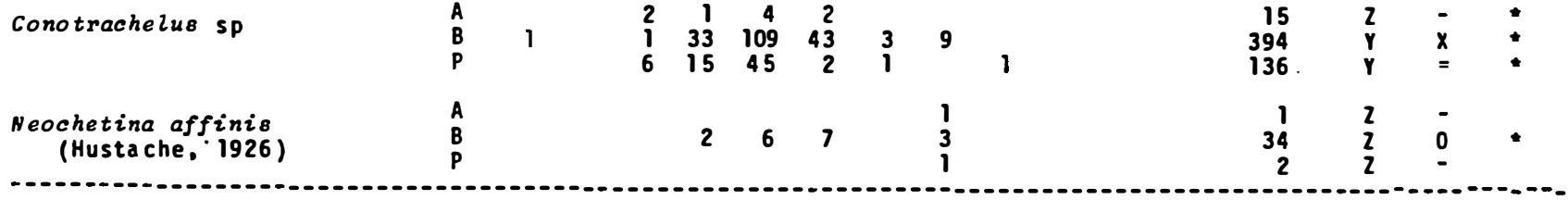

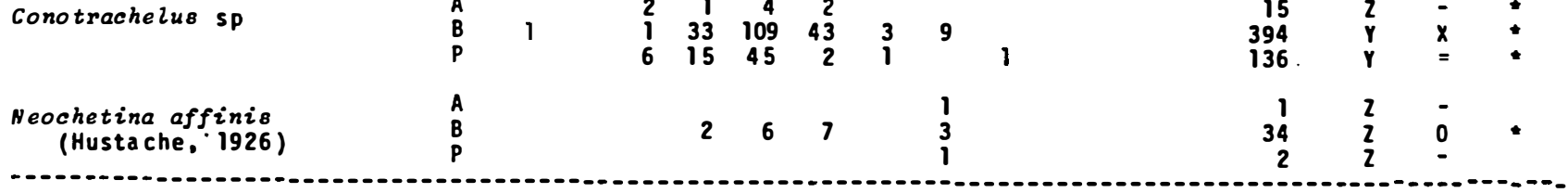

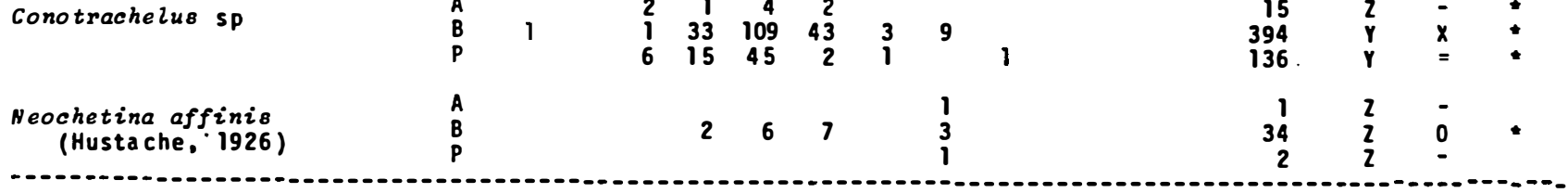

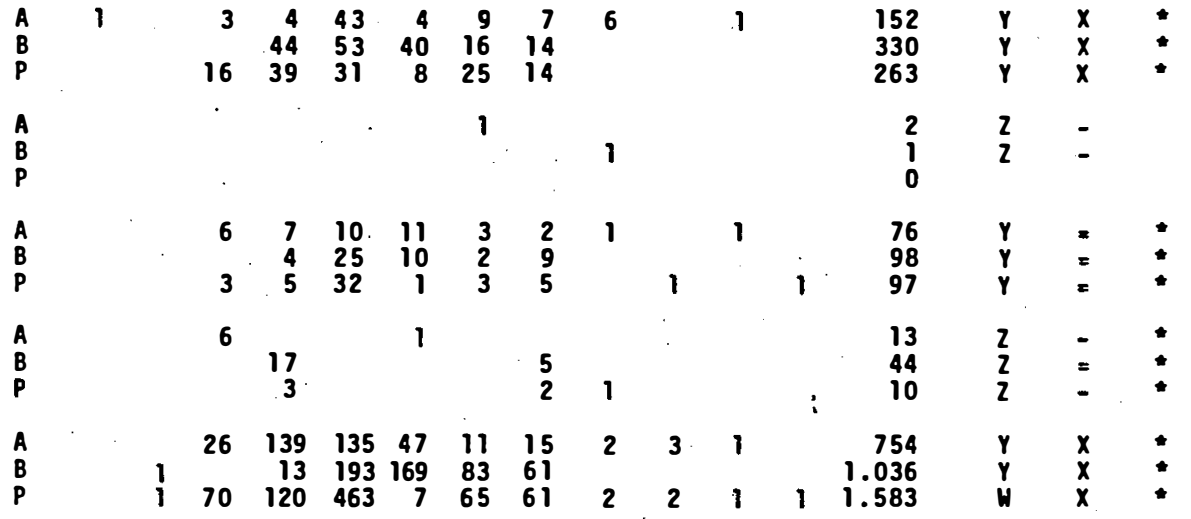

A
B
$\mathbf{P}$

$\begin{array}{rrrrrrrr}38 & 75 & 5 & 1 & 1 & 1 & \\ 1 & 1 & 9 & 17 & 1 & 6 & & 1\end{array}$

$\begin{array}{rrr}240 & y & x \\ 63 & 2 & = \\ 6 & 2 & - \\ 3 & z & - \\ 4 & 2 & - \\ 6 & 2 & - \\ 1 & 2 & - \\ 27 & 2 & - \\ 4 & 2 & - \\ 6 & 2 & - \\ 28 & 2 & - \\ 2 & 2 & - \\ 1 & 2 & - \\ 7 & 2 & -\end{array}$


TABEla 1 - Conlinuação

\begin{tabular}{|c|c|c|c|c|c|c|c|c|c|c|c|c|c|c|c|c|c|}
\hline \multirow{2}{*}{ Espēcies } & \multirow{2}{*}{ Locais } & \multicolumn{11}{|c|}{ Meses } & \multirow[b]{2}{*}{$\mathbf{J}$} & \multirow{2}{*}{$\begin{array}{l}\text { Total } \\
2 \text { anos }^{\top}\end{array}$} & \multicolumn{3}{|c|}{ Ind. Faunist. } \\
\hline & & A & $\mathbf{S}$ & 0 & N & $\therefore 0$ & J & $\mathbf{F}$ & $M$ & A & $M$ & $\mathbf{J}$ & & & $C(8)^{\prime}$ & $\bar{A}$ & $D$ \\
\hline Familia Curculionidae & & & & & & & & & & & & & & & & & \\
\hline Phyrdenus sp & $\begin{array}{l}A \\
B \\
P\end{array}$ & & & & 1 & $\begin{array}{l}2 \\
5 \\
2\end{array}$ & $\begin{array}{l}3 \\
1\end{array}$ & & 1 & & & & & $\begin{array}{r}6 \\
16 \\
7\end{array}$ & $\begin{array}{l}2 \\
2 \\
2\end{array}$ & - & : \\
\hline $\begin{array}{l}\text { Ty Zoderma brassicae } \\
\text { Costa Lima, } 1938\end{array}$ & $\begin{array}{l}A \\
B \\
P\end{array}$ & & 1 & $\begin{array}{r}2 \\
11\end{array}$ & $\begin{array}{l}3 \\
2 \\
4\end{array}$ & 23 & & & & & 1 & & & $\begin{array}{r}10 \\
6 \\
76\end{array}$ & $\begin{array}{l}2 \\
2 \\
2\end{array}$ & : & 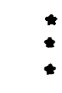 \\
\hline Familia Dryopidae & & & & & & & & & & & & & & & & & \\
\hline Pezonomus sp. & $\begin{array}{l}A \\
B \\
P\end{array}$ & & 1 & $\begin{array}{l}1 \\
1\end{array}$ & $\begin{array}{r}68 \\
18 \\
4\end{array}$ & $\begin{array}{r}42 \\
38 \\
2\end{array}$ & $\begin{array}{l}7 \\
15\end{array}$ & & 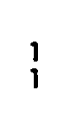 & & & & & $\begin{array}{r}238 \\
143 \\
14\end{array}$ & $\begin{array}{l}y \\
z \\
z\end{array}$ & $\begin{array}{l}x \\
x \\
-\end{array}$ & : \\
\hline Familia Dytiscidae & & & & & & & & & & & & & & & & & \\
\hline $\begin{array}{c}\text { Thermonetus circuonscripta } \\
\text { Latreille, } 1809\end{array}$ & $\begin{array}{l}A \\
B \\
P\end{array}$ & 1 & $\begin{array}{l}4 \\
1\end{array}$ & 1 & $\begin{array}{l}1 \\
2 \\
6\end{array}$ & $\begin{array}{r}1 \\
29 \\
6\end{array}$ & 1 & 1 & $?$ & $\mathbf{i}$ & 2 & 1 & & $\begin{array}{l}18 \\
68 \\
29\end{array}$ & $\begin{array}{l}2 \\
2 \\
2\end{array}$ & $\overline{0}$ & 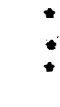 \\
\hline Familia Elateridae & & & & & & & & & & & & & & & & & \\
\hline $\begin{array}{l}\text { Conoderus geminatus } \\
\text { (Germar, 1824) }\end{array}$ & $\begin{array}{l}A \\
B \\
P\end{array}$ & & 3 & 4 & 3 & & & & & & & & & $\begin{array}{r}0 \\
0 \\
18\end{array}$ & 2 & - & $\bullet$ \\
\hline $\begin{array}{c}\text { Conoderus scalaris } \\
\text { (Germar, } 1824 \text { ) }\end{array}$ & $\begin{array}{l}A \\
B \\
P\end{array}$ & $\begin{array}{r}5 \\
14 \\
76\end{array}$ & $\begin{array}{r}3 \\
27 \\
309\end{array}$ & $\begin{array}{c}83 \\
33 \\
204\end{array}$ & $\begin{array}{r}81 \\
22 \\
362\end{array}$ & $\begin{array}{l}35 \\
26 \\
84\end{array}$ & $\begin{array}{r}10 \\
29 \\
5\end{array}$ & $\begin{array}{r}99 \\
6\end{array}$ & $\begin{array}{r}3 \\
18 \\
6\end{array}$ & 2 & 1 & & 1 & $\begin{array}{r}454 \\
383 \\
2.103\end{array}$ & $\begin{array}{l}H \\
H \\
H\end{array}$ & $\begin{array}{l}x \\
x \\
x\end{array}$ & $:$ \\
\hline $\begin{array}{c}\text { Conoderus stigmosus } \\
\text { Germar, } 1839\end{array}$ & $\begin{array}{l}A \\
B \\
P\end{array}$ & $\begin{array}{l}1 \\
7\end{array}$ & $\begin{array}{r}2 \\
11\end{array}$ & $\begin{array}{r}3 \\
14\end{array}$ & $\begin{array}{r}2 \\
28\end{array}$ & $\begin{array}{r}4 \\
2 \\
23\end{array}$ & 2 & & 1 & & & & & $\begin{array}{r}21 \\
12 \\
165\end{array}$ & $\begin{array}{l}2 \\
2 \\
2\end{array}$ & $\dot{-}$ & : \\
\hline Conoderus SP & $\begin{array}{l}A \\
B \\
P\end{array}$ & & & 1 & $\begin{array}{l}3 \\
1\end{array}$ & 2 & 1 & & & & & & & $\begin{array}{r}11 \\
2 \\
0\end{array}$ & $\begin{array}{l}2 \\
2\end{array}$ & - & - \\
\hline Conoderus $\mathrm{SP}_{2}$ & $\begin{array}{l}A \\
B \\
P\end{array}$ & & 2 & $\begin{array}{r}2 \\
1 \\
16\end{array}$ & 3 & & & & & & . & & & $\begin{array}{r}3 \\
6 \\
37\end{array}$ & $\begin{array}{l}2 \\
2 \\
2\end{array}$ & $\dot{0}$ & * \\
\hline Conoderus $\mathrm{SP}_{3}$ & $\begin{array}{l}A \\
B \\
P\end{array}$ & & & 1 & 11 & & & & & & & & & $\begin{array}{r}1 \\
21 \\
0\end{array}$ & $\begin{array}{l}2 \\
2\end{array}$ & $=$ & * \\
\hline Conoderus $\mathrm{SP}_{4}$ & $\begin{array}{l}A \\
B \\
P\end{array}$ & & & 9 & 10 & & & & & & & & & $\begin{array}{r}38 \\
0 \\
0\end{array}$ & 2 & 0 & * \\
\hline Conoderus $\mathrm{SP}_{5}$ & $\begin{array}{l}A \\
B \\
P\end{array}$ & & & $\begin{array}{l}6 \\
3\end{array}$ & $\begin{array}{r}10 \\
5 \\
2\end{array}$ & $\begin{array}{r}21 \\
7\end{array}$ & $\begin{array}{l}2 \\
3\end{array}$ & $\begin{array}{l}1 \\
6\end{array}$ & 2 & 2 & 1 & 1 & 1 & $\begin{array}{l}36 \\
63 \\
43\end{array}$ & $\begin{array}{l}z \\
y \\
y\end{array}$ & $\begin{array}{l}0 \\
= \\
0\end{array}$ & : \\
\hline Conoderus $\mathrm{SP}_{6}$ & $\begin{array}{l}A \\
B \\
P\end{array}$ & & & $\begin{array}{r}22 \\
4 \\
15\end{array}$ & $\begin{array}{r}94 \\
5 \\
20\end{array}$ & $\begin{array}{r}62 \\
128 \\
55\end{array}$ & $\begin{array}{r}19 \\
34 \\
1\end{array}$ & $\begin{array}{r}5 \\
1 \\
27\end{array}$ & $\begin{array}{r}2 \\
25 \\
3\end{array}$ & $\begin{array}{l}4 \\
1\end{array}$ & $\begin{array}{l}1 \\
1 \\
3\end{array}$ & 7 & 4 & $\begin{array}{l}405 \\
399 \\
268\end{array}$ & $\begin{array}{l}Y \\
y \\
Y\end{array}$ & $\begin{array}{l}x \\
x \\
x\end{array}$ & " \\
\hline Conoderus $\mathrm{SP}_{7}$ & $\begin{array}{l}A \\
B \\
P\end{array}$ & & & 1 & 3 & 18 & & 1 & & & & & & $\begin{array}{r}5 \\
0 \\
44\end{array}$ & $\begin{array}{l}2 \\
2\end{array}$ & - & - \\
\hline Heteroderes $\mathrm{Sp}_{1}$ & $\begin{array}{l}A \\
B \\
P\end{array}$ & & & & $\begin{array}{c}1 \\
131 \\
1\end{array}$ & $\begin{array}{l}1 \\
1\end{array}$ & 2 & 2 & & & . & & & $\begin{array}{r}2 \\
262 \\
10\end{array}$ & $\begin{array}{l}2 \\
2 \\
2\end{array}$ & $\bar{x}$ & * \\
\hline Heteroderes $\mathrm{SP}_{2}$ & $\begin{array}{l}A \\
B \\
P\end{array}$ & & & $\begin{array}{l}2 \\
3\end{array}$ & $\begin{array}{r}6 \\
2 \\
10\end{array}$ & $\begin{array}{l}17 \\
15\end{array}$ & $\begin{array}{l}1 \\
8\end{array}$ & & 1 & 1 & 1 & & & $\begin{array}{l}16 \\
54 \\
57\end{array}$ & $\begin{array}{l}Z \\
Z \\
Y\end{array}$ & $\begin{array}{l}\overline{ } \\
\overline{ }\end{array}$ & \\
\hline
\end{tabular}


TABELA 1 - Continuaçāo

\begin{tabular}{|c|c|c|c|c|c|c|c|c|c|c|c|c|c|c|c|c|}
\hline \multirow{2}{*}{ Espécies } & \multirow{2}{*}{ Locais } & \multicolumn{11}{|c|}{ Meses } & \multirow{2}{*}{$\begin{array}{l}\text { Total } \\
2 \text { anos }\end{array}$} & \multicolumn{3}{|c|}{ Ind. Faunist. } \\
\hline & & $\mathbf{s}$ & 0 & H & $\mathbf{D}$ & $\mathbf{J}$ & $\mathbf{F}$ & $M$ & A & M & $\mathbf{J}$ & $\mathbf{J}$ & & $C(z)$ & A & D \\
\hline \multicolumn{17}{|l|}{ Familia Elateridae } \\
\hline Ischiodontus SP, & $\begin{array}{l}A \\
B \\
P\end{array}$ & & & $\begin{array}{r}91 \\
3\end{array}$ & $\begin{array}{l}33 \\
16\end{array}$ & $\begin{array}{r}16 \\
4\end{array}$ & & & & & & & $\begin{array}{r}280 \\
45 \\
0\end{array}$ & $\begin{array}{l}Y \\
\mathbf{Z}\end{array}$ & $x$ & * \\
\hline Ischiodontus $\mathrm{SP}_{2}$ & $\begin{array}{l}A \\
B \\
P\end{array}$ & & 3 & 4 & 1 & & & & & & & & $\begin{array}{r}0 \\
0 \\
16\end{array}$ & 2 & - & • \\
\hline Physodactilus SP, & $\begin{array}{l}\mathbf{A} \\
\mathbf{B} \\
\mathbf{P}\end{array}$ & & 1 & $\begin{array}{l}2 \\
2\end{array}$ & & & & & & & & $\cdot$ & $\begin{array}{l}4 \\
0 \\
4\end{array}$ & $\begin{array}{l}2 \\
2\end{array}$ & - & \\
\hline Physodactilus $\mathrm{SP}_{2}$ & $\begin{array}{l}A \\
B \\
P\end{array}$ & & 2 & 3 & & & & & $\cdot$ & & & : & $\begin{array}{l}0 \\
0 \\
9\end{array}$ & 2 & - & • \\
\hline Pomachilius SP & $\begin{array}{l}\mathbf{A} \\
\mathbf{B} \\
\mathbf{P}\end{array}$ & & 1 & 77 & 30 & $\begin{array}{r}10 \\
4\end{array}$ & 1 & & & & & & $\begin{array}{r}233 \\
9 \\
0\end{array}$ & $\begin{array}{l}2 \\
2\end{array}$ & $\begin{array}{l}x \\
-\end{array}$ & 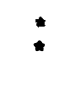 \\
\hline
\end{tabular}

Familia Hydrophilidae

Neohydrophilus politus Laporte, 1840

Stetoxus ater (Olivier, 1792)

Tropisternus collaris Fabricius, 1775

Tropisternus Zaevis Sturm. 1826

Familia Lagridae

Disema Sp,

Disema $\mathrm{SP}_{2}$

Lagria villosa

Fabricius, 1783

Familia Lycidae

Mesopterum angulicolle (Lucas, 1857)

Familia Meloidae

Epicauta excavata (k)ug, 1825)

\begin{tabular}{|c|c|c|c|c|c|c|c|c|c|c|}
\hline $\begin{array}{l}A \\
B \\
P\end{array}$ & 1 & & 1 & 22 & $\begin{array}{l}5 \\
1\end{array}$ & 2 & $\begin{array}{l}2 \\
1\end{array}$ & 1 & 1 & $\begin{array}{r}0 \\
64 \\
20\end{array}$ \\
\hline $\begin{array}{l}A \\
B \\
P\end{array}$ & & & $\begin{array}{l}1 \\
1 \\
3\end{array}$ & $\begin{array}{l}3 \\
1\end{array}$ & & & & & & $\begin{array}{l}1 \\
7 \\
6\end{array}$ \\
\hline $\begin{array}{l}A \\
B \\
P\end{array}$ & 1 & 7 & $\begin{array}{r}43 \\
12 \\
7\end{array}$ & $\begin{array}{c}22 \\
142 \\
10\end{array}$ & $\begin{array}{r}1 \\
48\end{array}$ & $\begin{array}{l}2 \\
3\end{array}$ & $\begin{array}{l}5 \\
6\end{array}$ & 1 & & $\begin{array}{r}130 \\
416 \\
63\end{array}$ \\
\hline $\begin{array}{l}A \\
B \\
P\end{array}$ & 1 & & $\begin{array}{r}8 \\
1 \\
52\end{array}$ & $\begin{array}{c}3 \\
161 \\
11\end{array}$ & 74 & \} & 2 & & & $\begin{array}{r}23 \\
475 \\
128\end{array}$ \\
\hline
\end{tabular}

(Klug. 1825)
$A$
$B$
$P$
$\begin{array}{llll}1 & 3 & 2 & 3\end{array}$
$\begin{array}{llll} & & 1 & \\ 1 & 2 & 1\end{array}$
$\begin{array}{rrr}3 & 2 & - \\ 17 & 2 & -\end{array}$ 
TABELA 1 - Continuação

\begin{tabular}{|c|c|c|c|c|c|c|c|c|c|c|c|c|c|c|c|c|}
\hline \multirow{2}{*}{ Espēcies } & \multirow{2}{*}{ Locaiss } & \multicolumn{11}{|c|}{ Meses } & \multirow{2}{*}{$\begin{array}{l}\text { Total } \\
2 \text { anos }\end{array}$} & \multirow{2}{*}{$\frac{\text { Ind. }}{c(x)^{\prime}}$} & \multicolumn{2}{|c|}{ Faunist. } \\
\hline & & $A$ & $\mathbf{s}$ & 0 & N. & 0 & $\mathbf{J}$ & $\mathbf{F}$ & $M$ & A & $M$ & J. J & & & A & 0 \\
\hline Familia Meloidae & & & & & & & & & $\cdot$ & & & & & & & \\
\hline $\begin{array}{c}\text { Epicauta grammica } \\
\text { Fisher. } 1927\end{array}$ & $\begin{array}{l}\hat{A} \\
\mathbf{B} \\
\mathbf{P}\end{array}$ & & & 2 & $\begin{array}{l}4 \\
3\end{array}$ & $\begin{array}{l}1 \\
2\end{array}$ & & 1 & $\begin{array}{l}2 \\
1 \\
2\end{array}$ & 1 & & & $\begin{array}{r}14 \\
15 \\
5\end{array}$ & $\begin{array}{l}2 \\
2 \\
2\end{array}$ & $\overline{-}$ & 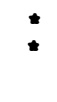 \\
\hline $\begin{array}{l}\text { Pyrota vittigera } \\
\text { (BIanchard, 1843) }\end{array}$ & $\begin{array}{l}\hat{A} \\
\hat{B} \\
\mathbf{P}\end{array}$ & & 1 & & 1 & & & & & & & & $\begin{array}{l}0 \\
1 \\
1\end{array}$ & 2 & - & \\
\hline Familia Mitidulidae & & & & & & & & & & & & & & & & \\
\hline $\begin{array}{l}\text { Lobiopa insularis } \\
\text { (Laporte. 1840) }\end{array}$ & $\begin{array}{l}A \\
B \\
P\end{array}$ & & 3 & $\begin{array}{l}29 \\
28\end{array}$ & $\begin{array}{r}5 \\
6 \\
10\end{array}$ & $\begin{array}{l}1 \\
31 \\
30\end{array}$ & 4 & & 1 & & & . & $\begin{array}{r}71 \\
82 \\
142\end{array}$ & $\begin{array}{l}2 \\
2 \\
2\end{array}$ & $\begin{array}{l}= \\
= \\
=\end{array}$ & 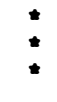 \\
\hline Familia Pașsalidae & & & & & . & & & & & & & & & & & \\
\hline $\begin{array}{l}\text { Passalus coniferus } \\
\text { Eschscholtz. } 1829\end{array}$ & $\begin{array}{l}\text { A } \\
\stackrel{B}{P}\end{array}$ & & & 1 & 1 & & & 1 & & & . & & $\begin{array}{l}1 \\
2 \\
0\end{array}$ & $\begin{array}{l}z \\
z\end{array}$ & - & . \\
\hline $\begin{array}{l}\text { Passalus punctiger } \\
\text { (Serville. I825) }\end{array}$ & $\begin{array}{l}\text { A } \\
\text { B } \\
P\end{array}$ & & & & & 1 & & & & & & & $\begin{array}{l}0 \\
1 \\
0\end{array}$ & 2 & - & \\
\hline $\begin{array}{l}\text { Paxillus leashi } \\
\text { Mac Leay, } 1819\end{array}$ & $\begin{array}{l}\text { A } \\
\text { B } \\
\mathbf{P}\end{array}$ & . & & 1 & & & & & & & & & $\begin{array}{l}0 \\
1 \\
0\end{array}$ & 2 & - & \\
\hline Familia Platypodidae & & & & & & & & & & & & & & & & \\
\hline Platypus SP & $\begin{array}{l}A \\
\mathbf{B} \\
\mathbf{P}\end{array}$ & & & $\begin{array}{l}3 \\
3\end{array}$ & $\begin{array}{r}8 \\
35\end{array}$ & $\begin{array}{r}29 \\
3\end{array}$ & $\begin{array}{l}7 \\
1\end{array}$ & & 1 & 1 & 1 & & $\begin{array}{r}34 \\
133 \\
8\end{array}$ & $\begin{array}{l}2 \\
2 \\
2\end{array}$ & $\begin{array}{l}0 \\
x \\
-\end{array}$ & : \\
\hline Tesserocerus SP & $\begin{array}{l}A \\
8 \\
P\end{array}$ & & & & $\begin{array}{r}3 \\
10\end{array}$ & 5 & 3 & & & & & & $\begin{array}{r}12 \\
28 \\
0\end{array}$ & $\begin{array}{l}2 \\
2\end{array}$ & - & * \\
\hline
\end{tabular}

Familia Scarabaidae

Subfamil ia Acanthocerinae

Ceratocantious semipunctatus (Germar. 1843)

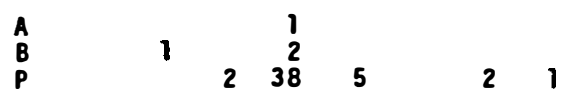

$\begin{array}{lll}1 & 2 & - \\ 5 & 2 & =\end{array}$ Perty. 1830

e
21
$\begin{array}{lll}3 & 2 & - \\ 1 & 2 & -\end{array}$
A
B
$\mathbf{P}$

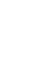

Subfamīlia Aphodiinae

Aphodius lividus

(0livier, 1789)

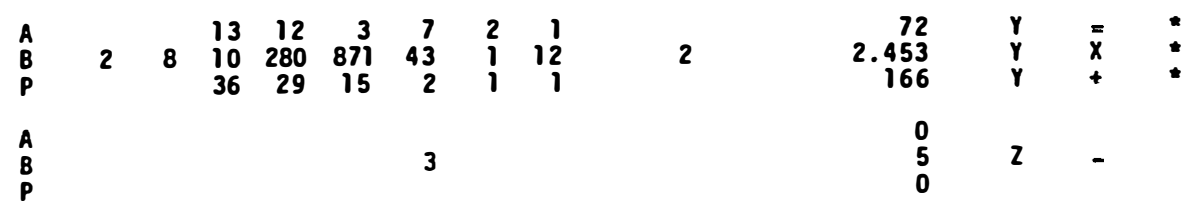

Ataenius picinus
Harold. 1867

Subfamilia Dynastinae

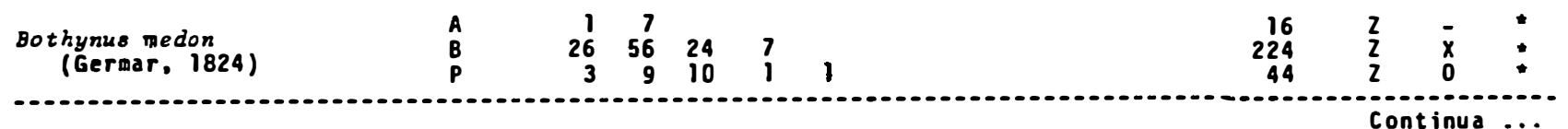


TABELA 1 - contInunç̌o

\begin{tabular}{|c|c|c|c|c|c|c|c|c|c|c|c|c|c|c|c|c|c|}
\hline \multirow{2}{*}{ Espéctes } & \multirow{2}{*}{ Locai st } & \multicolumn{12}{|c|}{ Meses } & \multirow{2}{*}{$\begin{array}{l}\text { Total } \\
2 \text { anos }\end{array}$} & \multicolumn{3}{|c|}{ Ind. Faunist. } \\
\hline & & A & $\mathbf{S}$ & 0 & $N$ &. $\mathrm{D}$ & $\mathbf{J}$ & $\mathbf{F}$ & $M$ & A & $M$ & $\mathbf{J}$ & J & & C (z) & A & D \\
\hline Familia Scarabaetdae & & & & & & & & & & & & & & & & & \\
\hline Subfamilia Dynastinae & & & & & & & & & & & & & & & & & \\
\hline $\begin{array}{l}\text { Chalepides fuliginosa } \\
\text { (Burmeister, 1847) }\end{array}$ & $\begin{array}{l}\mathbf{A} \\
\mathbf{B} \\
\mathbf{P}\end{array}$ & & $\begin{array}{l}1 \\
4\end{array}$ & $\begin{array}{l}1 \\
2\end{array}$ & 2 & 1 & 2 & 1 & 2 & & & & & $\begin{array}{r}3 \\
8 \\
18\end{array}$ & $\begin{array}{l}2 \\
2 \\
2\end{array}$ & $\overline{-}$ & $\bullet$ \\
\hline $\begin{array}{c}\text { Cyclocephala atricapilla } \\
\text { Mannerheim, } 1829\end{array}$ & $\begin{array}{l}\hat{A} \\
\hat{B} \\
\mathbf{P}\end{array}$ & & $\begin{array}{l}2 \\
2\end{array}$ & 35 & 3 & 3 & 1 & 20 & 1 & - & & & & $\begin{array}{l}72 \\
11 \\
47\end{array}$ & $\begin{array}{l}2 \\
2 \\
2\end{array}$ & $\begin{array}{l}= \\
=\end{array}$ & 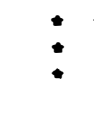 \\
\hline $\begin{array}{l}\text { Cyclocephala försteri } \\
\text { Endrodi }\end{array}$ & $\begin{array}{l}A \\
B \\
P\end{array}$ & & & $\begin{array}{l}1 \\
3\end{array}$ & $\begin{array}{l}1 \\
4 \\
6\end{array}$ & $\stackrel{8}{1}$ & & & & & & & & $\begin{array}{r}3 \\
23 \\
20\end{array}$ & $\begin{array}{l}2 \\
2 \\
2\end{array}$ & $=$ & 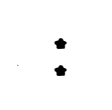 \\
\hline $\begin{array}{l}\text { Cyclocephala mecynotarsis } \\
\text { H8hne, } 1923\end{array}$ & $\stackrel{A}{A}$ & & & $\begin{array}{l}2 \\
1 \\
2\end{array}$ & 8 & 30 & & 1 & & & & & & $\begin{array}{r}5 \\
78 \\
5\end{array}$ & $\begin{array}{l}2 \\
2 \\
2\end{array}$ & $\begin{array}{l}- \\
-\end{array}$ & $\bullet$ \\
\hline $\begin{array}{l}\text { Cyclocephala melanocephala } \\
\text { (Fabricius, } 1775 \text { ) }\end{array}$ & $\begin{array}{l}A \\
B \\
P\end{array}$ & & $\begin{array}{l}2 \\
3\end{array}$ & $\begin{array}{r}96 \\
3 \\
15\end{array}$ & $\begin{array}{r}433 \\
22 \\
10\end{array}$ & $\begin{array}{l}22 \\
13 \\
10\end{array}$ & $\begin{array}{r}28 \\
2 \\
6\end{array}$ & $\begin{array}{r}39 \\
1 \\
6\end{array}$ & $\begin{array}{r}32 \\
1 \\
8\end{array}$ & $\begin{array}{l}2 \\
4\end{array}$ & 1 & 1 & & $\begin{array}{r}1.304 \\
: \quad 81 \\
118\end{array}$ & $\begin{array}{l}W \\
Y \\
W\end{array}$ & $\begin{array}{l}x \\
= \\
=\end{array}$ & $:$ \\
\hline $\begin{array}{l}\text { Cyclocephala ohausiana } \\
\text { Höhne, } 1923\end{array}$ & $\begin{array}{l}\mathbf{A} \\
\mathbf{B} \\
\mathbf{P}\end{array}$ & & & 1 & 1 & & & & & & & & & $\begin{array}{l}1 \\
0 \\
1\end{array}$ & $\begin{array}{l}2 \\
2\end{array}$ & - & \\
\hline $\begin{array}{l}\text { Cyclocephala putrida } \\
\text { Burmeister, } 1847\end{array}$ & $\begin{array}{l}\text { A } \\
\text { B } \\
\mathbf{P}\end{array}$ & & & & & 1 & 1 & & & & & & & $\begin{array}{l}0 \\
2 \\
0\end{array}$ & 2 & - & \\
\hline $\begin{array}{l}\text { Cyclocephala signaticollis } \\
\text { Burme ister, } 1847\end{array}$ & $\begin{array}{l}\mathbf{A} \\
\mathbf{B} \\
\mathbf{P}\end{array}$ & & & 2 & 10 & $\begin{array}{l}2 \\
6\end{array}$ & $\begin{array}{l}2 \\
6\end{array}$ & $\begin{array}{l}1 \\
7\end{array}$ & 3 & & & & & $\begin{array}{r}0 \\
9 \\
63\end{array}$ & $\begin{array}{l}z \\
Y\end{array}$ & $\overline{-}$ & $\bullet$ \\
\hline Cyclocephala sp & $\begin{array}{l}\cdot A \\
B \\
P\end{array}$ & & & & 4 & & & & & & & & & $\begin{array}{l}0 \\
0 \\
8\end{array}$ & 2 & - & $\bullet$ \\
\hline $\begin{array}{l}\text { Discynetus dubius } \\
\text { (Olivier, 1789) }\end{array}$ & $\begin{array}{l}\mathbf{A} \\
\mathbf{B} \\
\mathbf{P}\end{array}$ & $\begin{array}{r}4 \\
28\end{array}$ & $\begin{array}{r}4 \\
19\end{array}$ & $\begin{array}{l}7 \\
7 \\
7\end{array}$ & $\begin{array}{r}4 \\
19 \\
30\end{array}$ & $\begin{array}{l}7 \\
17 \\
16\end{array}$ & $\begin{array}{l}8 \\
5 \\
6\end{array}$ & $\begin{array}{r}1 \\
8 \\
12\end{array}$ & $\begin{array}{l}1 \\
6 \\
8\end{array}$ & $\begin{array}{l}1 \\
6 \\
9\end{array}$ & 7 & $\mathbf{i}$ & 2 & $\begin{array}{r}44 \\
164 \\
397\end{array}$ & $\begin{array}{l}Y \\
W \\
W\end{array}$ & $\begin{array}{l}\bar{x} \\
\bar{x}\end{array}$ & $\bullet$ \\
\hline Enema sp & $\begin{array}{l}A \\
B \\
P\end{array}$ & & & & 2 & 1 & & 1 & & & & & & $\begin{array}{l}0 \\
8 \\
0\end{array}$ & 2 & - & $\bullet$ \\
\hline $\begin{array}{l}\text { Euetheola humilis } \\
\text { (Burmeister, 1747) }\end{array}$ & $\begin{array}{l}\text { A } \\
\mathbf{B} \\
\mathbf{P}\end{array}$ & & & $\begin{array}{r}1 \\
15\end{array}$ & $\begin{array}{l}3 \\
4\end{array}$ & & $\begin{array}{l}1 \\
2\end{array}$ & $\begin{array}{l}3 \\
\mathbf{3}\end{array}$ & $\begin{array}{l}2 \\
2\end{array}$ & & & & & $\begin{array}{r}0 \\
18 \\
49\end{array}$ & Y & $\bar{z}$ & : \\
\hline $\begin{array}{l}\text { Ligyrus fossor } \\
\text { Latreille, } 1833\end{array}$ & $\begin{array}{l}A \\
B \\
P\end{array}$ & 2 & 2 & & 2 & 20 & 16 & 7 & 2 & 5 & 2 & & $\mathbf{1}$ & $\begin{array}{r}0 \\
114 \\
0\end{array}$ & $\mathbf{Y}$ & + & $\bullet$ \\
\hline $\begin{array}{l}\text { Ligyrus gyas } \\
\text { (Erichson, 1848) }\end{array}$ & $\begin{array}{l}A \\
B \\
P\end{array}$ & & $\begin{array}{l}1 \\
6\end{array}$ & $\begin{array}{r}4 \\
43\end{array}$ & $\begin{array}{r}3 \\
12 \\
30\end{array}$ & $\begin{array}{l}13 \\
19\end{array}$ & 1 & 4 & $\begin{array}{l}1 \\
9\end{array}$ & & & & 1 & $\begin{array}{r}7 \\
61 \\
218\end{array}$ & $\begin{array}{l}z \\
y \\
y\end{array}$ & $\overline{\bar{x}}$ & 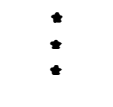 \\
\hline Phileurus SP & $\begin{array}{l}A \\
B \\
P\end{array}$ & & & & 1 & 1 & & & 1 & & & & & $\begin{array}{l}1 \\
1 \\
2\end{array}$ & $\begin{array}{l}2 \\
2 \\
2\end{array}$ & $=$ & \\
\hline Stenocrates SP, & $\begin{array}{l}A \\
B \\
P\end{array}$ & & $\begin{array}{l}\mathbf{5} \\
\mathbf{5}\end{array}$ & 2 & $\begin{array}{l}8 \\
2 \\
1\end{array}$ & & & & & & & & . & $\begin{array}{r}29 \\
14 \\
1\end{array}$ & $\begin{array}{l}2 \\
2 \\
2\end{array}$ & $=$ & 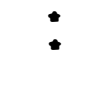 \\
\hline Stenocrates $\mathrm{SP}_{2}$ & $\begin{array}{l}A \\
B \\
P\end{array}$ & & & 5 & 10 & & & & & & & & & $\begin{array}{r}0 \\
29 \\
0\end{array}$ & 2 & - & • \\
\hline Stenocrates $\mathrm{SP}_{3}$ & $\begin{array}{l}A \\
B \\
P\end{array}$ & & & & 2 & 3 & & & & 2 & & 1 & 1 & $\begin{array}{r}0 \\
0 \\
15\end{array}$ & 2 & - & • \\
\hline
\end{tabular}


TABELA 1 - Continuaçāo

Espécies

Familia Scarabaeidae

Subfamĩlia Dynastinae

strategus validus

(Fabricius, 1775)

$\begin{array}{lll}\mathbf{A} & 3 \\ \mathbf{B} & \mathbf{1} & \mathbf{1}\end{array}$

$\begin{array}{lll}6 & 2 & 2 \\ 2 & 2 & 2\end{array}$

Subfamillia Geotrupinae

Bolboceras lucidula

KI U9, 1843

A
B
P

Bolboceras minuta Luederwaldt, 1929

Bolboceras quadrispinosa Luederwaldt, 1929

Neoathyreus sexdentatus

(Laporte, 1840)

Parathyreus trituberculatus

(Kiug. 1843)

\begin{tabular}{|c|c|c|c|c|}
\hline $\begin{array}{r}70 \\
1 \\
2\end{array}$ & $\begin{array}{r}22 \\
26 \\
2\end{array}$ & $\begin{array}{l}3 \\
1 \\
1\end{array}$ & $\begin{array}{l}1 \\
1\end{array}$ & 2 \\
\hline $\begin{array}{l}2 \\
1\end{array}$ & $\begin{array}{l}1 \\
3 \\
1\end{array}$ & 1 & & \\
\hline $\begin{array}{l}1 \\
1\end{array}$ & $\begin{array}{l}1 \\
1\end{array}$ & 1 & 1 & \\
\hline & 1 & 2 & & \\
\hline
\end{tabular}

\begin{tabular}{|c|c|c|}
\hline $\begin{array}{l}2 \\
0 \\
0\end{array}$ & $\mathbf{Z}$ & - \\
\hline $\begin{array}{r}189 \\
59 \\
9\end{array}$ & $\begin{array}{l}Y \\
Z \\
Z\end{array}$ & $\begin{array}{l}x \\
=\end{array}$ \\
\hline $\begin{array}{r}4 \\
10 \\
2\end{array}$ & $\begin{array}{l}\mathbf{Z} \\
\mathbf{Z} \\
\mathbf{Z}\end{array}$ & $\overline{-}$ \\
\hline $\begin{array}{l}9 \\
7 \\
0\end{array}$ & $\begin{array}{l}\mathbf{Z} \\
\mathbf{Z}\end{array}$ & - \\
\hline $\begin{array}{l}\mathbf{8} \\
0 \\
0\end{array}$ & $\mathbf{Z}$ & - \\
\hline
\end{tabular}

Subfanilia Hybosorinae

Chaztodus piceus
Hestwood 1846

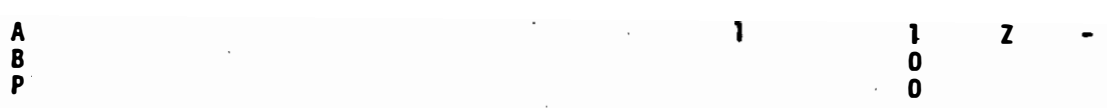

Subfamīlia Melolonthinae

Astaena terelza

Burme ister. 1855

Astaena $\mathrm{SP}_{1}$

3

$\begin{array}{lll}1 & 30 & 10 \\ 1 & 17 & 51\end{array}$

$\begin{array}{llll}10 & 2 & 5 & 2 \\ 51 & 1 & & 1 \\ 2 & & 1\end{array}$

2

A
$\mathbf{B}$
$\mathbf{P}$

$\begin{array}{lllll}126 & 18 & 5 & 3 & 1\end{array}$

$+2$

$2 \quad 14$

26

Astaena $\mathrm{SP}_{2}$

A
B
P.

Liogenys suturalis

BI.

A
B
P

Plectris nitida

Frèy

A
B
P

Plectris SP,

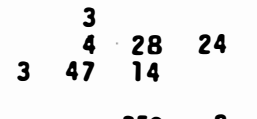

$\begin{array}{llll}4 & & 350 & 2 \\ 4 & 126 & 2\end{array}$

13

$\begin{array}{rrr}106 & Y & + \\ 104 & Z & = \\ 40 & Z & 0 \\ 305 & Y & x \\ 97 & Z & = \\ 36 & Z & 0 \\ 5 & Z & - \\ 111 & Z & = \\ 126 & Z & = \\ 703 & Z & x \\ 0 & & \\ 068 & Z & \\ 0 & & \\ 0 & & \\ 25 & Z & - \\ 0 & & \\ 2 & Z & - \\ 9 & Z & - \\ 0 & & \\ 226 & Z & \\ 0 & & \end{array}$


TABELA 1 - Continuação

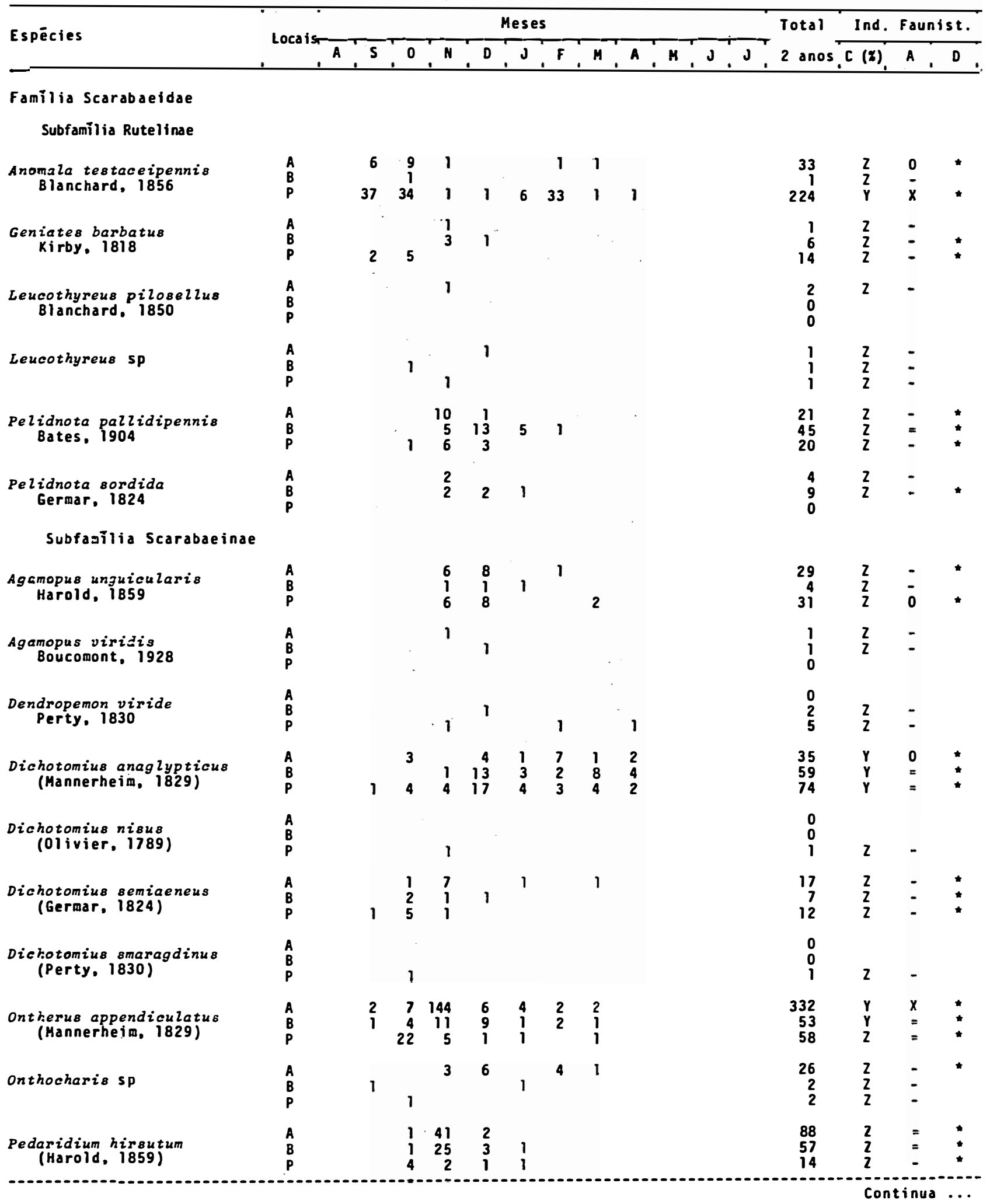


TABELA I Continuacao

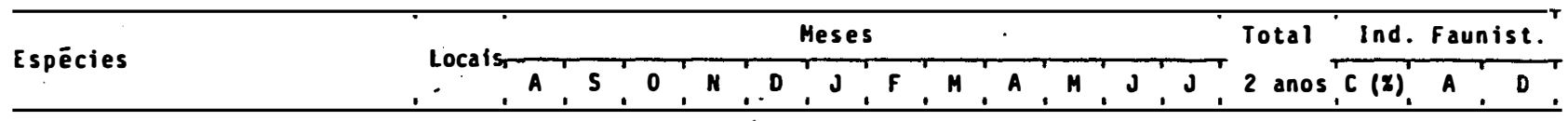

Familia Scarabaeidae

Subfamīlia Scarabaeinae

Pedaridium paranense

Arrow. 1932

$\begin{array}{ll}\text { A } & \text { I } \\ \text { B } & \\ \text { P } & \end{array}$

Pseudocanthon xanthurum

(Blanchard, 1843)

A 1

Trichillion extemepunctation

Preud homme. 1880

$\begin{array}{rrrrrr}A & 1 & 6 & & & \\ B & & 16 & 4 & 1 & 1 \\ P & 16 & 5 & 3 & 2 & 5\end{array}$

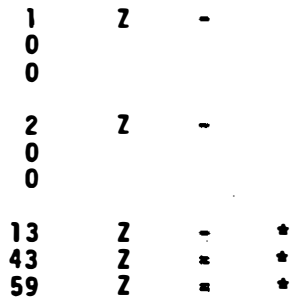

Subfamilia Troginae

Trox borrei

Harold. 1872

Trox persuberosus

Vaurie, 1962

Trox sp

A
B
$\mathbf{P}$

$\begin{array}{llllllll}A & & 1 & 7 & 1 & 1 & 1 & \\ B & & & 4 & 10 & 1 & 1 & 1 \\ P & 1 & 6 & 10 & 1 & 1 & 2 & \end{array}$

$\begin{array}{ll}\text { A } & \\ \text { P } & 1\end{array}$

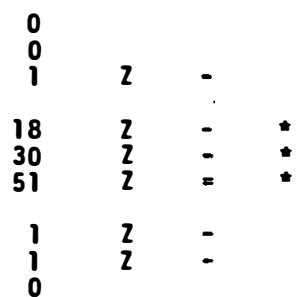

Familia Silphidae

Hyponecrodes discicollis Brullé, 1840

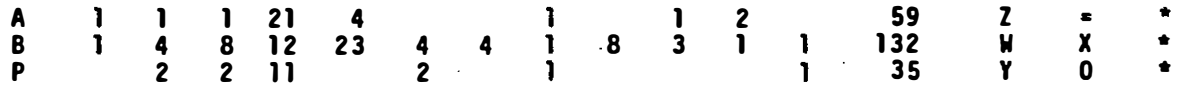

Familia Staphylinidae

Homoeotarsus sp

$\begin{array}{llllllll}A & 3 & & 2 & & 7 \\ B & & 24 & 43 & & 8 & \end{array}$

Ochthephilum SP,

$\begin{array}{llll}A & 2 & 3 & \\ B & 3 & 12 \\ P & 1 & 48\end{array}$

Ochthephilum Sp?

Paederus sp

Pinophilus proximus Sharp. 1876

A
B

$\begin{array}{lllllllr}A & & 1 & 1 & 2 & 7 & 11 & 36 \\ \text { P } & 2 & 1 & 2 & 36 & 9 & & 4\end{array}$

$\begin{array}{lllllllll}A & & 2 & 2 & 2 & & & 1 & 1 \\ \text { P } & 3 & 1 & 27 & 11 & 5 & & 1 & \end{array}$

$\begin{array}{rll}24 & 2 & - \\ 150 & 2 & x \\ 36 & 2 & 0 \\ 9 & 2 & - \\ 30 & 2 & = \\ 96 & 2 & =\end{array}$

Familia Tenebrionidae

Alphitobius diaperinus (Panzer. 1797)

Anaedus punctatissimus Blanchard. 1843

Epitragus similis Steinheil. 1872

\begin{tabular}{|c|c|c|c|c|c|c|c|c|c|c|c|c|c|c|}
\hline $\begin{array}{l}A \\
B \\
P\end{array}$ & & & 1 & 2 & & 30 & & & 2 & & & $\begin{array}{r}67 \\
3 \\
0\end{array}$ & $\begin{array}{l}2 \\
2\end{array}$ & $=$ \\
\hline $\begin{array}{l}A \\
B \\
P\end{array}$ & & & 6 & 16 & $\begin{array}{r}2 \\
7 \\
55\end{array}$ & $\begin{array}{l}1 \\
4\end{array}$ & & & & & & $\begin{array}{r}6 \\
21 \\
153\end{array}$ & $\begin{array}{l}2 \\
2 \\
2\end{array}$ & $\overline{-}$ \\
\hline $\begin{array}{l}A \\
B \\
P\end{array}$ & 1 & $\begin{array}{l}3 \\
1\end{array}$ & $\begin{array}{r}15 \\
4 \\
7\end{array}$ & $\begin{array}{r}52 \\
35 \\
4\end{array}$ & $\begin{array}{l}17 \\
26 \\
22\end{array}$ & $\begin{array}{r}5 \\
12 \\
9\end{array}$ & $\begin{array}{l}2 \\
3 \\
5\end{array}$ & $\begin{array}{l}7 \\
3 \\
9\end{array}$ & $\begin{array}{l}5 \\
3\end{array}$ & & 1 & $\begin{array}{l}211 \\
163 \\
120\end{array}$ & $\begin{array}{l}W \\
Y \\
W\end{array}$ & $\begin{array}{l}x \\
x \\
=\end{array}$ \\
\hline $\begin{array}{l}A \\
B \\
P\end{array}$ & & & & 1 & 4 & 2 & & & & & & $\begin{array}{r}1 \\
10 \\
1\end{array}$ & $\begin{array}{l}2 \\
2 \\
2\end{array}$ & E \\
\hline
\end{tabular}


Local:

$$
\begin{aligned}
& A=\text { Assis, } \\
& B=\text { Barra Bonita, } \\
& P=\text { Pradópolis. }
\end{aligned}
$$

Ind. Faunist. = Indices Faunisticos

Indices Faunisticos: $C(\%)=$ constância,

$$
\begin{array}{ll}
A & =\text { abundāncia, } \\
D & =\text { domināncia. }
\end{array}
$$

Constância:

$$
\begin{aligned}
& W=\text { constante, } \\
& Y=\text { acessoria, } \\
& Z=\text { acidental. }
\end{aligned}
$$

Abundāncia:

$$
\begin{aligned}
& "=\text { excessivamente abundante } \\
& X=\text { muito abundante } \\
& +=\text { abundante } \\
& ==\text { comum } \\
& 0=\text { dispersa } \\
& -=\text { rara }
\end{aligned}
$$

Domināncia

$$
\text { * = dominante }
$$

Total de coleópteros coletados

$\begin{array}{ll}\text { em Assis: } & 20.238 \\ \text { em Barra Bonita: } & 44.372 \\ \text { em Pradópolis: } & 26.587\end{array}$

Total Geral: 
Pela Tabela 1 , observa-se que foram coletados um to tal de 91.197 coleópteros pertencentes a 449 espécies, das quais 207 eram diferentes. Em Assis, capturou-se 23 familias, 141 espēcies e 20.238 indivĩduos; em Barra Bonita, 23 famīlias, 167 espécies e 44.372 indivíduos e em Pradópolis 22 famīlias, 141 espécies e 26.587 indivĩduos.

Nessas localidades, as famīlias Carabidae, Scarabaei dae, Chrysomelidae e Elateridae superaram as demais em número de espécies e indivíduos. Dentre elas, Carabidae apresentouse com maior número de indivíduos, sendo que em Barra Bonita, capturou-se 30 espécies e 33.605 indivĩduos, em Pradópolis 29 espēcies e 13.779 indivĩduos e em Assis 22 espécies e 11.633 indivĩduos. Nessa famīlia destacou-se a espécie SeZenophorus sp, da qual 31.378 indivíduos foram coletados em Barra Bonita, 12.668 em Pradópolis e 10.523 em Assis, formando portanto uma grande população, devido provavelmente, ou possuir boa adapta bilidade à cultura da cana, ou ser muito atraída pela luz. Nota-se ainda, que as espēcies Arthrostictus speciosus (De jean), Galerita collaris Dejean, G. occidentalis (0liv.) e G. costalimai Reichardt foram coletadas nas trēs localidades.

Com relação à famīlia Scarabaeidae, em Barra Bonita capturou-se 46 espécies e 4.026 indivĩduos, em Assis 43 espé cies e 3.524 indivĩduos e em Pradópolis 43 espécies e 3.375 indi vĩduos. Nas trēs localidades foram coletadas as espécies Bothy nus medon (Germ.), Cyclocephala melanocephala (Fabr.), Euetheo la homilis (Burm.) - exceto Assis - Pelidnota pallidpennis Bates 
e P. sordida Germ. - exceto Pradópolis -, assim como maior nū mero de espécies pertencentes a gēnero Cyclocephala.

Quanto à famīlia Chrysomelidae, em Pradópolis foram coletadas 10 espécies e 2.465 indivĩduos, em Barra Bonita 13 espécies e 2.163 indivĩduos e em Assis 11 espécies e 1.854 in divíduos. Nessa famîlia, as espécies Costalimaita ferruginea (Fabr.) , Diabrotica speciosa (Germ.) e Paranapiacaba significata (Gahan) foram comuns aos referidos locais.

Finalmente, da famīlia Elateridae 12 espécies 2.774 indivíduos foram capturados em Pradópolis, 14 espécies e 1.509 indivīduos em Assis e 11 espécies, 1.256 indivíduos em Barra Bonita. Nas trēs localidades coletou-se as espécies Conoderus scalaris (Germ.) e C. stigmosus Germ., sendo que o gènero Conoderus destacou-se com o maior nūmero de espécies. De acordo com SILVEIRA NETO (1972), as espécies referidas acima como comuns às très localidades, também foram observadas em quase todas as nove localidades estudadas por aquele autor, e tais resultados sugerem que elas possuem uma ampla distribuição no Estado de São Paulo.

Segundo SILVA (1968), GUAGLIUMI (1972) e GALLO et alii (1978), os coleópteros reconhecidos como prejudiciais à cultura da cana-de-açūcar, pertencem às famīlias Chrysomeli dae, Elateridae e Scarabaeidae, sendo nesta ūltima princi palmente as espécies das subfamīlias Dynastinae, Melolonthi nae e Rutelinae. Desta maneira, a Tabela 2 mostra o total de coleópteros adultos capturados, relativos aquelas famīlias, en 
quanto na Tabela 3 observa-se os resultados obtidos para essas subfamīlias.

TABELA 2 - Total de coleópteros coletados nas trēs localidades, pertencentes às famīlias prejudiciais à cultura da cana. $(1976 / 78)$

\begin{tabular}{lccc}
\hline Famĩlias & \multicolumn{3}{c}{ Locais } \\
& Assis & Barra Bonita & Pradōpolis \\
\hline Chrysomelidae & 1.854 & 2.163 & 2.465 \\
Elateridae & 1.509 & 1.256 & 2.774 \\
Scarabaeidae & 3.524 & 4.026 & 3.375 \\
\hline Total & 6.887 & 7.445 & 8.614 \\
\hline em relação ao & 34,0 & 16,8 & 32,4 \\
total coletado & & & \\
\hline
\end{tabular}


TABELA 3 - Total de coleópteros coletados nas trēs localidades, pertencentes às subfamílias de Scarabaeidae. $(1976 / 78)$

\begin{tabular}{lccc}
\hline Subfamílias & \multicolumn{3}{c}{ Locais } \\
\hline Dynastinae & 1.491 & 847 & 1.007 \\
$\begin{array}{l}\text { Melolonthinae } \\
\text { Rulelinae }\end{array}$ & 1.119 & 318 & 1.530 \\
\hline \multicolumn{1}{|c|}{ Total } & 62 & 62 & 259 \\
\hline $\begin{array}{l}\text { \% em relação ao } \\
\text { total de Sca- } \\
\text { rabaeidae }\end{array}$ & 2.672 & 1.227 & 2.796 \\
\hline
\end{tabular}

Pela Tabela 2 nota-se que, apesar do total de coleóp teros coletados apresentarem pouca diferença entre as localida des, a porcentagem destes em relação ao total coletado em Barra Bonita $(16,8 \%)$ è prōxima à metade da obtida para Assis (34\%). e Pradópolis $(32,4 \%)$.

Por outro lado, a Tabela 3 indica que foram coletados em Barra Bonita, um número de coleópteros pertencentes aquelas subfamilias, menor que a metade dos obtidos nos outros locais, sendo que em Barra Bonita esse total representou apenas $30,5 \%$ do total de escarabeídeos capturados, enquanto em Assis este valor foi de $75,8 \%$ e em Pradópolis $82,8 \%$. 
Esses resultados evidenciam a existēncia de uma maior quantidade de coleópteros prejudiciais à cultura da cana em Assis e Pradópolis, em relação à Barra Bonita.

\section{2 - Medidas de Fauna}

\subsection{1 - Constāncia}

A separação das espécies de acordo com a constāncia já constou na Tabela 1 , sendo que na Tabela 4 pode ser observado o número e a porcentagem de espécies para a presente medida.

TABELA 4 - Número e porcentagem de coleópteros classificados quanto à constância para as très localidades. $(1976 / 78)$

\begin{tabular}{lrrrrrr}
\hline \multirow{2}{*}{ Espécies } & \multicolumn{6}{c}{ Locais } \\
\cline { 2 - 8 } & \multicolumn{2}{c}{ Assis } & \multicolumn{2}{c}{ Barra Bonita } & \multicolumn{2}{c}{ Pradópolis } \\
\hline Constantes & 5 & 3,55 & 4 & 2,40 & 5 & 3,50 \\
Acessōrias & 19 & 13,47 & 21 & 12,57 & 21 & 15,00 \\
Acidentais & 117 & 82,98 & 142 & 85,03 & 115 & 81,50 \\
\hline Total & 141 & 100 & 167 & 100 & 141 & 100 \\
\hline
\end{tabular}


A Tabela 4 mostra a maior parte das espécies como a cidentais, e as explicações para elucidarem o fato delas terem ocorrido poucas vezes no total de amostras do levantamento são muitas, podendo ser até devido à própria característica dos ecossistemas subtropicais em possuirem grande diversidade de espécies com pequeno nūmero de indivíduos.

0 ciclo biológico longo mostrado pelos coleópteros e uma possīvel característica dessas espécies de apresentarem a emergência de seus adultos em épocas próximas, contribuiriam também para o ocorrido, favorecendo a ocorrēncia de coletas com muitos indivíduos por noite, fato observado por LINK (1976), onde mostrou que $12,9 \%$ do total de Scarabaeiodea coletados com armadilha luminosa em Santa Maria, RS, ocorreu em apenas uma noite.

A eficiēncia da lāmpada BL também influiria, pois conforme estudos feitos por OSANGER e DAY (1973), ficou evi denciado que Conoderus falli Lane só è atraído por esse tipo de lâmpada quando estā a uma distāncia de 5 a 7 metros da fon te luminosa, e mesmo dentro deste raio de ação, a eficiência da luz foi avaliada em torno de $28-62 \%$, fato este agravado, pela pouca atividade de vōo geralmente apresentada pelos coleōpteros.

As espécies constantes foram: Selenophorus sp, Maecolaspis perturbata Weise, Paranapiacaba significata (Gahan), Conoderus scalaris (Germ.), Cyclocephala melanocephala (Fabr.), Discynetus dubius (0liv.), Hyponecrodes dis- 
cicollis Brullé e Epitragus similis Steinheil. Elas estive ram presentes na maior parte das coletas feitas, devido prova velmente, ou serem muito atraídas pela luz, ou terem grande ocorrência na região.

\section{2 .2 - Domināncia.}

Constou na Tabela 1 , a classificação das espécies quanto à domināncia. Por aqueles resultados nota-se que em Assis foram assinaladas 82 espécies dominantes $(58,2 \%)$, em Barra Bonita $109(65,3 \%)$ e em Pradópolis 98 (69,5\%).

Por esses resultados, observa-se que mais da metade das espécies coletadas foram consideradas dominantes nos trēs locais. Essa anālise, que foi empregada por LINK (1976) para estudar a fauna de Scarabaeiodea em Santa Maria (RS), não per mitiu, neste trabalho, restringir o número de espécies para proporcionar, juntamente com outras medidas de fauna, um sele cionamento das espécies, como foi feito por COELHO (1977).

\section{2 .3 - Abundância}

A classificação das espécies quanto à abundāncia jā constou na Tabela 1 , enquanto que na Tabela 5 observa-se 0 nūmero e a porcentagem de espécies para esta medida. 
TABELA 5 - Número e porcentagem de coleópteros classificados quanto à abundāncia nas trēs localidades. (1976/78)

\begin{tabular}{|c|c|c|c|c|c|c|}
\hline \multirow{3}{*}{ Espécies } & \multicolumn{6}{|c|}{ Locais } \\
\hline & \multicolumn{2}{|c|}{ Assis } & \multicolumn{2}{|c|}{ Barra Bonita } & \multicolumn{2}{|c|}{ Pradōpol is } \\
\hline & Nūmero & $\%$ & Nūmero & $\%$ & Nūmero & $\%$ \\
\hline $\begin{array}{l}\text { Excessivamente } \\
\text { abundante }\end{array}$ & 1 & 0,71 & 1 & 0,60 & 1 & 0,71 \\
\hline Muito abundantes & 21 & 14,89 & 25 & 14,97 & 12 & 8,50 \\
\hline Abundantes & 2 & 1,42 & 1 & 0,60 & 5 & 3,55 \\
\hline Comuns & 10 & 7,09 & 31 & 18,56 & 30 & 21,28 \\
\hline Dispersas & 5 & 3,55 & 2 & 1,20 & 15 & 10,64 \\
\hline Raras & 102 & 72,34 & 107 & 64,07 & 78 & 55,32 \\
\hline Total & 141 & 100 & 167 & 100 & 141 & 100 \\
\hline
\end{tabular}

Pelos resultados da Tabela 5 , pode-se notar que em Assis ocorreram 102 espécies raras, 21 muito abundantes e 10 comuns. Em Barra Bonita 107 espēcies raras foram encontra das, 31 comuns e 25 muito abundantes. Enquanto que em Pradópolis encontrou-se 78 espécies raras, 30 comuns, 15 dispersas e 12 muito abundantes.

Dentre as espécies muito abundantes e abundantes encontradas, observa-se que em Assis destacaram-se as famílias Chrysomelidae com as espécies: Costalimaita ferruginea (Fabr.), Diabrotica speciosa (Germ.), Maecolaspis pertur- 
bata Weise e Paranapiacaba significata (Gahan); a familia Ela teridae com as espécies: Conoderus scalaris (Germ.), Conode rus $\mathrm{sp}_{6}$, Ischiodontus $\mathrm{sp}_{1}$ e Pomachilius sp e a famīia Scara baeidae com as espécies: Bolboceras minuta Lued. (Geotrupi nae), Astaena tenelza Burm. , Astaena sp 1 , Liogenys suturalis Bl. (Melolonthinae) e ontherus appendiculatus (Mannh.) (Scarabaeinae).

Em Barra Bonita destacou-se a familia Carabidae com as espēcies: Anisotarsus cupripennis Germ., Arthrostictus puberulus (Dejean), Arthrostictus sulcatulus (Dejean), Aspi dogrossa sp, Polpochiza sp e Lebia concinna Brullé.

Enquanto em Pradópolis foi a famīlia Scarabaeidae, representada pelas espécies Anomala testaceipennis Blanch. (Rutelinae), Aphodius lividus (0liv.) (Aphodiinae), Discyne tus dubius (0liv.), Ligyrus gyas (Erichson) (Dynastinae), Liogenys suturalis Bl. e Rhinaspis sp (Melolonthinae).

\subsection{4 - Indice de diversidade}

A Tabela 6 mostra os índices encontrados para as trēs localidades.

Pela Tabela 6 , observa-se que houve muita semelhança entre os valores obtidos, assim, em Barra Bonita encontrouse 15,51, em Pradópolis 13,74 e em Assis 14,12, o qual difere do encontrado por SILVEIRA NETO (1972), quando estudou a fauna de coleópteros em. Assis, que foi de 7,4. 
TABELA 6 - Nūmero de espécies (S), nūmero de indivĩduos (N) e indice de diversidade $(\alpha)$ da fauna de coleóp teros estudada nas très localidades (1976/78).

\begin{tabular}{cccc}
\hline & \multicolumn{3}{c}{ Locais } \\
\cline { 2 - 4 } & Assis & Barra Bonita & Pradópolis \\
\hline S & 141 & 167 & 141 \\
$N$ & 20.238 & 44.372 & 26.587 \\
$\alpha$ & 14,12 & 15,51 & 13,74 \\
\hline
\end{tabular}

Esses indices podem ser considerados altos, e diferem muito dos obtidos por COELHO (1977), que estudando lepi dōpteros em Piracicaba, encontrou um índice médio de 2,46 para a familia Sphingidae e 2,05 para Pyralidae.

5.2.5 - Quociente e porcentagem de similaridade
0s quocientes e porcentagens de similaridade, calcu lados para se comparar entre si as trēs localidades, podem ser observadas na Tabela 7 .

Pelo cálculo do quociente de similaridade, notou-se que ocorreu uma média similaridade ambiental entre os trés locais, para as espécies consideradas excessivamente abundantes, muito abundantes, abundantes e comuns. Muito embora LINK 
(1976) tenha considerado os quocientes de 0,53 a 0,92 como in dicadores de alta similaridade, quando estudou alguns Scara baeiodea em Santa Maria, RS.

TABELA 7 - Quocientes e porcentagens de similaridade obtidos entre as localidades, referentes às espécies de coleópteros selecionados. (1976/78)

\begin{tabular}{lcc}
\hline Loca is comparados & Q.S. & $\%$ S \\
\hline Assis e Barra Bonita & 0,63 & 72,4 \\
Assis e Pradōpolis & 0,54 & 77,1 \\
Barra Bonita e Pradōpolis & 0,57 & 77,6 \\
\hline Intervalo de Confiança (5\%) & 0,47 a 0,69 & 68,6 a 82,8 \\
\hline
\end{tabular}

Quanto ao cálculo das porcentagens de similaridade, observou-se um aumento na similaridade entre as localidades, sendo este resultado já esperado, devido neste estudo só serem consideradas as espécies comuns às localidades comparadas. Mesmo assim, esses valores indicam uma similaridade ambiental média. 


\section{3 - Flutuações Populacionais e Influēncia dos Fatores Meteorológicos}

0 estudo das flutuações populacionais das espécies associadas à cultura da cana-de-açūcar, se acham nas figuras 2 a 11 , feitas a partir dos dados das médias mensais do nūmero de individuos coletados, mostrados pela Tabela 1

No estudo para avaliar a influēncia dos fatores me teorológicos, utilizou-se dados de coletas mensais das espécies, que constam na Tabela 8 e os respectivos dados meteoro lógicos que estão na Tabela 9 , enquanto os resultados obtidos na correlação estão na Tabela 10 . 


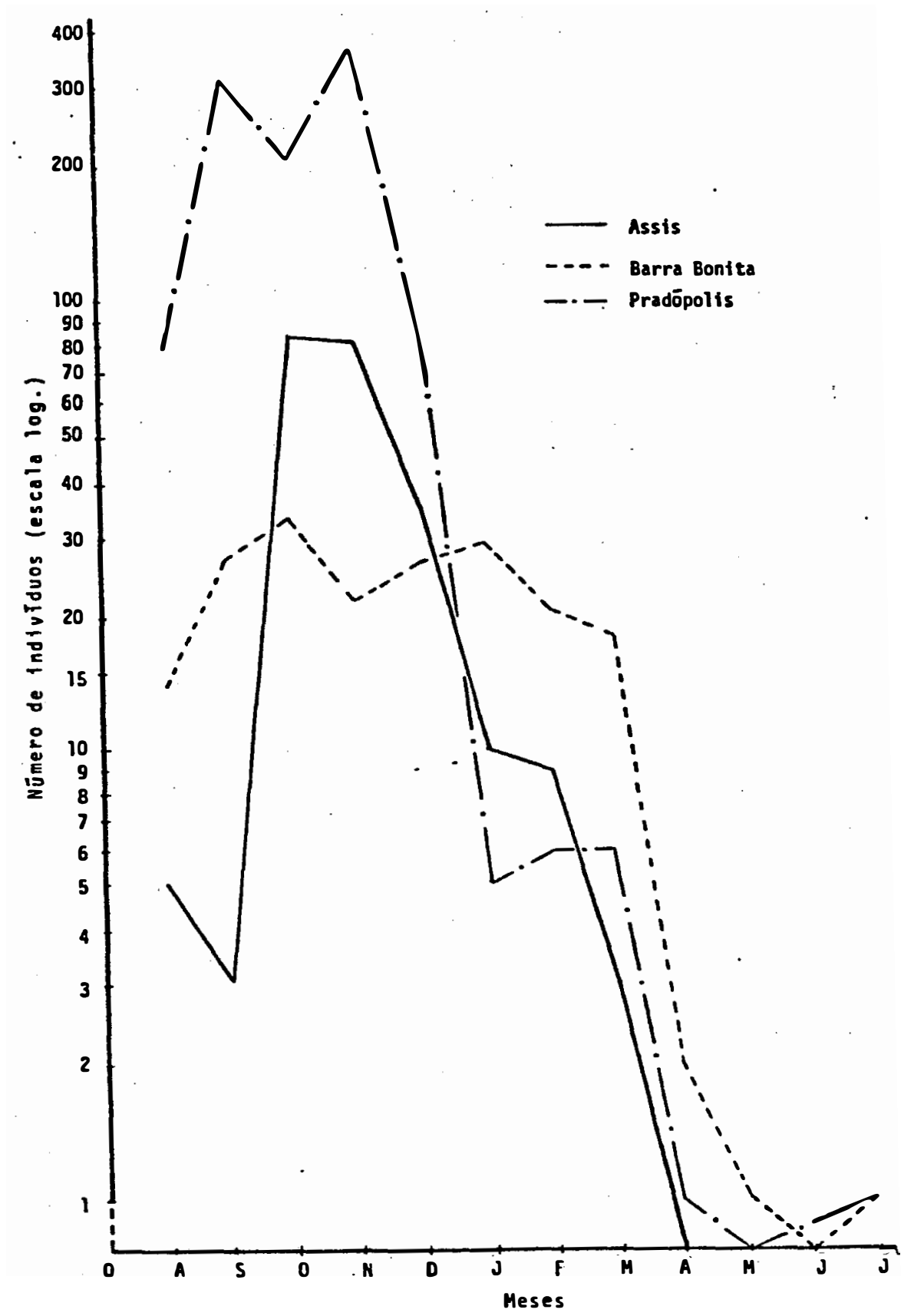

fig. 2 - Flutuação populacional de Conoderus scalaris (Germ.) nas trēs localidades. (1976/78). 
50 .

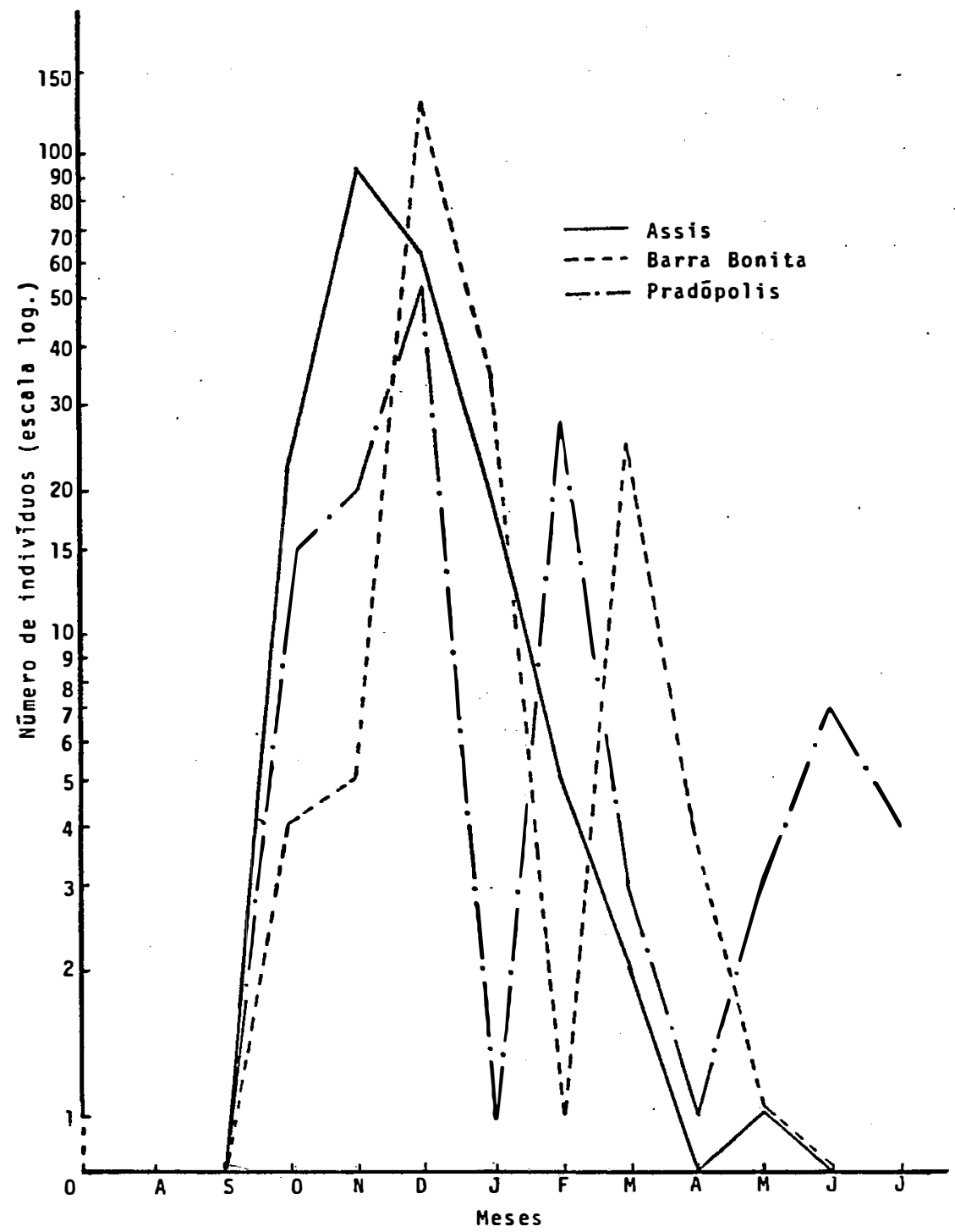

Fig. 3 - Flutuaçāo populacional de Conoderus $S P_{6}$ nas trēs localidades. (1976/78). 
51.

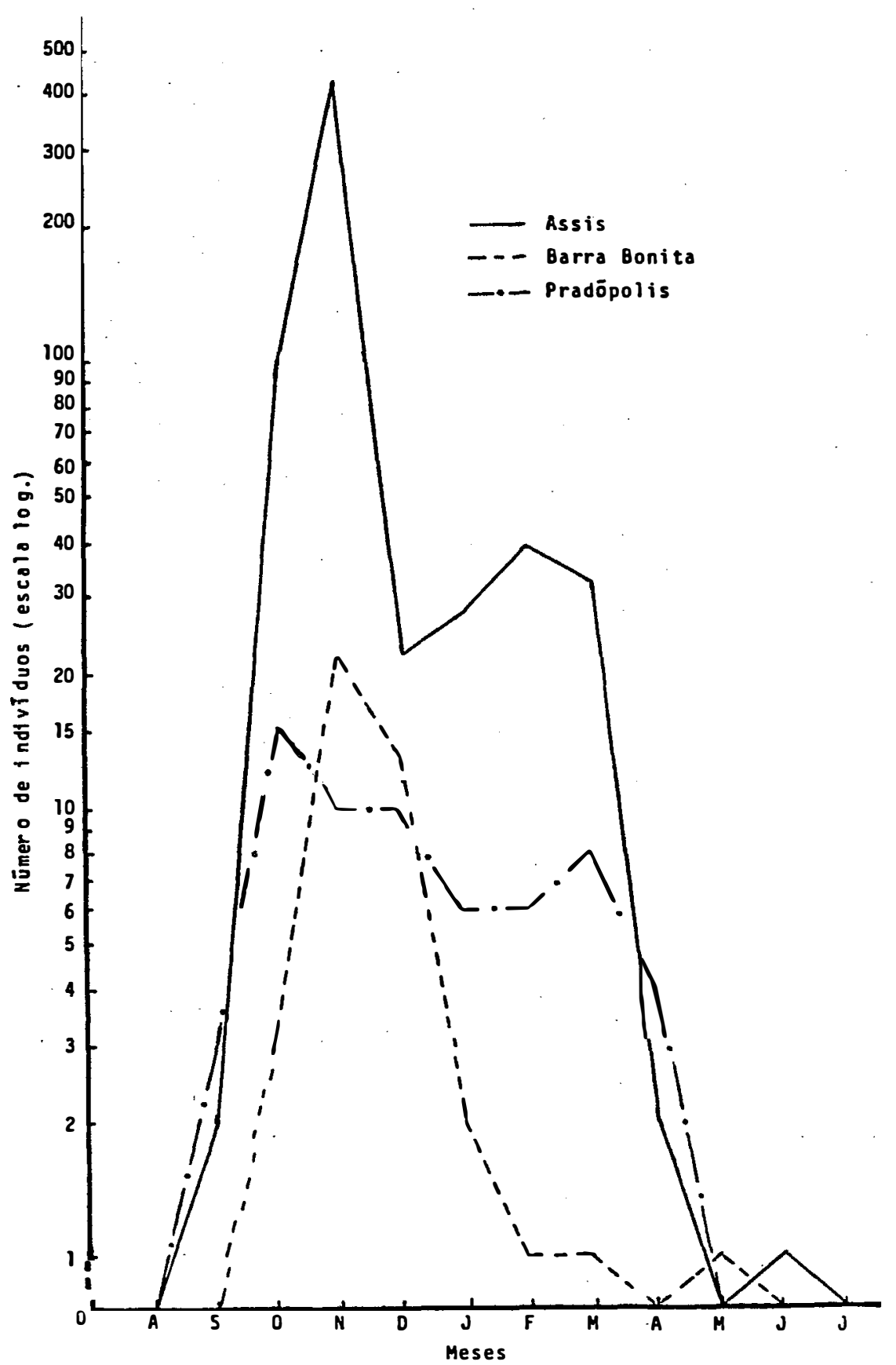

Fig. 4 - Flutuaçāo populacional de Cyclocephala melanophala (Fabr.) nas trēs localidades. (1976/78). 

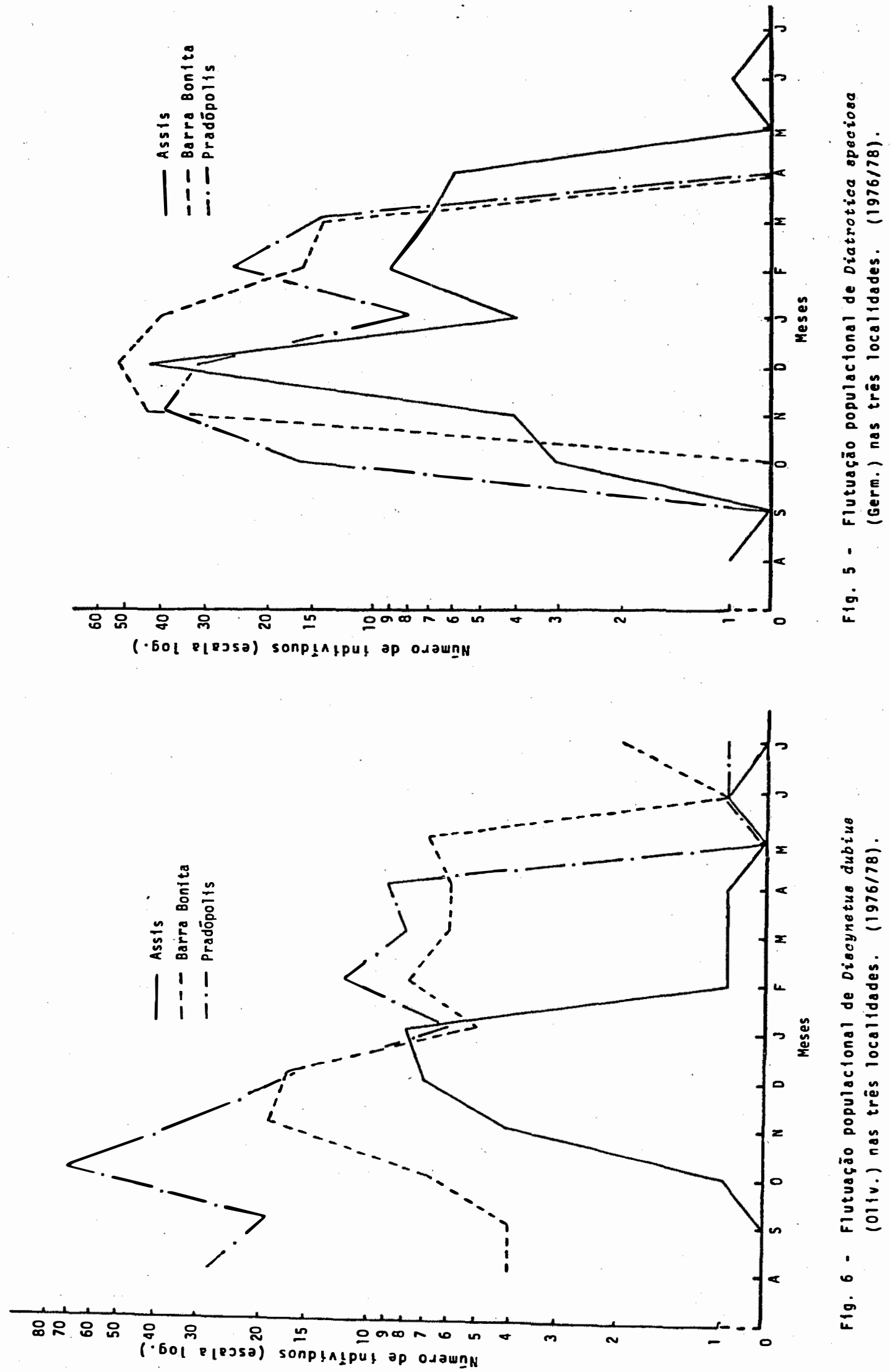
53.
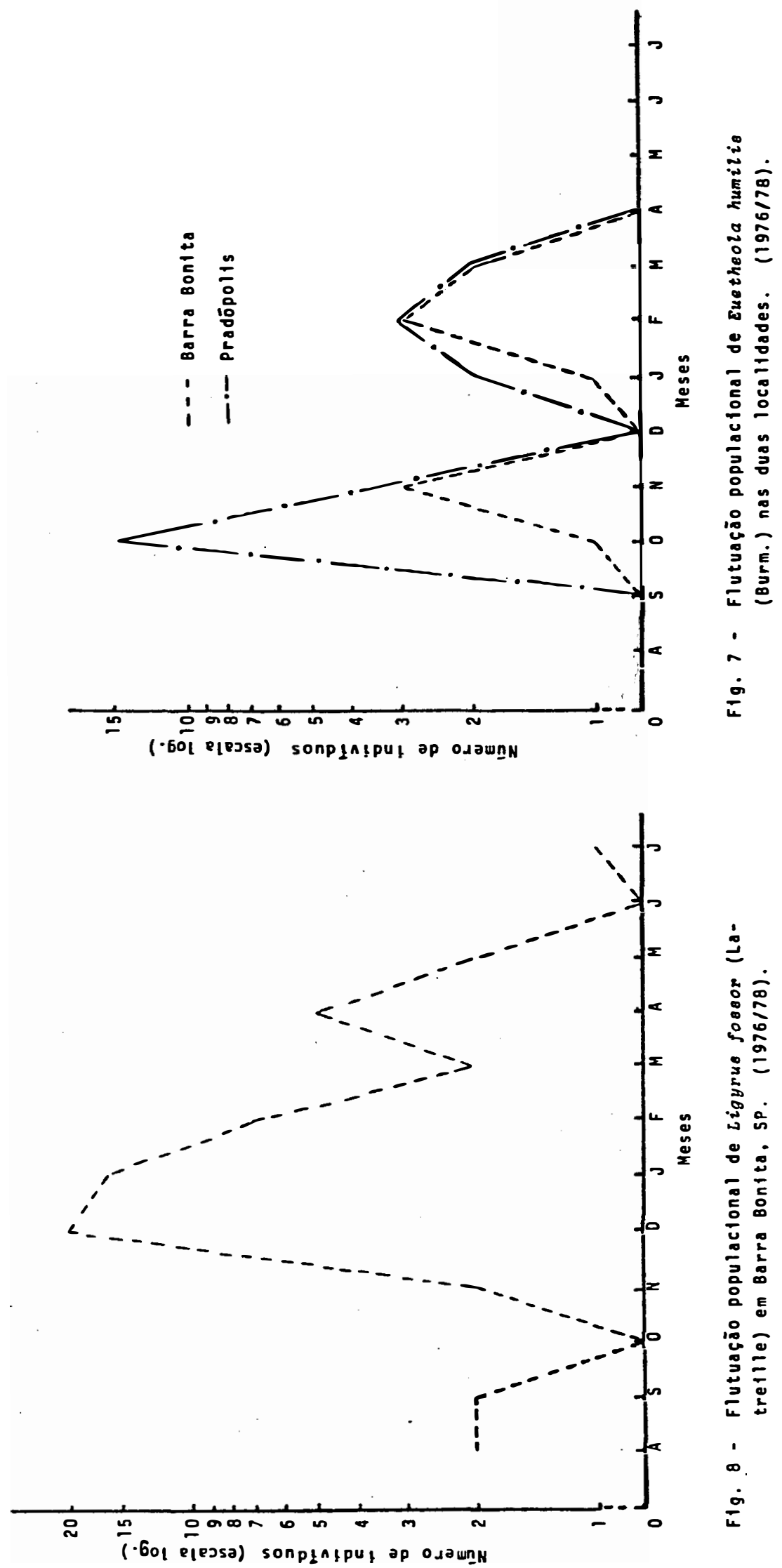

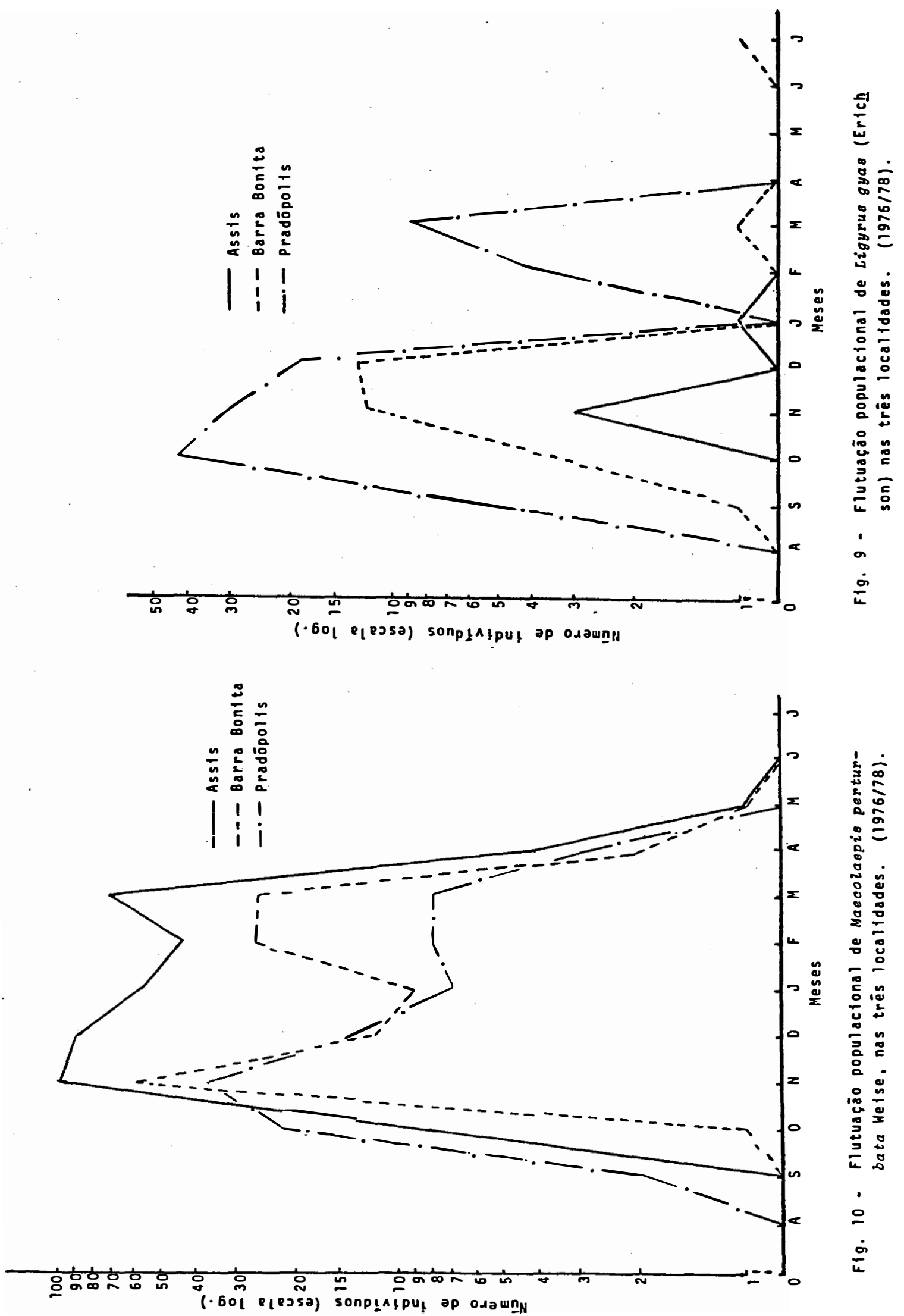


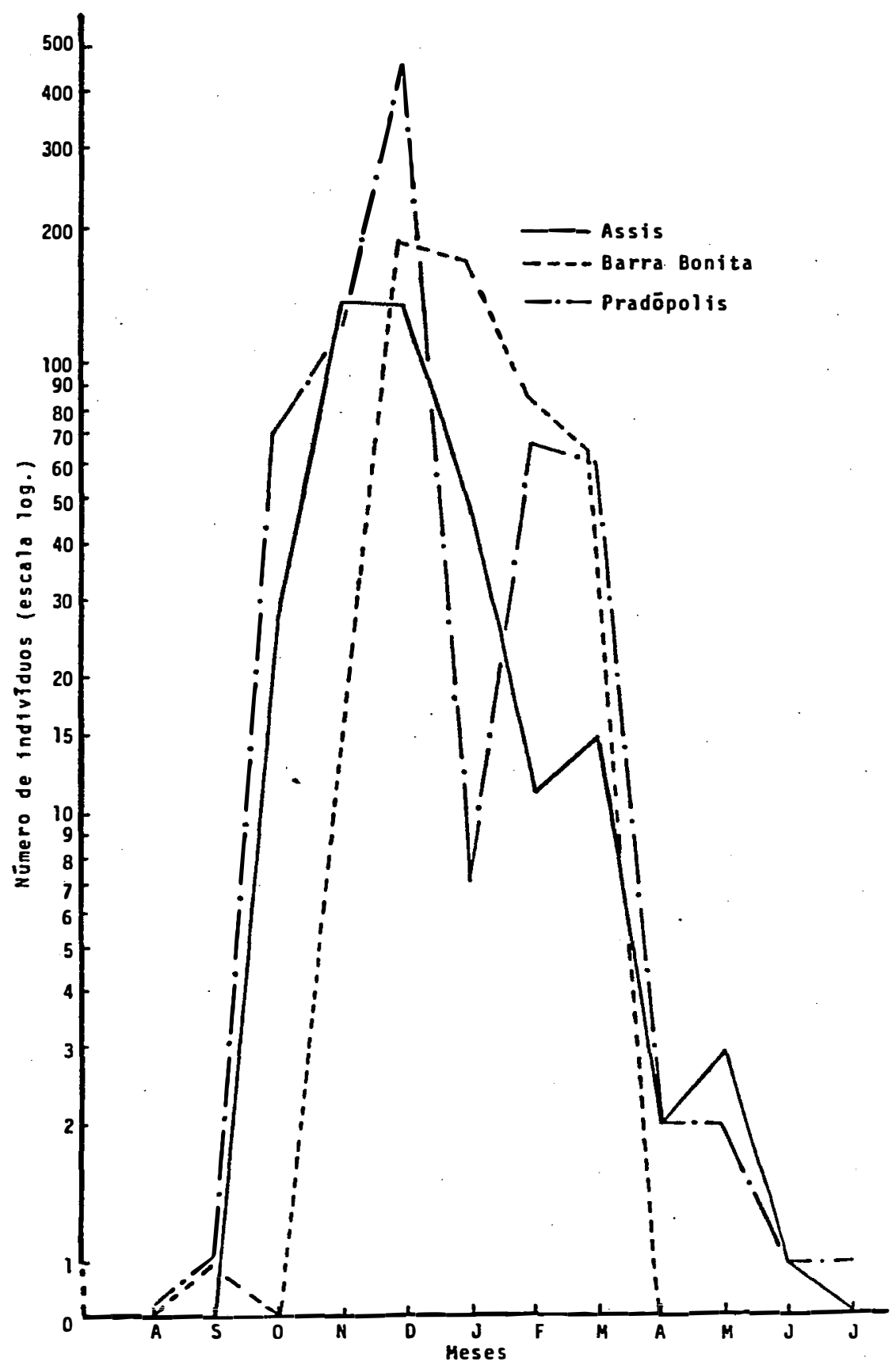

Fig. 11 - Flutuaçào populacional de Paranapiacaba signi ficata Gahan nas trés localidades. (1976/78). 


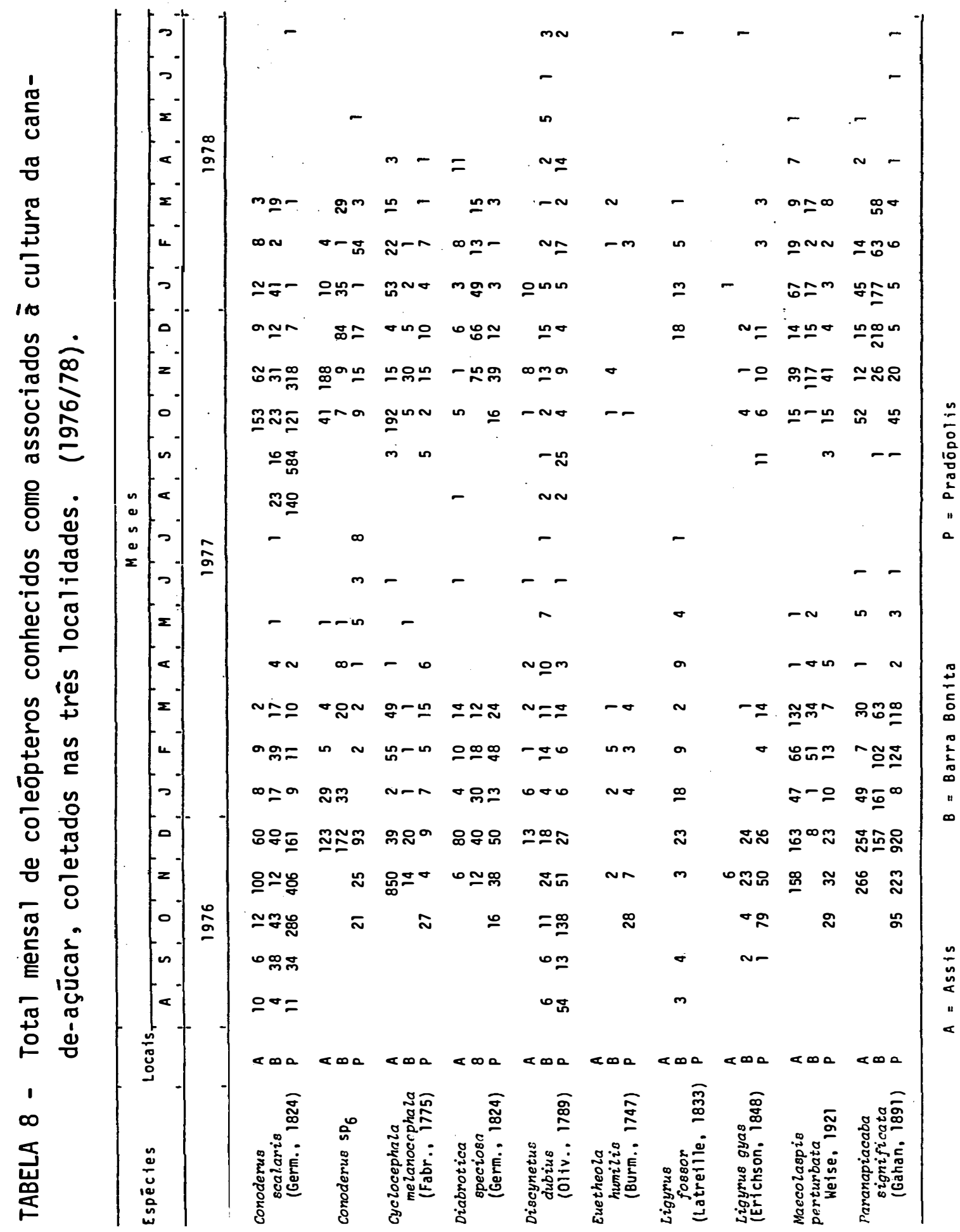


TABELA 9 - Médias mensais da temperatura e total mensal da precipitação, registradas nas trēs localidades $(1976 / 78)$

\begin{tabular}{|c|c|c|c|c|c|c|c|}
\hline \multirow{3}{*}{ Ano / Mēs } & \multicolumn{7}{|c|}{ Locais } \\
\hline & \multicolumn{3}{|c|}{ Assis } & \multicolumn{2}{|c|}{ Barra Bonita } & \multicolumn{2}{|c|}{ Pradōpolis } \\
\hline & & $\mathrm{T}(\mathrm{OC})$ & $P(\mathrm{~mm})$ & $T(O C)$ & $P(\mathrm{~mm})$ & $T(O C)$ & $\mathrm{P}(\mathrm{mm})$ \\
\hline \multicolumn{8}{|l|}{ 1976: } \\
\hline $\begin{array}{l}\text { Agos to } \\
\text { Setembro } \\
\text { Outubro } \\
\text { Novembro } \\
\text { Dezembro }\end{array}$ & & $\begin{array}{l}18,7 \\
19,2 \\
21,5 \\
24,3 \\
25,1\end{array}$ & $\begin{array}{l}182,5 \\
129,5 \\
163,0 \\
188,5 \\
217,0\end{array}$ & $\begin{array}{l}18,8 \\
19,2 \\
21,0 \\
23,3 \\
24,0\end{array}$ & $\begin{array}{l}113,9 \\
180,8 \\
137,2 \\
159,9 \\
181,8\end{array}$ & $\begin{array}{l}17,2 \\
17,6 \\
20,2 \\
21,6 \\
21,6\end{array}$ & $\begin{array}{r}95,3 \\
112,0 \\
177,0 \\
114,0 \\
309,7\end{array}$ \\
\hline \multicolumn{8}{|l|}{ 1977: } \\
\hline $\begin{array}{l}\text { Janeiro } \\
\text { Fevereiro } \\
\text { Março } \\
\text { Abril } \\
\text { Maio } \\
\text { Junho } \\
\text { Julho } \\
\text { Agosto } \\
\text { Setembro } \\
\text { Outubro } \\
\text { Novembro } \\
\text { Dezembro }\end{array}$ & & $\begin{array}{l}25,3 \\
26,2 \\
26,4 \\
21,5 \\
18,9 \\
18,2 \\
21,5 \\
20,9 \\
21,9 \\
25,0 \\
24,0 \\
24,3\end{array}$ & $\begin{array}{r}233,0 \\
132,5 \\
150,0 \\
75,0 \\
51,0 \\
111,0 \\
8,0 \\
20,0 \\
85,5 \\
52,0 \\
160,0 \\
204,0\end{array}$ & $\begin{array}{l}24,7 \\
25,4 \\
24,1 \\
21,3 \\
20,2 \\
19,2 \\
20,7 \\
21,4 \\
22,3 \\
24,6 \\
24,1 \\
23,3\end{array}$ & $\begin{array}{r}377,0 \\
80,2 \\
216,5 \\
90,7 \\
9,9 \\
88,1 \\
18,8 \\
11,3 \\
88,3 \\
72,5 \\
161,1 \\
341,6\end{array}$ & $\begin{array}{l}22,2 \\
23,2 \\
22,9 \\
19,7 \\
16,8 \\
17,1 \\
18,2 \\
19,5 \\
20,0 \\
22,5 \\
22,1 \\
21,4\end{array}$ & $\begin{array}{r}394,6 \\
29,3 \\
132,0 \\
133,0 \\
7,0 \\
23,0 \\
7,7 \\
28,0 \\
95,6 \\
39,2 \\
241,0 \\
276,1\end{array}$ \\
\hline \multicolumn{8}{|l|}{ 1978: } \\
\hline $\begin{array}{l}\text { Janeiro } \\
\text { Fevereiro } \\
\text { Março } \\
\text { Abril } \\
\text { Maio } \\
\text { Junho } \\
\text { Julho }\end{array}$ & & $\begin{array}{l}25,8 \\
26,6 \\
25,3 \\
22,6 \\
17,9 \\
17,7 \\
20,2\end{array}$ & $\begin{array}{r}138,0 \\
94,0 \\
318,0 \\
0,0 \\
178,0 \\
14,0 \\
157,0\end{array}$ & $\begin{array}{l}25,9 \\
26,0 \\
25,2 \\
23,1 \\
19,8 \\
18,6 \\
19,8\end{array}$ & $\begin{array}{r}140,5 \\
134,9 \\
227,6 \\
4,6 \\
147,6 \\
52,9 \\
99,2\end{array}$ & $\begin{array}{l}22,8 \\
22,6 \\
21,9 \\
19,1 \\
16,6 \\
15,7 \\
16,4\end{array}$ & $\begin{array}{r}173,0 \\
239,1 \\
174,1 \\
51,0 \\
111,3 \\
20,0 \\
59,4\end{array}$ \\
\hline
\end{tabular}


TABELA 10 - Valores obtidos no teste de correlação de Kendall entre as espécies selecionadas e os fatores meteorológicos, das três localidades. $(1976 / 78)$.

\begin{tabular}{|c|c|c|c|c|c|c|c|c|c|c|c|c|}
\hline \multirow{4}{*}{ Espëcies } & \multicolumn{12}{|c|}{ Locais } \\
\hline & \multicolumn{4}{|c|}{ Assis } & \multicolumn{4}{|c|}{ Barra Bonjta } & \multicolumn{4}{|c|}{ Pradópolis } \\
\hline & \multicolumn{2}{|c|}{ Temperatura } & \multicolumn{2}{|c|}{ Precipitaçāo } & \multicolumn{2}{|c|}{ Temperatura } & \multicolumn{2}{|c|}{ Precipitação } & \multicolumn{2}{|c|}{ Temperatura } & \multicolumn{2}{|c|}{ Precipitaçāo } \\
\hline & $\bar{i}$ & $a$ & $\bar{\tau}$ & $a$ & $\bar{i}$ & $a$ & $\bar{\tau}$ & $\alpha$ & $\bar{T}$ & $\alpha$ & $\bar{\tau}$ & $a$ \\
\hline $\begin{array}{l}\text { Conoderus } \\
\text { scalaris } \\
\text { (Germ., 1824) }\end{array}$ & 0,12 & n.s. & 0.17 & n.s. & 0,33 & 0,023 & 0,20 & n.s. & 0,17 & n.s. & 0,13 & n.s. \\
\hline Conoderus $\mathrm{SP}_{6}$ & $-0,08$ & n.s. & $-0,28$ & 0,059 & 0,09 & n.s. & 0,09 & n.s. & 0,15 & n.s. & 0.13 & n.s. \\
\hline $\begin{array}{l}\text { Cyclocephalala } \\
\text { melanocephaia } \\
\text { (Fabr., 1775) }\end{array}$ & 0,44 & 0,03 & 0,01 & n.s. & 0,04 & n.s. & $-0,09$ & n.s. & 0,34 & 0,02 & 0,38 & 0,01 \\
\hline $\begin{array}{l}\text { Disbrotica } \\
\text { speciosa } \\
\text { (Germ., 1824) }\end{array}$ & 0,25 & 0,09 & $-0,12$ & n.s. & 0,12 & n.s. & 0,08 & n.s. & 0,27 & 0,066 & 0,13 & n.s. \\
\hline $\begin{array}{l}\text { Discynetus dubius } \\
\text { (0liv., 1789) }\end{array}$ & $-0,14$ & n.s. & $-0,25$ & 0,082 & 0,07 & n.s. & 0,25 & 0,082 & 0,26 & 0,073 & 0,33 & 0,026 \\
\hline $\begin{array}{c}\text { Euetheola hami.itis } \\
\text { (Burm., 1747) }\end{array}$ & - & - & - & - & $-0,06$ & n.s. & $-0,25$ & 0,091 & $-0,20$ & n.s. & $-0,36$ & 0,015 \\
\hline $\begin{array}{l}\text { Ligyras fossor } \\
\text { (Latreille, } \\
\text { 1833) }\end{array}$ & - & - & - & - & $-0,02$ & n.s. & 0,04 & n.s. & - & - & - & - \\
\hline $\begin{array}{l}\text { Ligyrus gyas } \\
\text { (Erichson, } \\
\text { 1848) }\end{array}$ & $-0,76$ & $<0,0002$ & $-0,78$ & $<0,0002$ & $-0,37$ & 0,011 & $-0,14$ & n.s. & 0,07 & n.s. & 0,09 & n.s. \\
\hline $\begin{array}{l}\text { Yaccolaspis } \\
\text { perturbata } \\
\text { Weise, } 1921\end{array}$ & 0,41 & 0,005 & 0.15 & n.s. & 0,22 & n.s. & 0,0 & n.s. & 0,33 & 0,026 & 0,26 & 0,073 \\
\hline $\begin{array}{l}\text { Pararapiazaba } \\
\text { sianificata } \\
\text { (Gahan, 1891) }\end{array}$ & 0,25 & 0,09 & 0,06 & n.s. & 0,13 & n.s. & 0,05 & n.s. & 0,44 & 0,003 & 0,27 & 0,082 \\
\hline
\end{tabular}


$\mathrm{Na}$ anālise da flutuação populacional das espécies selecionadas, observa-se que:

Conoderus scalaris (Germ.)

Pela Figura 2, apresentou em Assis o periodo de maior ocorréncia de outubro a fevereiro e o pico populacional em outubro-novembro. Tais resultados assemelham-se aos encontrados em Assis por SILVEIRA NETO (1972), que indicou ser. de novembro a abril a época que apareceu com maior intensidade e ter o pico populacional em novembro. Assim, apesar das diferenças na época dos levantamentos e nas culturas, esta espécie manteve o mesmo comportamento durante o ano.

Em Barra Bonita teve um pico populacional em outubro e outro semelhante em janeiro, com período de maior ocorréncia de agosto a maio, enquanto em Pradópolis apareceu com maior in tensidade entre agosto e dezembro, com um pico populacional em setembro e outro em novembro, correspondendo em parte aos resultados obtidos em Jaboticabal por BUSQLI (1979), onde mostrou um pico populacional em setembro e outro em fevereiromarço.

Nas três localidades classificou-se como espécie cons tante, muito abundante e dominante, tendo mostrado correlação positiva com a temperatura em Barra Bonita. 
60.

Conoderus $\operatorname{sp}_{6}$

Observando-se a Figura 3 , pode-se notar que em A sis apresentou seu período de maior ocorrēncia entre outubro e fevereiro e um pico populacional em novembro, apresentando o comportamento semelhante ao $C$. scalaris na mesma localidade.

Já em Barra Bonita apresentou o acme populacional em dezembro e outro pico em março, enquanto em Pradópolis mostrou trēs picos populacionais, sendo o acme em dezembro, um pico em fevereiro e outro menor em junho.

Nessas localidades classificou-se como espécie aces sória, muito abundante e dominante, apresentando correlação ne gativa com a precipitação em Assis.

Cyclocephala melanocephala (Fabr.)

Pela Figura 4, nota-se que em Assis seu período de maior ocorrência se deu de outubro a março com pico populacio nal em novembro, resultados semelhantes aos encontrados por SILVEIRA NETO (1972) em Assis. Classificou-se como constan te, muito abundante e dominante, apresentando correlação pos $\underline{i}$ tiva com a temperatura.

Já em Barra Bonita foi entre outubro e janeiro que ocorreu em maior número, tendo seu pico populacional em novem bro. Foi considerada acessōria, comum e dominante, sem mostrar correlação com os fatores meteorológicos. 
Sua maior ocorrência em Pradópolis foi entre setembro e abril, com pico populacional em outubro. Classificou se como espécie constante, comum e dominante, apresentando correlação positiva com a temperatura e precipitação.

Diabrotica speciosa (Germ.)

Atravēs da Figura 5 , pode ser observado que seu periodo de maior ocorrência em Assis foi de novembro a abril, com acme populacional em dezembro e um outro pico em fevereiro, diferindo dos resultados encontrados em Assis por SILVEIRA NETO (1972), onde seu pico populacional ocorreu em novem bro.

Em Barra Bonita apresentou-se com maior nūmero entre novembro e março, tendo o pico populacional em dezembro, enquanto seu periodo de maior ocorrência em Pradópolis foi de outubro a março, apresentando o acme populacional em novembro e outro pico em fevereiro. Tais resultados mostraram-se próximos dos encontrados por BUSOLI (1979) em Jaboticabal, quando achou estar entre dezembro e abril a época de sua maior ocorrência e ter um único pico populacional em fevereiro.

Classificou-se nas trēs localidades como espécie acessōria, muito abundante e dominante, apresentando correla ção positiva com a temperatura em Assis e Pradópolis. 
Discynetus dubius (01iv.)

Pela Figura 6 , nota-se que em Assis seu periodo de maior ocorrēncia foi entre novembro e janeiro, apresentando o pico populacional em janeiro. Classificou-se em acessōria, comum e dominante, apresentando correlação negativa com a pre cipitação.

Já em Barra Bonita ocorreu um maior nūmero entre agosto e maio, com pico populacional em novembro. Foi conside rada constante, muito abundante e dominante, mostrou correlação positiva com a precipitação.

Seu período de maior intensidade em Pradópolis foi de agosto a abril, tendo o pico populacional em outubro. Clas sificou-se como constante, muito abundante e dominante, apresentando correlação positiva com a temperatura e precipitação. Comparando-se estes resultados com os obtidos por LINK (1976) em Santa Maria, RS, nota-se que naquela região a referida espécie não foi observada em junho, julho e agosto, apresentando os picos populacionais em janeiro (1971/72) e fe vereiro (1972/73 e 1973/74).

Euetheola humilis (Burm.)

Não foi observada em Assis, e a Figura 7 indica que não ocorreu durante o més de dezembro nas duas localidades, sendo que em Barra Bonita ocorreu um pico populacional em novembro e outro, de igual intensidade, em fevereiro. Classifi 
cou-se como acidental, rara e dominante, mostrando correlação negativa com a precipitação.

Já em Pradópolis ocorreu o acme populacional em outubro e um outro pico em fevereiro, diferindo dos resultados obtidos por BUSOLI (1979) em Jaboticabal, quando foi observado os picos populacionais em dezembro e março. Foi considera da acessória, comum e dominante, tendo apresentado correlação negativa com a precipitação.

Ligyrus fossor (Latreille)

Sua presença foi notada apenas em Barra Bonita, e a Figura 8 mostra que apresentou o acme populacional em dezem bro e outro pico em abril. Classificou-se como acessōria, abundante e dominante, não tendo mostrado correlação com os fá tores meteorológicos.

Ligyrus gyas (Erichson)

Atravēs da Figura 9 pode-se observar que em Assis sua presença foi restrita aos meses de novembro e janeiro, apresentando naquele mes seu acme populacional. Classificou se como acidental, rara e dominante, tendo apresentado correlação negativa com a temperatura e precipitação.

Já em Barra Bonita, teve seu perīodo de maior ocorrēncia entre outubro e dezembro, com o pico populacional em 
novembro-dezembro. Foi considerada acessōria, comum e domi nante, mostrando correlação negativa com a temperatura.

Em Pradópolis não foi observada em janeiro, tendo a presentado seu acme populacional em outubro e outro pico em março. Classificou-se como acessōria, muito abundante e domi nante, não mostrando correlação com a temperatura e precipita ção .

Maecolaspis perturbata Weise

Pela Figura 10 , pode-se observar que nas três loca lidades apresentou o acme populacional em novembro, tendo ocorrido em Assis um pico no mès de março e em fevereiro-março nas outras duas localidades.

Nesses lugares classificou-se como dominante e muito abundante, sendo constante em Assis e acessória em Barra Bonita e Pradópolis. Mostrou correlação positiva com a tempe ratura em Assis, e com a temperatura e precipitação em Pradópolis.

Paranapiacába significata (Gahan)

Atravēs da Figura 11, nota-se que em Assis apresentou o pico populacional em novembro-dezembro, sendo entre outubro e março a época de sua maior ocorrēncia, resultados que 
diferem dos encontrados por SILVEIRA NETO (1972) quando, em Assis, mostrou esta espécie representada por apenas trēs indi vĩduos. Classificou-se como acessōria, muito abundante e dominante, mostrando correlação positiva com a temperatura.

Em Barra Bonita apresentou o pico populacional em dezembro-janeiro, sendo classificada como acessōria, muito abundante e dominante, não apresentando correlação com os fato res meteorológicos.

Jā em Pradópolis teve o acme populacional em dezembro e outro pico em fevereiro-março, sendo considerada cons tante, muito abundante e dominante, mostrando correlação pos tiva com a temperatura e precipitação.

A Tabela 11 , mostra o número total de coleópteros capturados, pertencentes às espécies estudadas acima.

Tais resultados sugerem que em Pradópolis, as especies associadas à cultura da cana-de-açúcar ocorrem com maior frequência.

TABELA 11 - Total de coleópteros conhecidos como associados à cultura da cana-de-açūcar, coletados nas trēs localidades $(1976 / 78)$.

\begin{tabular}{lccc}
\hline & \multicolumn{3}{c}{ Locais } \\
\cline { 2 - 4 } & Assis & Barra Bonita & Pradópolis \\
\hline $\begin{array}{l}\text { Total } \\
\begin{array}{l}\% \text { em relação ao to- } \\
\text { tal coletado }\end{array}\end{array}$ & 3.859 & 2.855 & 5.194 \\
\hline
\end{tabular}


6 - CONCLUSOES

As principais conclusões deste trabalho são:

6.1 - Foram coletados nas très localidades, um total de 91.197 coleópteros de 207 espécies diferentes.

6.2 - O maior número de indivíduos foi coletado em Barra Bonita, que mostrou uma fauna de coleópteros prejudiciais à cultura da cana-de-açúcar menor do que a encontrada em Assis e Pradópolis.

6.3 - 0 maior número de espécies e indivíduos coletados nas trēs localidades, pertenceram às famîlias: Carabidae, Chrysomelidae, Elateridae e Scarabaeidae.

6.4 - A espécie Selenophorus sp (Carabidae) foi a mais numerosa nos trés locais, com um total de 54.569 indivíduos coletados, representando $59,8 \%$ do total.

6.5 - Das espécies coletadas, foram constantes apenas 5 espécies em Assis, 4 em Barra Bonita e 5 em Pradópolis, as demais foram acessórias ou acidentais. 
67.

6.6 - Pelo levantamento foram assinaladas 82 espécies domi nantes em Assis, 109 em Barra Bonita e 98 em Pradópo lis.

6.7 - Além da espēcie selenophorus sp, que foi excessivamente abundante, foram ainda muito abundantes ou abundantes 23 espécies em Assis, 26 em Barra Bonita e 17 em Pradópolis.

6.8 - Os indices de diversidade encontrados foram de 14,1 pa ra Assis, 15,5 para Barra Bonita e 13,7 para Pradópolis.

6.9 - As trēs localidades apresentaram uma similaridade considerada média.

6.10 - As espécies associadas à cultura da cana-de-açūcar, e que tiveram sua flutuação populacional estudada foram: Conoderus scalaris (Germ., 1824); Conoderus sp 6 ; Cyclocephala melanocephala (Fabr., 1775); Diabrotica speciosa (Germ., 1824) ; Discynetus dubius (01iv., 1789) ; Euetheola humilis (Burm., 1747) ; Ligyrus fossor (Latreille, 1833) ; Ligyrus gyas (Erichson, 1848); Maecolaspis perturbata Weise, 1921 e Paranapiacaba sig nificata (Gahan, 1891).

6.11 - Apresentaram correlação positiva com a temperatura: Conoderus scalaris (Germ., 1824); Cyclocephala melano cephala (Fabr., 1775) ; Diabrotica speciosa (Germ, 1824) ; Discynetus dubius (01iv., 1789) ; Maecolaspis perturbata Weise, 1921 e Paranapiacaba significata (Ga han, 1891).

6.12 - Ligyrus gyas (Erichson, 1848), apresentou correlação ne gativa com a temperatura. 
68 .

6.13 - Apresentaram correlação positiva com a precipitação: Cyclocephala melanocephala (Fabr., 1775) ; Maecolaspis perturbata Weise, 1921 e Paranapiacaba significata (Gahan, 1891).

6.14 - Apresentaram correlação negativa com a precipitação: Conoderus $\mathrm{sp}_{6}$; Euetheola humilis (Burm., 1747) e Ligyrus gyas (Erichson, 1848). 
69.

7 - SUMMARY

In the present work, a survey of the Coleoptera fau na inhabiting sugar cane fields was conducted in Assis, Barra Bonita and Pradōpolis, three distinct sugar cane producing areas of the State of São Paulo, by means of 1 ight traps. The constancy, abundance, dominance, diversity indice, quocient and percentage of similarity among species as well as the populational fluctuations and correlation with meteorological factors were investigated for some species associated to sugar cane in the sampled regions.

The analysis of results showed that:

a. $\quad 91.197$ beetles corresponding to 207 different species were collected in the three locations;

b. Barra Bonita had the smallest coleoptera fauna with damage potencial to sugar cane; 
c. The families Carabidae, Chrysomelidae, Elateridae, and Scarabaeidae were the ones found in greatest numbers;

d. The species Selenophorus sp (Carabidae) represented $59,8 \%$ of the total number of specimens collected;

e. Only 5 species were constant in Assis, 4 in Barra Bonita, and 5 in Pradópolis;

f. Eighty two species were dominant in Assis, 109 in Barra Bonita, and 98 in Pradópolis;

g. Twenty three species were very abundant or abundant in Assis, 26 in Barra Bonita, and 17 in Pradópolis;

h. The indice of diversity presented by the Assis, Barra Bonita, and Pradópolis fauna was 14,$1 ; 15,5$; and 13,7 ; respectively;

i. The three regions presented mean similarity; and

j. The montly average temperature was the factor which had the greatest number of positive correlations with the po pulational fluctuations of the studied species, which were: Conoderus scalaris (Germ., 1824) ; Conoderus sp 6 ; Cyclocephala melanocephala (Fabr., 1775); Diabrotica speciosa (Germ., 1824) ; Discynetus dubius (01iv.,1789); Euetheola humilis (Burm., 1747) ; Ligyrus fossor (Latrei1 1e, 1833); Ligyrus gyas (Erichson, 1848) ; Maecolaspis perturbata Weise, 1921 and Paranapiacaba significata (Ga han, 1891). 
ALVES, M. L. G., 1976. Entomofauna of Carbora Bassa: Results of the Entomological Brigade of the Institute for Scien tific Investigation of Mozambique. V Coleoptera (family Carabidae). Garcia de Orta Ser. Zool., Lisboa, 5(2): 67-74. Apud: Abstracts of Entomology, Philadelphia, g $(6): 80,1978$.

ANDERSEN, T. e L. GREVE, 1975. Neuroptera in light-traps at Osteroy, Hordaland. Norw. J. Entomol., 22(2): 123-128. Apud: Abstracts of Entomology, Philadelphia, $\underline{7}(4): 41$, 1976.

BARNES, R. D. e B. M. BARNES, 1955. The spider population on the abstract broomsedge community of the Southeastern Piedmont. Ecology, 36(4): 658-666.

BINAGHI, G., 1972/1973. Materials for the study of the palustrine Coleoptera fauna of the island of Elba. Ann. Mus. Civ. Stor. Nat. "Giacomo Doria", 79: 6-17. Apud: Abstracts of Entomology, Philadelphia, $\underline{6}(9): 872,1975$. 
72 .

BINAGHI, G., 1974/1975. Contribution to the geonomy of the Italian Coleoptera fauna: II. Ann. Mus. Civ. Stor. Nat. "Giacomo Doria", 80: 119-129. Apud: Abstracts of Ento mology, Philadelphia, $\underline{7}(10): 24,1976$.

BOSC, F., 1977. Survey of the Coleoptera fauna of the gorges of the Aveyron. Entomologiste, Paris, 33(1): 23-25. Apud: Abstracts of Entomology, Philadelphia, $\underline{9}(1): 21$, 1978.

BOTELHO, P. S. M., 1975. Fenologia do curuquerē do algodão Alabama argilzacea (Hueb., 1818). Piracicaba, ESALQ/USP, 92 p. (Dissertação de Mestrado).

BUSOLI, A. C., 1979. Levantamento, constāncia e flutuação populacional de alguns insetos coletados com armadilhas luminosas em Jaboticabal, SP., Piracicaba, ESALQ/USP, 100 p. (Dissertação de Mestrado).

CAMPOS, H. de, 1979. Estatística Experimental Não-Paramétri cá, 3a. ed., Piracicaba, ESALQ/USP., Depto. de Matemát $\overline{\mathbf{i}}$ ca e Estatistica. 343 p.

CHANTAL, C., 1975. Additions à la faune des coléoptēres du Québec. Le Naturaliste Canadien, Quebec, 102(6): 853854 .

COELHO, I. P., 1977. Anālise faunística das famīlias Pyralidae e Sphingidae (Lepidoptera) através de levantamentos com armadilhas luminosas em Piracicaba, SP. Piracicaba, ESALQ/USP, 121 p. (Dissertação de Mestrado).

DAJŌZ, R., 1973. Ecologia Geral. 2a ed., São Paulo. Editora Vozes, $471 \mathrm{p}$. 
DAY, A. ; J. M. STANLEY ; J. C. WEBB e J. G. HARTSOCK, 1973. Southern potato wireworms: light-trap catches of adults in a isolated agricultural area. Journal of Economic Entomology, 66 (3): 757-760.

DEVEAUX, D., 1978. Distribution and diversity of carabid populations in western enclosed and open field ecossystems. Apud: Rev. of Appl. Entomol., 67(1): 9, 1979.

EL-BOROLLOSY, F. M. e K. T. AWADALLAH, 1974. On the seasonal abundance of the carabid beetle, Calosoma chlorostic tum chlorostictum Deg. (Coleoptera : Carabidae). Bulletin Sociētē Entomologique d'Egypte, 57: 247-250. Apud: Abstracts of Entomology, Philadelphia, $\underline{6}(5):$ 409, 1975 .

ELLIOTT, W. M., 1977. Mating frequency of the female European corn borer, Ostrinia nubizalis (Lepidoptera : Pyralidae), in Southwestern Ontario. Canadian Entomologist, 109(1): 117-122.

FERREIRA, G. V. da, 1976. The entomofauna of Carbora Bassa: Results of the Entomological Brigade of the Institute for Scientific Investigation of Mozambique. VII Coleoptera (Cerambycidae). Garcia de Orta Serv. Zool.. 5 $5(2): 139-$ 236. Apud: Abstracts of Entomology, Philadelphia, g(12): 19,1978 .

FERREIRA, M. C., 1976.a. The entomofauna of Carbora Bassa: Results of the Entomological Brigade of the Institute for Scientific Investigation of Mozambique: IV Coleoptera (family Scarabaeidae, subfamily Coprinae). Garcia de Orta Serv. Zool., 5 $5(2):$ 75-138. Apud: Abstracts of Entomology, Philadelphia, $\underline{9}(12): 69,1978$. 
FERREIRA, M. C., 1976.b. The entomofauna of Carbora Bassa: Results of the Entomological Brigade of the Institute for Scientific Investigation of Mozambique: VIII Coleoptera (family Scarabaeidae, subfamilies Cetoniinae and Trichinae). Garcia de Orta Serv. Zool., 5(2): 237-248. Apud: Abstracts of Entomology, Philadelphia, $\underline{9}(12): 69,1978$.

FROST, S. W., 1952. Light traps for insect collection, survey and control. Pennsylvania State Univ. Agr. Exp. Sta. Bull, Pennsylvania, $32 \mathrm{p}$.

GALLO, D. ; O. NAKANO ; S. SILVEIRA NETO ; R. P. L. CARVALHO; G. C. BATISTA ; E. BERTI FILHO ; J.R. P. PARRA ; R. A. ZUCCHI e S. B. ALVES, 1978. Manual de Entomologia Agrícola, São Paulo, Editora Agronōmica Ceres, $531 \mathrm{p}$.

GARCIA, J. L., 1978. Influência de los factores ambientales sobre la captura nocturna de Sphingidae (Lepidoptera) em Rancho Grande, Estado Aragua, Venezuela. Revista de la Faculdade de Agronomia, Universidade Central de Venezuela. Maracay, $\underline{9}(4)$ : 63-107.

GENUNG, W. G., 1972. Seasonal occurrence of click beetles (Coleoptera : Elateridae) in the Everglades as measured by two types of traps. Florida Entomologist, 55(1): 35-41. Apud: Rev. Appl. Ent., Ser. A, London, 62(4): 340, 1974.

GUAGLIUMI, P., 1972/73. Pragas da Cana-de-Açūcar, no Nordes. te do Brasil. $622 \mathrm{p}$. Coleção Canavieira, nọ 10 . 
HAGEN, A. F., 1976. A fourteen-year summary of light trap catches of the western bean cutworm in Nebraska Loxagrotis albicosta (Smith) (Lepidoptera : Noctuidae). Journal of the Kansas Entomological Society, $\underline{49}(4):$ 537-540.

HIENTON, T. E., 1974. Summary of investigations of eletric traps. Tech. Bull. USDA. Washington, (1498): 136.

ISMAIL, I. I., 1974. Seasonal abundance of the rove-beetle, Paederus alfieri Koch (Coleoptera : Staphylinidae). Bulletin Sociēté Entomologique d'Egypte, 58: 213-216. Apud: Rev. Appl. Ent., Ser. A, London, 64(7): 1178, 1976.

JONES, M. G., 1976. The carabid and staphylinid fauna of winter wheat and fallow on a clay with flints soil. Jour nal of Applied Ecology. 0xford, 13(3): 775-791.

KNIE, J., 1975. Comparative ecological study on the Carabidae fauna of different localities in the Kottenforst near Bonn. Decheniana. Bonn, 128: 3-19. Apud: Abstracts of Entomology, Philadelphia, $\underline{7}(1):$ 5, 1976.

KNIE, J., 1977. Ecologic study of the beetle fauna of selected streans of the Rhenish Schiefergebirge (Insecta : Coleoptera). Decheniana. Bonn, 130: 151-221. Apud: Abstracts of Entomology, Philadelphia, $\underline{9}(7): 6,1978$.

LARA, F. M., 1974. Influência de fatores ecológicos na cole ta de algumas pragas com armadilhas luminosas. Piracicaba, ESALQ/USP. 142 p. (Dissertação de Mestrado). 
LARA, F. M., 1976. Anālise da fauna de noctuídeos (Lepidoptera) de Jaboticabal e Piracicaba, SP: , através de levantamentos com armadilhas luminosas. Jaboticabal, F.C.A. V.J. - UNESP, 176 p. (Tese de Livre-Docēncia).

LINK, D., 1976. Abundāncia relativa e fenologia de alguns Scarabaeoidea fototáticos, na zona de campos de Santa Maria, RS. (Coleoptera). Curitiba, U.F.PR., 79 p. (Tese de Doutoramento).

LOUREIRO, M. C. e L. P. PEDIGO, 1977. Dinâmica de população de artropodos edáficos em agrossistemas. In: Congresso Brasileiro de Entomologia, VI, Goiānia, GO, 05-10 fev. (Resumos).

MALICKY, H., 1975. The significance of light trap results for field studies on Neuroptera. Anz. Schaedlingskd Pflanzenschutz Umwettschutz, 48(8): 120-124. Apud: Abstracts of Entomology, Philadelphia, $\underline{7}(4):$ 78, 1976.

MARGALEF, R., 1951. Diversidad de especies en las comunidades naturales. Publnes, Inst. Biol. Apl., Barcelona, $\underline{6}$ : 59-72.

MESZAROS, Z. ; A. PODLUSSANY e I. RETEZAR, 1976. Studies of swarning in Coleoptera with the aid of light traps. Folia Entomologica Hungarica, Budapeste, 29(1): 49-58. Apud: Rev. Appl. Ent., Ser. A, London, 65(10): 1409, 1977.

MIKSIC, R., 1977. New contributions to the knowledge of the Coleoptera fauna of the Coastal area of Montenegro. Glas. Repub. Zovoda Zast. Prir. Muz. Titogradu (10): 37-40. Apud: Abstracts of Entomology, Philadelphia, $\underline{9}(11): 61$, 1978. 
MURDOCK, W. W. ; F. C. EVANS e C. H. PETERSON, 1972. Diversity and pattern in plants and insects. Ecology, 53(5): 819-828.

ODUM, H. T. ; J. E. CANTLON e L. S. KORNICKER, 1960. An organizational hierarchy postulate for the interpretation of species individual distributions, species entropy, ecosystem evolution, and the meaning of a species - variety index. Ecology, 4l(2): 395-399.

OSANGER, J. A. e A. DAY, 1973. Efficiency and effective radius of blacklight traps against southern potato wireworm. Journal of Economic Entomology, 66(2): 403-409.

OSANGER, J. A., 1976. Influence of weather on capture of adult southern potato wireworm in blacklight traps. Technical Bulletin Agricultural Research Service, USDA, (1527): 1-27.

OWEN, D. F. e D. 0. CHANTER, 1972. Species diversity and seasonal abundance in Charaxes butterflies (Nymphalidae). Journal of Economic Entomology, 46(2): 135-143.

PAL, S. K., 1976. A study of the relative abundance of scarabaeid beetles on light trap. Z. Angew. Zool., 63(3): 375-378. Apud: Abstracts of Entomology, Philadelphia, 8(9): 73,1977 .

PALM, T., 1977. The beetle fauna of the Canary Islands 2122: The genera Cercyon and Pachysternum Motsch (Coleoptera: Hydrophilidae). Entomol. Scand, Copenhague, $\underline{8}(3)$ : 191-196. Apud: Abstracts of Entomology, Philadelphia, $\underline{9}(3): 53,1978$. 
PERRAULT, G., 1977. The carabidae fauna of Tahiti. Nouv. Rev. Entomol., $\underline{7}(3):$ 283-290. Apud: Abstracts of Entomology, Philadelphia, $\underline{9}(6): 34,1978$.

PIANKA, E. R., 1973. The struture of lizard comunities. Annual Review of Ecology and Systematics. Palo Alto, 4 : 53-74.

RIVARD, I., 1974. Fauna of Carabidae in an experimental orchard. Phytoprotection, Quebec, 55(2): 55-63. Apud: Abstracts of Entomology, Philadelphia, $\underline{6}(3): 186,1975$.

SAKAGAMI, S. H. F. E T. MATSUMURA, 1967. Relative abundance phenology and flowe preference of andremid bees in Sapporo, North Japan (Hymenoptera, Apoidea). Japan. J. Ecol. Tokio, 16(6): 237-250.

SHILOV, V. F., 1975. Zonal ecological distribution and zoogeographical analysis of beetles of the subfamily Steninae (Coleoptera : Staphylinidae) of the fauna of the Komi ASSR. Vestn. Leningr. Univ. Biol., 2: 56-60. Apud: Abstracts of Entomology, Philadelphia, $\underline{7}(4): 32,1976$.

SILFVERBERG, H., 1977. Deletions from the Finnish fauna: I I Coleoptera. Notulae Entomologicae, 57(4): 104. Apud: Rev. Appl. Ent., Ser. A, London, 66(6): 376, 1978.

SILVA, A. G. A. d' ; C. R. GONÇALVEZ ; D. M. GALVAO ; A. J. L. GONÇALVEZ ; J. GOMES ; M. N. SILVA e L. SIMONI, 1968. Quarto Catálogo dos Insetos que Vivem nas Plantas do Brasil, seus Parasitos e Predadores. Min. Agr. Dept. Def. San. Veget., Rio de Janeiro, GB. Parte II, 10 Tomo, $622 \mathrm{p}$. 
Silveira neto, S. ; R. P. L. CARVALhO e S. B. PARANHOS, 1968. Flutuação populacional de pragas da cana-de-açūcar em Pira cicaba. In: I Reunião Anual da Sociedade Brasileira de Entomologia, Piracicaba, SP. p. 26-27.

Silveira Neto, S. e A. C. SIlveirA, 1969. Armadilha luminosa modelo "Luiz de Queiroz". $\underline{0}$ Solo, Piracicaba, 61(2): 19-21.

SILVEIRA NETO, S., 1972. Levantamento de insetos e flutuação da população de pragas da ordem Lepidoptera, com o uso de armadilhas luminosas em diversas regiões do Estado de São Paulo. Piracicaba, ESALQ/USP. $183 \mathrm{p}$. (Tese de Livre-Docēncia).

Silveira neto, S. ; E. Berti filho e R. P. L. CARVALhO, 1973. Flutuação populacional de algumas pragas de soja em Assis,

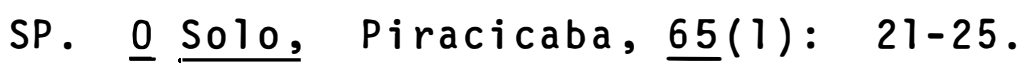

Silveira neto, S.; O. NAKANO;D. BARBin e N. A. Villanova, 1976. Manual de Ecologia dos Insetos, São Paulo, Editora Agronómica Ceres, $419 \mathrm{p}$.

SORENSEN, T., 1948. A method of stablishing groups of equal amplitude in plant sociology basead on similarity of species content and its aplication to analyses of the vegetation on Danish commons. Biol.Skr., Estocolmo, $\underline{5}$ : $1-34$.

SOUTHWO0D, T.R. E., 1971. Ecological Methods, 3. ed., London, Chapman and Hall, $391 \mathrm{p}$. 
80 .

SRIVASTAVA, A. S. ; V. NATH ; S. RAJENDRA ; R. S. VERMA e K. DHARI, 1976. Assesment of light trap for control of adult white grub (Holotrichia consanguinia Blanch.). Entomologists' Newletter, $6(11 / 12)$ : 64. Apud: Rev. Appl. Ent., Ser. A, London, 65(12): 1822, 1977.

TADIC, M., 1974. Attractiveness of ultraviolet light for species of the genus Balaninus (Coleoptera : Curculionidae). Zastita Bilja, Belgrado, 25(128/129): 205-208. Apud: Rev. Appl. Ent., Ser. A, London, 64(8): 1428, 1976 .

TADIC, M., 1976. Some experiences in work with light traps. Zastita Bilja, Belgrado, 27(135): 37-45. Apud: Abs tracts of Entomology, Philadelphia, $8(9): 50,1977$.

TADIC, M., 1977. The categorisation of insects caught in ultraviolet-light traps. Zastita Bilja, Belgrado, 28 (3): 269-278. Apud: Rev. Appl. Ent., Ser. A, London, $\underline{66}(12): 774,1978$.

TARRAGō, M. F. S., 1973. Levantamento da famīlia Noctuidae através de armadilhas luminosas e influēncia fenológica na flutuação populacional de espēcies pragas, em Santa Maria, RS, Piracicaba, ESALQ/USP. 92 p. (Dissertação de Mestrado).

TEetes, G. L. ; L. J. WADE ; R. C. McintYRE e C. A. SChAEFER, 1976. Distribution an seasonal biology of PhyZlophaga crinita in the Texas High Plains. Journal of Economic Entomology, 69(1): 59-63. 
VEERESH, G. K., 1974. Light trap for the control of Adore tus bicolor Brenske (Rutelidae : Coleoptera), a pest of grapevine. Mysore Journal of Agricultural Sciences, 395-400. Apud: Abstracts of Entomology, Philadelphia, $\underline{6}(8): 802,1975$.

WOOLDRIDGE, D. P., 1976. Paracymus of the Australian faunal region (Coleoptera : Hydrophilidae). J. Kans. Entomol. Soc., 49(3): 453-462. Apud: Abstracts of Entomology, Phyladelphia, $8(1): 61$, 1977 . 